Chemical Technology Division

\title{
FY 1995 SEPARATION STUDIES FOR LIQUID LOW-LEVEL WASTE TREATMENT AT OAK RIDGE NATIONAL LABORATORY
}

D. T. Bostick, W. D. Arnold, M. W. Burgess, D. J. Davidson, J. H. Wilson, W. D. Bostick, T. A. Dillow, G. Abotsi, * P. A. Taylor, D. R. McTaggart, S. C. Osborne, and T. E. Kent

\footnotetext{
* Clark Atlanta University, Atlanta, Georgia.
}

Date Prepared: August 1995

Date Published: January 1996

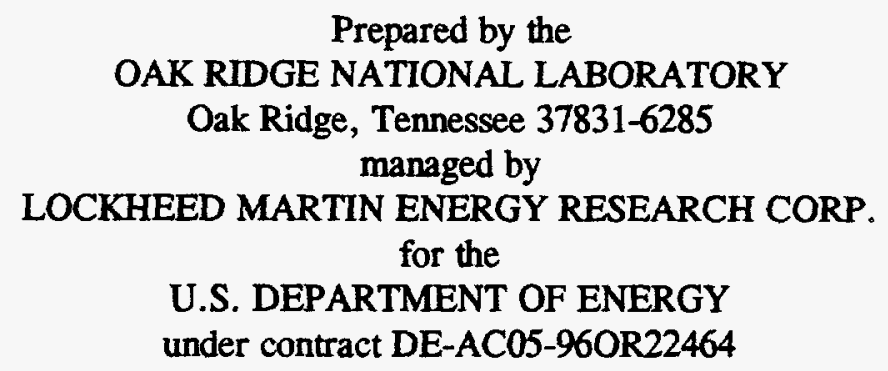




\section{DISCLAMER}

This report was prepared as an account of work sponsored by an agency of the United States Government. Neither the United States Government nor any agency thereof, nor any of their employees, makes any warranty, express or implied, or assumes any legal liability or responsibility for the accuracy, completeness, or usefulness of any information, apparatus, product, or process disclosed, or represents that its use would not infringe privately owned rights. Reference herein to any specific commercial product, process, or service by trade name, trademark, manufacturer, or otherwise does not necessarily constitute or imply its endorsement, recommendation, or favoring by the United States Government or any agency thereof. The views and opinions of authors expressed herein do not necessarily state or reflect those of the United States Government or any agency thereof. 


\section{DISCLAMMER}

Portions of this document may be illegible in electronic image products. Images are produced from the best available original document. 


\section{TABLE OF CONTENTS}

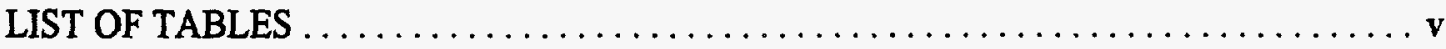

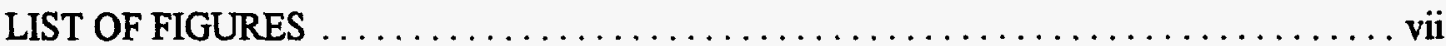

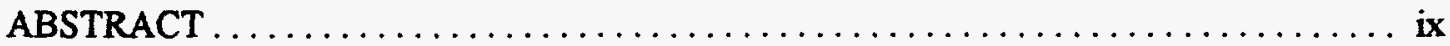

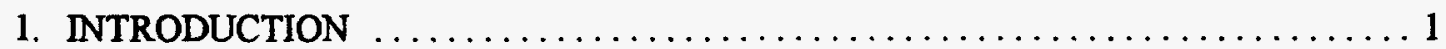

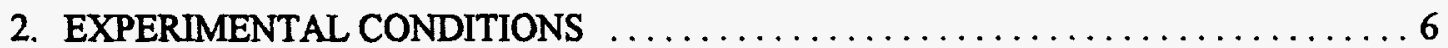

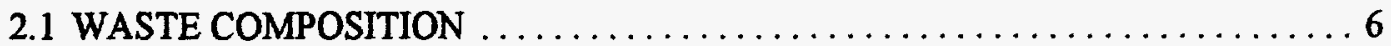

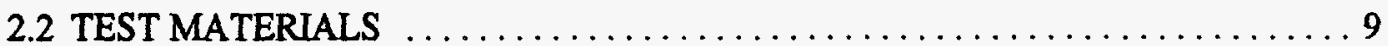

2.3 TEST PROCEDURES $\ldots \ldots \ldots \ldots \ldots \ldots \ldots \ldots \ldots \ldots \ldots \ldots, \ldots \ldots \ldots$

3. IMPACT OF WASTE COMPOSITION ON THE PROPOSED NGLLLW

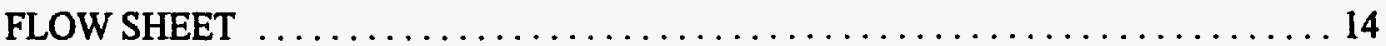

3.1 ALTERATION OF NGLLLW COMPOSITION $\ldots \ldots \ldots \ldots \ldots \ldots \ldots \ldots \ldots \ldots \ldots$

3.2 VARIATION IN CESIUM CONCENTRATION ..................... 15

3.3 DECONTAMINATION OF NGLLLW BLENDED WITH MVST

SUPERNATE-SIMULANT TESTING $\ldots \ldots \ldots \ldots \ldots \ldots \ldots \ldots \ldots \ldots \ldots$

3.4 TREATING NGLLLW SIMULANT BLENDED WITH ACTUAL MVST

SUPERNATE .................................... 20

3.5 EFFECT OF ORGANIC COMPOUNDS ON THE NGLLLW FLOW SHEET . . . . 27

4. LIQUID/SOLID SEPARATION TEST RESULTS $\ldots \ldots \ldots \ldots \ldots \ldots \ldots \ldots \ldots \ldots$

4.1 POLYMERIC SETTLING AGENTS ........................... 30

4.2 LIQUID/SOLID SEPARATION USING CROSS-FLOW FILTRATION ....... 36

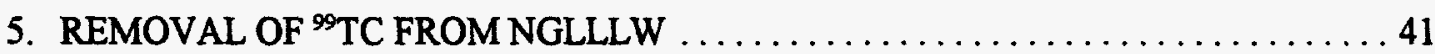

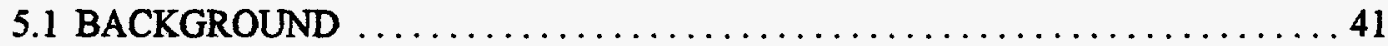

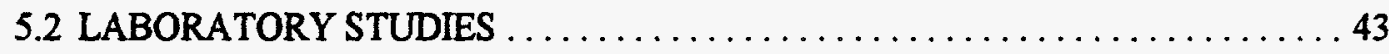

5.3 RECOMMENDATIONS $\ldots \ldots \ldots \ldots \ldots \ldots \ldots \ldots \ldots \ldots \ldots \ldots \ldots \ldots, 48$

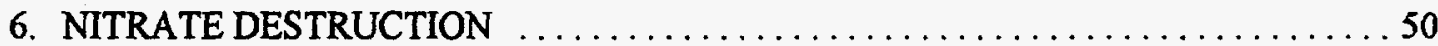

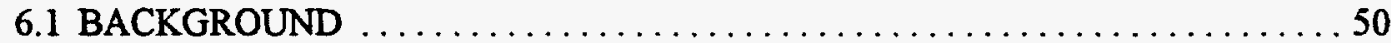

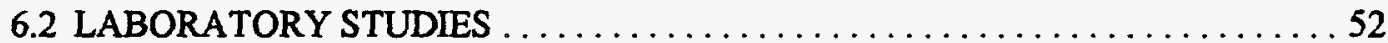

7. LITERATURE SURVEY: SAFETY OF CESIUM REMOVAL WITH KCCF . ..... 56

7.1 BACKGROUND ...................................... 56

7.2 HANFORD WASTES AND TREATMENT FLOW SHEET $\ldots \ldots \ldots \ldots \ldots \ldots 57$

7.3 STABILITY OF SOLID HEXACYANOFERRATES $\ldots \ldots \ldots \ldots \ldots \ldots \ldots . \ldots 59$

7.4 STABILITY OF SOLUBLE HEXACYANOFERRATES $\ldots \ldots \ldots \ldots \ldots \ldots, 61$

7.5 IMPLICATIONS FOR ORNL TREATMENT FLOW SHEET $\ldots \ldots \ldots \ldots \ldots \ldots, 64$ 
8. EVALUATION OF INTERIM AND FINAL WASTE FORMS FOR THE

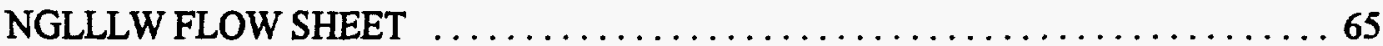

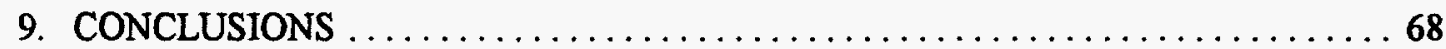

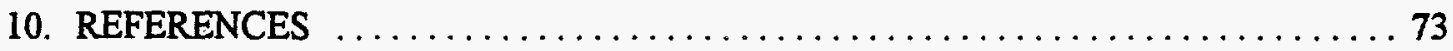




\section{LIST OF TABLES}

Table

Page

1 Composition of simulated waste solutions $\ldots \ldots \ldots \ldots \ldots \ldots \ldots \ldots$

2 Effect of NGLLW simulant composition on $\mathrm{Sr}$ and $\mathrm{Cs}$ removal $\ldots \ldots \ldots \ldots \ldots$

3 Effects of cesium concentration on KCCF treatment for cesium removal ....... 16

4 Analytical data for MVST supernatants $\ldots \ldots \ldots \ldots \ldots \ldots \ldots \ldots \ldots \ldots \ldots \ldots \ldots \ldots \ldots \ldots$

5 NGLLLW flow sheet processing of pretreated actual MVST supernate in

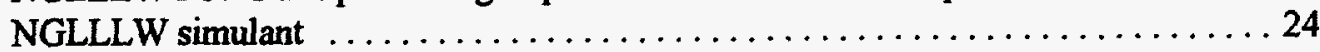

6 NGLLLW flow sheet processing of NGLLLW simulant blended with untreated

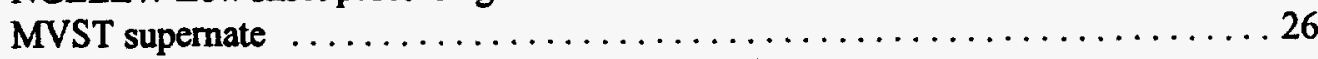

7 NGLLLW flow sheet processing of NGLLLW simulant containing organic

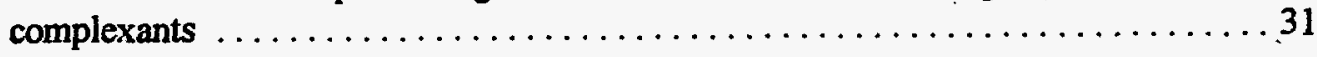

8 Strontium and cesium decontamination factors using polymeric flocculating

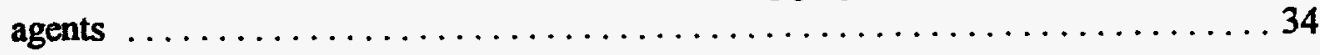

9 Sequential filtering of $\mathrm{SrCO}_{3}$ and $\mathrm{KCCF}$ solids after addition of flocculating

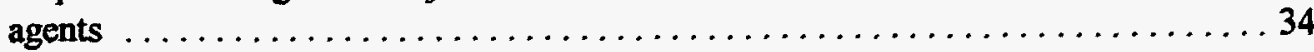

10 NAC processing of 75-mL NGLLLW/MVST supernate samples $\ldots \ldots \ldots \ldots \ldots 53$

11 Composition of dried solids from $\mathrm{Cs}$ separation $\ldots \ldots \ldots \ldots \ldots \ldots \ldots \ldots$ 


\section{LIST OF FIGURES}

Figure

Page

1 Flow sheet of the ORNL liquid waste treatment system with proposed

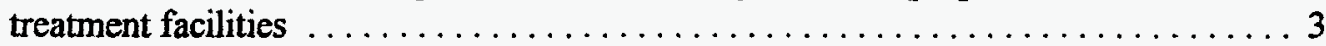

2 Proposed flow sheet for the treatment of NGLLLW $\ldots \ldots \ldots \ldots \ldots \ldots \ldots$

3 Strontium DF in NGLLLW simulant blended with MVST supernate simulant . . . 18

4 Cesium DF in NGLLLW simulant blended with MVST supernate simulant . . . . . 19

5 Flow diagram for the bench-scale NGLLLW flow sheet test unit $\ldots \ldots \ldots \ldots \ldots$

6 Adsorbent removal efficiency as a function of $\mathrm{pH}(0.01 \mathrm{~g}$ of adsorbent per milliliter

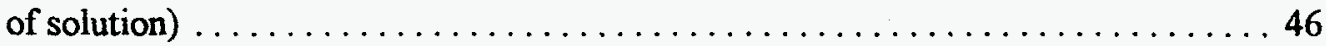

7 Breakthrough test for ${ }^{99} \mathrm{Tc}$ (using Dowex ${ }^{\mathrm{TM}} 1-\mathrm{X} 8$ resin in surrogate ORNL NGLLLW) 


\begin{abstract}
During FY 1995, studies were continued to develop improved methods for centralized treatment of liquid low-level waste (LLLW) at Oak Ridge National Laboratory (ORNL). Focus in this reporting period was on (1) identifying the parameters that affect the selective removal of ${ }^{90} \mathrm{Sr}$ and ${ }^{137} \mathrm{Cs}$, two of the principal radioactive contaminants expected in the waste; (2) validating the effectiveness of the treatment methods by testing an actual Melton Valley Storage Tank (MVST) supernate; (3) evaluating the optimum solid/liquid separation techniques for the waste; (4) identifying potential treatment methods for removal of technetium from LLLW; and (5) identifying potential methods for stabilizing the high-activity secondary solid wastes generated by the treatment.

The treatment methods involve chemical precipitation and ion-exchange operations. In the process flow sheet, ${ }^{90} \mathrm{Sr}$ removal is based on coprecipitation from the strongly alkaline waste by adding stable strontium to the solution. Ferric iron, added with the stable strontium, improves ${ }^{90} \mathrm{Sr}$ removal and aids in flocculation of the $\mathrm{SrCO}_{3}$ precipitate. After separation of the $\mathrm{SrCO}_{3}$ precipitate, the resultant liquid is adjusted to $\mathrm{pH} 8.0$ for the cesium removal treatment. Upon $\mathrm{pH}$ adjustment, aluminum precipitates from the waste and sorbs an additional amount of ${ }^{90} \mathrm{Sr}$. Cesium is removed from the adjusted waste by a two-stage treatment with potassium cobalt hexacyanoferrate (KCCF) slurry formed in situ by the addition of potassium ferrocyanide $\left[\mathrm{K}_{4} \mathrm{Fe}(\mathrm{CN})_{6}\right]$ and cobalt nitrate $\left[\mathrm{Co}\left(\mathrm{NO}_{3}\right)_{2}\right]$ solutions.

The treatment operations could potentially be applied to treat both MVST supernate and newly generated LLLW (NGLLLW). NGLLLW refers to LLLW anticipated to be generated from future ORNL program activities. NGLLLW is typically about $0.1 \mathrm{M} \mathrm{NaOH}$ and about
\end{abstract}


$0.1 M \mathrm{Na}_{2} \mathrm{CO}_{3}$, with minor amounts of $\mathrm{NaNO}_{3}$ and $\mathrm{NaCl}$. It is expected that the concentrations of the major components of the waste matrix could vary substantially in actual operations. The MVST supernate composition used in the study is based on the current composition in tank W-29, which is about $5 \mathrm{MNaNO}_{3}, 0.3 \mathrm{MNaOH}, 0.3 \mathrm{M} \mathrm{KNO}$, and $0.2 M$ $\mathrm{Na}_{2} \mathrm{CO}_{3}$.

Laboratory testing in FY 1995 was conducted to determine the impact of variations in waste composition on the proposed flow sheet. The NGLLLW flow sheet was tested with NGLLLW simulants representing (1) the less caustic waste that currently is generated after an operational change at the Radiochemical Engineering Development Center (REDC), (2) NGLLLW that is contaminated with organic complexants that have been associated with previous transuranic processing activities at ORNL, and (3) LLLW in which NGLLLW is blended with MVST supernate. Results from these studies indicate that strontium removal from LLLW is more efficient as the carbonate content in the waste is reduced. However, smaller particles of KCCF solids are formed in the lower-salt waste solutions, requiring more efficient filtration systems to obtain an equivalent decontamination of cesium. Organic complexant compounds, introduced into NGLLLW from processing operations at REDC, appear to further impact cesium decontamination by complexing the cobalt required in the formation of KCCF sorbent and by reducing KCCF particle size. The introduction of MVST supernate simulant into NGLLLW simulant also reduces the removal of strontium and cesium from the mixed waste simulant samples. However, even with the continuous loss of strontium and cesium decontamination, the cumulative decontamination factors (DFs) in $100 \%$ MVST supernate simulant samples exceed those required by the NGLLLW flow sheet.

The validity of the NGLLLW flow sheet was evaluated by treating NGLLLW simulant that had been blended with up to $75 \%$ actual MVST supernate. The first series of testing was 
performed using the supernate from tank W-29, in which the majority of cesium was removed with Savannah River resin to reduce personnel exposure. Only $15-25 \%$ of the strontium was removed from pretreated supernate samples.

It was later determined that the resin leaches an organic complexant that prevents strontium carbonate formation and precipitation. In a second series of experiments with untreated MVST supernate, the cumulative strontium DFs for 25 and $75 \%$ MVST supernate samples were 280 and 30 , respectively. The cumulative cesium DFs in the blended samples were 1100 and 775 , respectively.

Several peripheral studies were also initiated in this reporting period. The success of the NGLLLW flow sheet will be dependent upon the efficient removal of solids generated at the completion of each unit operation. A number of polymeric settling agents were studied in an effort to select appropriate flocculating agents for the strontium coprecipitation and KCCF unit operations. Since this study has met with only limited success, a bench-scale filtration unit was designed and constructed to study liquid/solid separation processes that can successfully remove the solids generated in the flow sheet. The need for treatment of ${ }^{99} \mathrm{Tc}$ in NGLLLW was also reviewed. $\mathrm{A}^{99} \mathrm{Tc} \mathrm{DF}$ of 30 will be required in the flow sheet; a recommendation was made to treat NGLLLW with Dowex ${ }^{7 M} 1-8 \mathrm{X}$ anion-exchange resin to remove the ${ }^{92} \mathrm{Tc}$. In addition, the nitrogen to ammonia and ceramic (NAC) process was evaluated as a mechanism for removing radionuclides and nitrate from NGLLLW, as well as creating a stabilized final waste form for the secondary solid low-level waste generated in the flow sheet. NAC processing removed the majority of strontium from NGLLLW, at the expense of creating a large amount of secondary solid low-level waste. This effort was supported by a literature survey to identify current interim and final waste forms that might be applicable to the 
immobilization of the solid low-level waste. The literature review is still in progress;

complete results of the study should be available in early FY 1996.

xii 


\section{INTRODUCTION}

The liquid low-level waste (LLLW) collection and treatment system at Oak Ridge National Laboratory (ORNL) currently treats over 400,000 gal of waste per year by evaporation to reduce the volume to approximately 20,000 gal of waste concentrate. The LLLW concentrate is stored in eight 50,000-gal vaulted underground storage tanks known as the Melton Valley Storage Tanks (MVSTs) and has been accumulating there since 1984. It was originally proposed that MVST concentrate, which consists of both solid sludges and liquid supernate, be further evaporated to a salt cake at the proposed Waste Handling and Packaging Plant (WHPP) to be constructed at ORNL. ${ }^{1}$ It was anticipated that this salt cake would be accepted for disposal at the U.S. Department of Energy (DOE) Waste Isolation Pilot Plant (WIPP) in Carlsbad, New Mexico. However, uncertainty associated with implementation of the WIPP has led to funding delays for the WHPP. To deal with continuing difficulties associated with limited LLLW concentrate storage capacity at the MVSTs, other treatment and disposal alternatives are being investigated. These new treatment methods must be capable of treating existing LLLW concentrate and also LLLW that will be generated in future ORNL activities (referred to as newly generated LLLW, or NGLLLW). Due to the overall limited space for storage and disposal of radioactive wastes on the Oak Ridge Reservation (ORR), the new treatment methods must generate the smallest possible volume of highly radioactive Greaterthan-Class-LII solid waste. These solid wastes might be permanently disposed of at DOE facilities (if available) or placed in retrievable storage facilities at ORNL until permanent disposal facilities are available. Treated liquids might be either discharged to the environment or solidified and disposed of on-site as Class LII waste. 
A block diagram showing the existing ORNL waste treatment facilities and the proposed LLLW treatment facility is shown in Fig. 1. As described previously, the current centralized treatment of these wastes involves evaporation of the LLLW and storage of the evaporator concentrate in the MVSTs. The solid sludges, which contain significant quantities of transuranic (TRU) contaminants, would be mixed with the liquid supernate at the proposed WHPP before evaporation to a salt cake. The salt cake would then be transported to the WIPP, which was designed for disposal of TRU wastes. No permanent disposal facilities for TRU wastes exist at ORNL. Retrievable storage facilities with limited capacity are available, but they are far too small for storage of MVST TRU sludges. Therefore, the WHPP cannot be initiated until the WIPP is available. To create additional storage space in the MVSTs without creating a TRU solid waste, only the MVST non-TRU supernate liquids can be treated. The MVST sludges would be stored in the MVSTs until the WHPP or an equivalent TRU sludge treatment facility is available. To prevent further addition of TRU waste to the LLLW system, facilities that produce TRU waste are making plans to segregate TRU at the source. One option for treatment of both NGLLLW and MVST supernate involves evaporation to a non-TRU salt cake using the WHPP systems; however, this treatment would result in a relatively large volume of Greater-than Class-LII waste composed primarily of contaminated sodium nitrate. This waste could not be disposed of on-site, and the sodium nitrate waste form is undesirable due to its solubility in water and its potential for dispersion if exposed to environmental conditions. The present study has focused on the use of inorganic ion-exchange materials that can selectively sorb the radioactive contaminants and produce a small volume of inorganic solid waste. The inorganic sorbents do not decompose, and the contaminants are more likely to remain sorbed if exposed to environmental conditions, a characteristic that makes them more amenable for long-term storage or disposal. Selective 


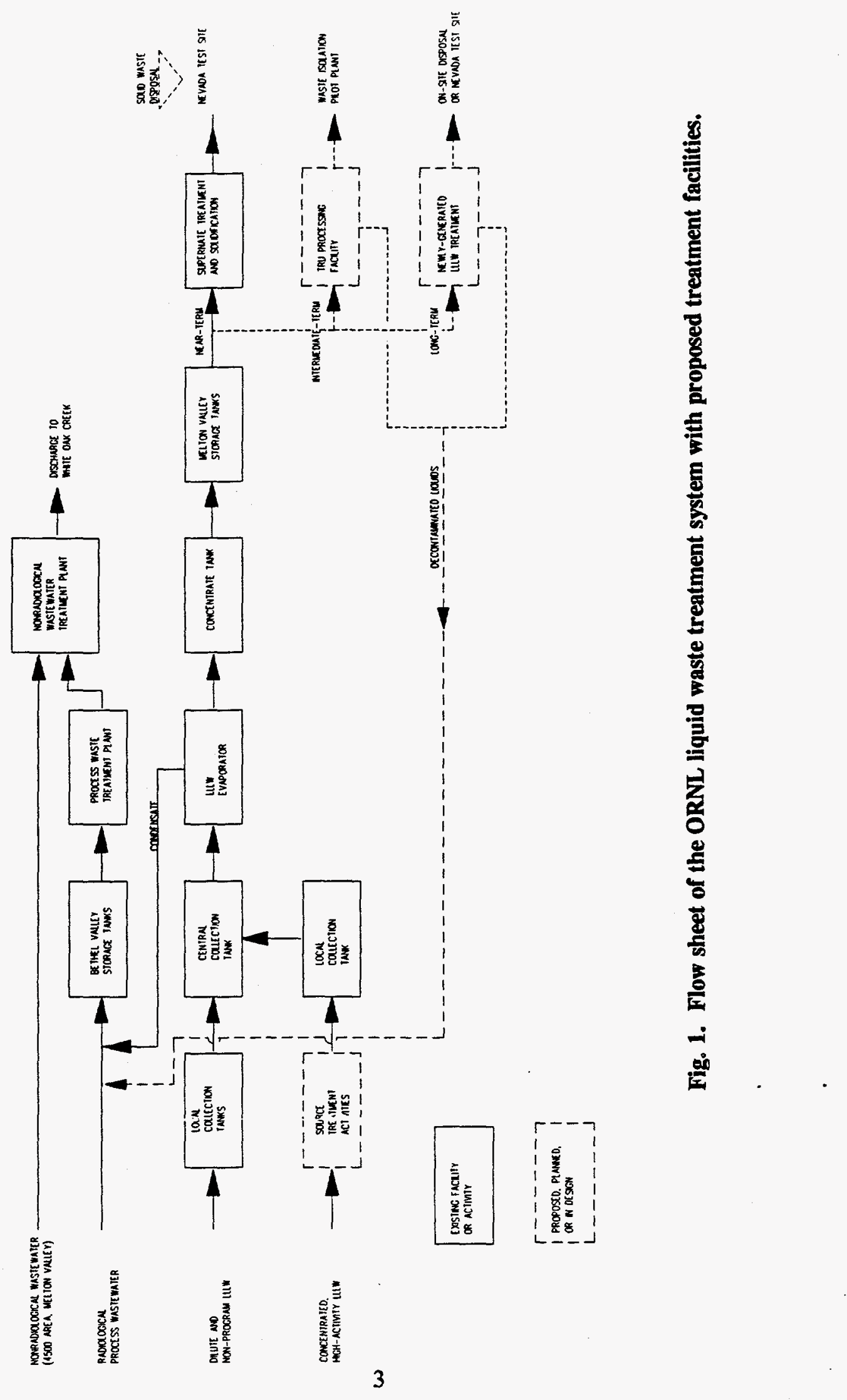


removal of the principal LLLW contaminants will greatly reduce the volume of Greater-thanClass LII waste and allow the solidification of the treated liquids for on-site disposal as Class LII wastes. The required decontamination factors (DFs) for the removal ${ }^{90} \mathrm{Sr}$ and ${ }^{137} \mathrm{Cs}$ from NGLLLW for discharge to the process waste system at ORNL are 78 and 1320 , respectively. The comparable required DFs from MVST supernate are 0.76 and 78 , respectively. ${ }^{2}$

Effective treatment methods for removing ${ }^{90} \mathrm{Sr}$ and ${ }^{137} \mathrm{Cs}$ from the waste solutions were identified earlier in the program. ${ }^{2}$ Of those tested, the most successful processing options identified are the removal of strontium by coprecipitation and the removal of cesium with the ion exchanger potassium cobalt hexacyanoferrate (KCCF). The proposed ORNL treatment flow sheet that includes these unit operations is shown in Fig. 2. The first unit operation removes ${ }^{90} \mathrm{Sr}$ by coprecipitation from strongly alkaline waste with the addition of stable strontium to the waste solution. Ferric sulfate, added with the stable strontium, improves the ${ }^{90} \mathrm{Sr}$ removal and aids in the flocculation of the $\mathrm{SrCO}_{3}$ precipitate. After separation of the solids, the resultant solution is adjusted to $\mathrm{pH} 8$ for the cesium removal unit operations. Upon $\mathrm{pH}$ adjustment, aluminum originally present in the untreated alkaline waste precipitates and sorbs an additional amount of ${ }^{90} \mathrm{Sr}$. Cesium-137 is removed from the neutralized waste by two sequential treatments with $\mathrm{KCCF}$ slurry formed by the addition of $\mathrm{K}_{4} \mathrm{Fe}(\mathrm{CN})_{6}$ and $\mathrm{Co}\left(\mathrm{NO}_{3}\right)_{2}$ solutions.

Maximum ${ }^{90} \mathrm{Sr}$ decontamination is obtained when at least $50 \mathrm{ppm}$ stable strontium is added to the waste. Because the formation of the $\mathrm{SrCO}_{3}$ is very rapid, efficient mixing of the strontium carrier into the waste is required. The stable strontium must be dispersed throughout the waste to equilibrate with the radioactive strontium before precipitation is completed. Precipitation of $\mathrm{SrCO}_{3}$ is most effective at $\mathrm{pH} 13$ and decreases dramatically below pH 11. Ferric ion, $25 \mathrm{ppm}$ iron as $\mathrm{Fe}_{2}\left(\mathrm{SO}_{4}\right)_{3}$, and $2 \mathrm{ppm}$ of an acrylic polymer are 
added to the treated waste to aid in the physical separation of the fine $\mathrm{SrCO}_{3}$ solids. Under optimum conditions, the ${ }^{90} \mathrm{Sr} \mathrm{DF}$, defined as the initial ${ }^{90} \mathrm{Sr}$ activity divided by the final ${ }^{90} \mathrm{Sr}$ activity in the treated waste, is 200 for the $\mathrm{SrCO}_{3}$ precipitation unit operation.

The LLLW contains approximately $335 \mathrm{ppm}$ aluminum that precipitates as $\mathrm{Al}(\mathrm{OH})_{3}$ as the $\mathrm{pH}$ of the waste is reduced from 13 to 8 . Sorption of ${ }^{90} \mathrm{Sr}$ remaining from the strontium coprecipitation unit operation is achieved by sorption onto the $\mathrm{Al}(\mathrm{OH})_{3}$ precipitate. The DF for the $\mathrm{pH}$ adjustment unit operation is typically 15 in small-scale simulant samples. Hence, the cumulative DF for the overall process is about 3000 . Strontium removal increases linearly with the concentration of aluminum in the waste. Therefore, the overall DF of the process can be increased by adding aluminum to the LLLW to elevate the concentration above the 335-ppm level already present. Addition of aluminum following $\mathrm{pH}$ adjustment does not improve the strontium DF. The precipitates generated from this unit operation are not separated until the LLLW is treated for the removal of cesium in the first KCCF treatment unit operation.

Cesium removal in the flow sheet is based on treatment at pH 8 with a slurry of KCCF, formed in situ by the sequential addition of stoichiometric amounts of $\mathrm{K}_{4} \mathrm{Fe}(\mathrm{CN})_{6}$ and $\mathrm{Co}\left(\mathrm{NO}_{3}\right)_{2}$ solutions to the waste. A DF of about 1000 is obtained in the first treatment with $100 \mathrm{ppm} \mathrm{KCCF}$ when high-speed centrifugation (5000 rcf) is used to separate the cesiumbearing solids. The $\mathrm{Al}(\mathrm{OH})_{3}$ that precipitates from the $\mathrm{LLLW}$ during the $\mathrm{pH}$ adjustment unit operation aids in the flocculation of the KCCF-cesium complex in the first treatment. Additional $\mathrm{K}_{4} \mathrm{Fe}(\mathrm{CN})_{6}$ and $\mathrm{Co}\left(\mathrm{NO}_{3}\right)_{2}$ solutions are added to the clarified LLLW in the second KCCF treatment to form a 50-ppm KCCF slurry. The cesium DF for the second unit operation is typically 3000 , so that the cumulative DF for both KCCF unit operations is greater than $1 \times 10^{6}$. 
This report describes continued studies of the strontium and cesium removal unit operations, with emphasis on the variables that affect their removal efficiency, such as waste composition and liquid/solid separation processes. The validity of the flow sheet was tested by treating samples of NGLLLW simulant blended with actual MVST supernate. The flow sheet development effort was also expanded this year to determine the need for treating ${ }^{99} \mathrm{Tc}$ that is present in NGLLLW and MVST supernate and to review possible treatment options for this nuclide. Additionally, a literature survey and limited laboratory testing were performed to help identify final waste forms that would be appropriate to stabilize the salt cake that will be generated upon the evaporation of the treated LLLW exiting the proposed flow sheet.

\section{EXPERIMENTAL CONDITIONS}

\subsection{WASTE COMPOSITION}

Two waste streams, MVST supernate and NGLLLW, are considered in this study. Although most of the principal contaminants are found in both wastes, the basic compositions are somewhat different (Table 1). The composition of the simulated MVST supernate is based on analysis of actual supernate samples taken from MVST W-29. ${ }^{3}$ The concentration of components in the supernate is expected to change as a result of the In-Tank Evaporation (ITE) process, which began in 1992. The ITE process involves sparging the MVSTs with dry air to evaporate water and create additional capacity for future waste storage. The concentrations of the constituents in the supernates have been increased by a factor of $30 \%$ over those presented in the Sears et al. report ${ }^{3}$ to reflect the concentration of the MVST supernate through air sparging of the tanks over the past several years. In addition, the inherent carbon dioxide sparged into the tanks along with the air is expected to be absorbed by 


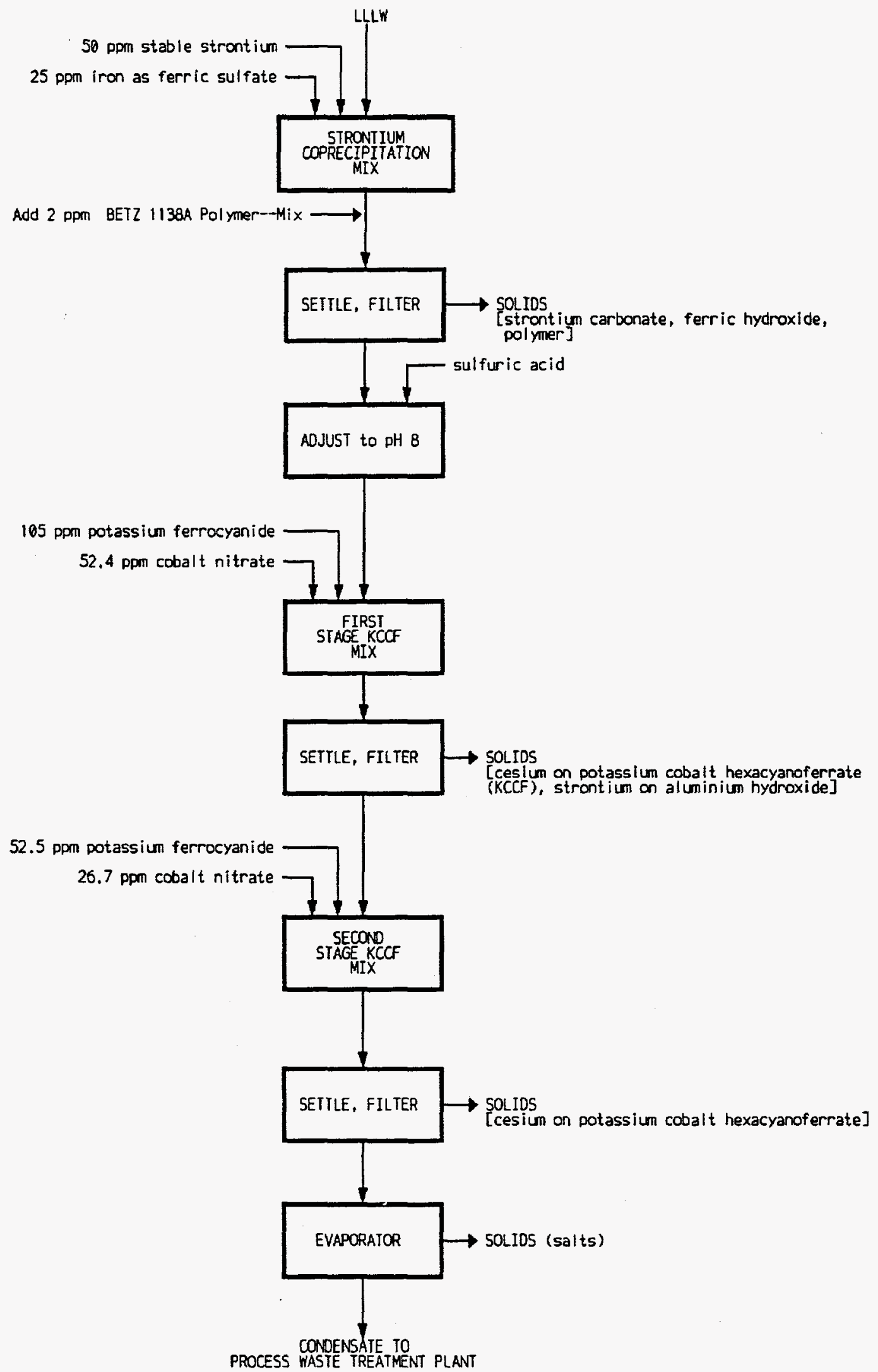

Fig. 2. Proposed flow sheet for the treatment of NGLLLW. 
Table 1. Composition of simulated waste solutions

\begin{tabular}{|c|c|c|c|c|c|}
\hline \multirow[b]{2}{*}{ Component } & \multicolumn{5}{|c|}{ Concentration (mol/L unless otherwise indicated) ${ }^{a}$} \\
\hline & $\begin{array}{c}\text { NGLLLW-A } \\
\mathrm{pH} \mathrm{13}\end{array}$ & $\underset{\mathrm{pH} 13}{\text { NGLLLW-B }}$ & $\frac{\substack{\text { NGLLLW-B } \\
\mathrm{pH} 8}}{2}$ & $\begin{array}{c}30 \% \\
\text { concentrated } \\
\text { MVST supernate } \\
\text { pH } 13 \\
\end{array}$ & $\begin{array}{c}30 \% \text { concentrated } \\
\text { MVST } \\
\text { supemate } \\
\mathrm{pH} 8 \\
\end{array}$ \\
\hline $\mathrm{NaOH}$ & 0.34 & .125 & $\mathrm{NP}$ & 0.313 & NP \\
\hline $\mathrm{Na}_{2} \mathrm{CO}_{3}$ & 59 & 0.1 & NP & 0.182 & NP \\
\hline $\mathrm{NaHCO}_{3}$ & NP & NP & 0.096 & NP & 0.167 \\
\hline $\mathrm{NaNO}_{3}$ & 0.061 & 0.061 & 0.059 & 5.07 & 4.64 \\
\hline $\mathrm{NaCl}$ & 0.034 & 0.034 & 0.033 & 0.13 & 0.119 \\
\hline $\mathrm{Na}_{2} \mathrm{SO}_{4}$ & NP & NP & 0.108 & NP & 0.227 \\
\hline $\mathrm{LiCl}$ & 0.025 & 0.025 & 0.024 & NP & NP \\
\hline $\mathrm{KNO}_{3}$ & $\mathrm{NP}$ & NP & NP & 0.312 & 0.286 \\
\hline $\mathrm{Al}\left(\mathrm{NO}_{3}\right)_{2}$ & NP & NP & NP & 0.0063 & NP \\
\hline $\mathrm{NaAlO}_{2}$ & 0.0117 & 0.0117 & NP & NP & NP \\
\hline $\mathrm{Al}(\mathrm{OH})_{3}$ & NP & NP & 0.0101 & NP & 0.0061 \\
\hline $\mathrm{CaCO}_{3}$ & NP & NP & NP & 0.00013 & 0.00012 \\
\hline $\mathrm{Zn}\left(\mathrm{NO}_{3}\right)$ & NP & NP & NP & 0.0013 & 0.0012 \\
\hline${ }^{90} \mathrm{Sr}, \mathrm{mCl} / \mathrm{L}$ & 19.4 & 19.4 & & 0.26 & \\
\hline${ }^{134,139} \mathrm{Cs}, \mathrm{mCi} / \mathrm{L}$ & 99.5 & 99.5 & & 7.9 & \\
\hline${ }^{100,106} \mathrm{Ru}, \mathrm{mCi} / \mathrm{L}$ & 132 & 132 & & $<5 \mathrm{E}-8$ & \\
\hline pH & 13.1 & 12.7 & 8.0 & 13.1 & 8.0 \\
\hline Density, $g / \mathrm{mL}$ & 1.074 & 1.020 & 1.01 & 1.308 & 1.608 \\
\hline
\end{tabular}

NGLLLW-A = newly generated liquid low-level waste prior to 1994; NGLLLW-B = newly generated liquid low-level waste after 1994; 
the supernate and lower the $\mathrm{pH}$ of the waste. Calculations were performed that predict that one-half of the carbon dioxide entering with the air will be absorbed and that over a 2-year period the $\mathrm{pH}$ of the supernate will drop below $9 .^{4}$

Because similar analytical data are not available for NGLLLW, generator surveys, forecasts of future ORNL program activities, and changes in process operating conditions were used to estimate the composition of NGLLLW. The rationale for choosing the composition of simulated NGLLLW was described in detail in a previous report. ${ }^{5}$ The $\mathrm{NaOH}$ and $\mathrm{Na}_{2} \mathrm{CO}_{3}$ concentrations in the NGLLLW simulant were derived from the composition of the vessel off-gas scrubber used at the Radiochemical Engineering Development Center (REDC). Until 1993, the scrubber solution typically contained 5.5 M KOH in a carbonate matrix. At the time the composition of the simulant was being formulated, it was known that the scrubber solution would eventually change from a potassium-based to a sodium-based solution, and the initial NGLLLW simulant was prepared containing $0.335 M \mathrm{NaOH}$ and $0.587 \mathrm{M} \mathrm{Na}_{2} \mathrm{CO}_{3}$. The composition and quantity of the $\mathrm{REDC}$ waste were changed in late 1994, resulting in a reformulation of the NGLLLW simulant to contain $0.125 \mathrm{M} \mathrm{NaOH}$ and $0.100 \mathrm{M} \mathrm{Na}_{2} \mathrm{CO}_{3}$ (NGLLLW-B). In Table 1 and the remainder of this report, the initial simulant is identified as NGLLLW-A and the reformulated simulant is identified as NGLLLW-B.

\subsection{TEST MATERIALS}

A single sorption experiment was performed to compare nuclide removal from each of the two NGLLLW waste simulants listed in Table 2. All remaining sorption tests were conducted using the reformulated simulant, NGLLLW-B. The solutions were prepared by dissolving reagent-grade chemicals in water. Because most process solutions at ORNL are 
Table 2. Effect of NGLLLW simulant composition on $\mathrm{Sr}$ and $\mathrm{Cs}$ removal ${ }^{a}$

\begin{tabular}{|c|c|c|c|c|c|}
\hline \multirow{2}{*}{ Simulant } & \multirow{2}{*}{ Unit operation } & \multicolumn{2}{|c|}{ Sr decontamination factor } & \multicolumn{2}{|c|}{ Cs decontamination factor } \\
\hline & & $\begin{array}{c}\text { Unit } \\
\text { operation }\end{array}$ & Cumulative & $\begin{array}{c}\text { Unit } \\
\text { operation }\end{array}$ & Cumulative \\
\hline \multirow[t]{4}{*}{ NGLLLW-A ${ }^{b}$} & Sr coprecipitation & 200 & -- & 1.0 & -- \\
\hline & $\mathrm{Al}(\mathrm{OH})_{3}$ sorption & 1.8 & 360 & 1.16 & 1.16 \\
\hline & $\begin{array}{l}\text { First KCCF } \\
\text { treatment }\end{array}$ & -- & - & 1,500 & 1,700 \\
\hline & $\begin{array}{l}\text { Second KCCF } \\
\text { treatment }\end{array}$ & - & - & 350 & 600,000 \\
\hline \multirow[t]{4}{*}{ NGLLLW-B ${ }^{b}$} & Sr coprecipitation & 200 & - & 1.0 & - \\
\hline & $\mathrm{Al}(\mathrm{OH})_{3}$ sorption & 15 & 3,000 & 1.07 & 1.07 \\
\hline & $\begin{array}{l}\text { First KCCF } \\
\text { treatment }\end{array}$ & - & - & 700 & 700 \\
\hline & $\begin{array}{l}\text { Second KCCF } \\
\text { treatment }\end{array}$ & - & - & 120 & 90,000 \\
\hline
\end{tabular}

Procedure: $\mathrm{Sr}$ Coprecipitation- $\mathrm{Stable} \mathrm{SrCl}_{2}(50 \mathrm{ppm} \mathrm{Sr})$ and $\mathrm{Fe}_{2}\left(\mathrm{SO}_{4}\right)_{3}(25 \mathrm{ppm} \mathrm{Fe}$ ) were added to NGLLLW simulants (0.141 ppm Sr, $3.48 \mathrm{ppm} C s$, and $0.0337 \mathrm{ppm} \mathrm{Ru}$, traced with ${ }^{85} \mathrm{Sr}$ and $\left.{ }^{137} \mathrm{Cs}\right)$, and the solutions were mixed for $1 \mathrm{~h}$ with a magnetic stirrer. The solutions were mixed an additional $10 \mathrm{~min}$ after the addition of $1 \mathrm{ppm}$ BetzQ1138 polymer and centrifuged for $30 \mathrm{~min}$ at $5000 \mathrm{rcf}$. The ${ }^{85} \mathrm{Sr}$ and ${ }^{137} \mathrm{Cs}$ count rates of the centrifuged solutions were measured. $\mathrm{Al}(\mathrm{OH})_{3}$ Sorption-The centrifuged solutions were adjusted to $\mathrm{pH} 8$ with $5.4 \mathrm{~N} \mathrm{H}_{2} \mathrm{SO}_{4}$ and mixed for $1 \mathrm{~h}$ with a magnetic stirrer. Aliquots of the adjusted solutions were centrifuged for $30 \mathrm{~min}$ at $5000 \mathrm{rcf}$, and the ${ }^{85} \mathrm{Sr}$ and ${ }^{137} \mathrm{Cs}$ count rates of the centrifuged solutions were measured. First KCCF Treatment- The uncentrifuged solutions from the pH adjustment step were mixed for $1 \mathrm{~h}$ on a Labquake shaker with $100 \mathrm{ppm} \mathrm{KCCF}$ slurry, formed in situ by the sequential addition of $\mathrm{K}_{4} \mathrm{Fe}(\mathrm{CN})_{6}$ and $\mathrm{Co}\left(\mathrm{NO}_{3}\right)_{2}$ solutions. The samples were mixed for an additional $10 \mathrm{~min}$ after the addition of $2 \mathrm{ppm}$ MagniFloc@ 1885 A polymer. The samples were centrifuged for $30 \mathrm{~min}$ at $5000 \mathrm{rcf}$, and the ${ }^{85} \mathrm{Sr}$ and ${ }^{137} \mathrm{Cs}$ count rates were measured. Second KCCF Treatment- The centrifuged solutions from the first KCCF treatment were mixed for $1 \mathrm{~h}$ on a Labquake shaker with $50 \mathrm{ppm}$ in situ KCCF slurry. The samples were mixed for an additional $10 \mathrm{~min}$ after the addition of $2 \mathrm{ppm}$ MagniFloc@ 1885 A polymer. The samples were centrifuged for $30 \mathrm{~min}$ at $5000 \mathrm{rcf}$ and the ${ }^{85} \mathrm{Sr}$ and ${ }^{137} \mathrm{Cs}$ count rates measured.

${ }^{B}$ NGLLLW-A = newly generated liquid low-level waste prior to 1994 ; NGLLLW-B = newly generated liquid low-level waste after 1994. 
based on tap water, the two simulated NGLLLW compositions and the MVST supernate simulant were prepared from tap water. Small amounts of finely divided precipitate $\left(\mathrm{CaCO}_{3}\right.$ from calcium in the process water) formed in the simulant solutions when the alkaline components were added. The precipitate was not filtered from the solution and was present in the test solutions. Stock solutions of the simulants were mixed thoroughly before aliquots were removed for testing. The stable $\mathrm{Sr}, \mathrm{Cs}$, and $\mathrm{Ru}$ representing the expected molar concentrations of the radioactive contaminants were added to the waste simulants in the form of chloride salts, as were the radioactive tracer solutions. The ${ }^{85} \mathrm{Sr}$ was obtained from NEN Research Products, Boston, Massachusetts, and the ${ }^{137} \mathrm{Cs}$ (and ${ }^{99} \mathrm{Tc}$ ) were obtained from Amersham Corporation, Arlington Heights, Illinois.

The strontium chloride used in coprecipitation tests was a high-purity laboratory chemical. A ferric sulfate solution (Ferri Floc, Tennessee Chemical Company, Atlanta, Georgia) was used to aid in the flocculation of the finely divided $\mathrm{SrCO}_{3}$ solids. The cesium sorption studies were performed using $\mathrm{KCCF}$. The $\mathrm{K}_{4} \mathrm{Fe}(\mathrm{CN})_{6}$ and $\mathrm{Co}\left(\mathrm{NO}_{3}\right)_{2}$ solutions added to precipitate KCCF within the waste samples were prepared from high-purity laboratory chemicals. The polymers used for liquid/solid separation studies were obtained from American Cyanamid Company (Wayne, New Jersey), Betz Chemical Company (Trevose, Pennsylvania), and Calgon Corporation (Pittsburgh, Pennsylvania).

\subsection{TEST PROCEDURES}

Most of the sorption measurements were obtained in batch equilibration tests, with three samples included in most data sets. The solutions contained $\mathrm{SrCl}_{2}, \mathrm{CsCl}$, and $\mathrm{RuCl}_{3}$ equivalent to the molar concentrations of the radioactive contaminants expected in the actual waste solutions and were traced with ${ }^{85} \mathrm{Sr}$ and/or ${ }^{137} \mathrm{Cs}$. The strontium coprecipitation tests 
were conducted in $20-\mathrm{mL}$ polyethylene vials. In this unit operation, measured volumes of $\mathrm{SrCl}_{2}$ solution and $\mathrm{Fe}_{2}\left(\mathrm{SO}_{4}\right)_{3}$ solutions were added to simulated waste samples that were being stirred vigorously with magnetic stirrers. The treatment of the waste simulants with the combination of $\mathrm{SrCl}_{2}$ and ferric sulfate is referred to in the remainder of this report as the strontium coprecipitation.

After the mixing period, a liquid/solid separation was made by either filtering the treated solution with a nylon filter membrane or transferring the test mixtures to centrifuge tubes and centrifuging for $30 \mathrm{~min}$ at $5000 \mathrm{rcf}$. The ${ }^{85} \mathrm{Sr}$ count rates of aliquots of the clarified solutions were measured. The solutions were then adjusted to $\mathrm{pH} 8$ with $\mathrm{H}_{2} \mathrm{SO}_{4}$. Strontium removal by sorption on the $\mathrm{Al}(\mathrm{OH})_{3}$ that precipitated during the $\mathrm{pH}$ adjustment was determined by measuring the ${ }^{85} \mathrm{Sr}$ count rate of aliquots of the neutralized solutions after centrifugation for 30 $\min$ at 5000 ref.

Cesium sorption tests were performed in $30-\mathrm{mL}$ centrifuge tubes with the waste simulants adjusted to $\mathrm{pH} 8$. The adjusted solutions containing precipitated $\mathrm{Al}(\mathrm{OH})_{3}$ were not centrifuged before the cesium sorption tests. Solutions of $\mathrm{K}_{4} \mathrm{Fe}(\mathrm{CN})_{6}$ were mixed with the waste samples, and $\mathrm{Co}\left(\mathrm{NO}_{3}\right)_{2}$ solutions were then added to form in situ precipitates of KCCF. The test mixtures were either filtered with a nylon filter membrane or centrifuged for $30 \mathrm{~min}$ at 5000 rcf, and cesium sorption was determined by comparing the ${ }^{137} \mathrm{Cs}$ count rates of aliquots of the clarified solutions with the count rates of untreated head solutions. A second-stage KCCF treatment was usually performed by repeating the procedure on the clarified solution from the first KCCF treatment.

Liquid/solid separations were occasionally performed using small plastic syringes fitted with nylon membrane filters (Gelman Acrodisc ${ }^{\bullet}$, Gelman Sciences, Ann Arbor, Michigan). A more suitable filtering system was used in the testing of NGLLLW simulant blended with 
actual MVST supernate. The Whatman Autovial ${ }^{\oplus}$ syringeless filter (Whatman, Inc., Clinton, New Jersey) is constructed with a glass microfiber prefilter and a nylon- 66 membrane filter as integral parts of the unit. Filtering with this system created less shear stress on the fragile KCCF particles, which resulted in significantly better liquid/solid separation.

Test data were used in the following calculations:

Decontamination factor $(\mathrm{DF})=C_{i} / C_{f}$,

Sorption ratio $\left(R_{s}, \mathrm{~L} / \mathrm{kg}\right)=\left(C_{i}-C_{f}\right) V / C_{f} W$,

Concentrations in solution $\left(M_{f}, \operatorname{meq} / \mathrm{L}\right)=M_{i} C_{f} / C_{\mathrm{i}}$,

Concentrations on the exchangers $\left(M_{c}, \mathrm{meq} / \mathrm{kg}\right)=M_{f} R_{s}$,

where

$$
\begin{aligned}
& C_{i}=\text { count rate of the initial solution, } \\
& C_{f}=\text { count rate of the final solution, } \\
& V=\text { initial volume of the solution }(\mathrm{mL}), \\
& W=\text { weight of the exchanger }(\mathrm{g}), \\
& M_{i}=\text { concentration in initial solution }(\mathrm{meq} / \mathrm{L}) .
\end{aligned}
$$

Larger-scale 1.5-L tests were performed to evaluate various polymers for flocculation of precipitates. These tests were conducted in glass or plastic vessels and were stirred with magnetic stirrers or with paddle-type stirrers. After performing the strontium coprecipitation or KCCF treatment under the proper conditions, the polymeric materials were added to the vessels and mixed for $10 \mathrm{~min}$. Then the stirrer speed was reduced, and the stirring was continued for $30 \mathrm{~min}$ to allow flocculation of the solids. The stirring was stopped, and the 
settling rates of the solids were determined by visual observation or by optical measurement of the turbidity of the clarified solutions. Samples of the clarified supernate were also withdrawn to determine the remaining ${ }^{90} \mathrm{Sr}$ or ${ }^{137} \mathrm{Cs}$ activity.

\section{IMPACT OF WASTE COMPOSITION ON THE PROPOSED NGLLLW FLOW SHEET}

\subsection{ALTERATION OF NGLLLW WASTE COMPOSITION}

The LLLW from REDC makes up a major proportion of NGLLLW that will be treated at the planned centralized waste treatment facility. The chemical process at REDC was altered in late FY 1994 such that the sodium hydroxide and sodium carbonate in the waste were significantly reduced. The reformulation of the NGLLLW simulant, as presented in Table 2 , reflects the compositional change in the waste. The old formulation of the simulant (NGLLLW-A) and the newer, less caustic (NGLLLW-B) wastes were used in a comparison test. The studies were conducted to determine whether strontium removal by coprecipitation and cesium removal by ion exchange on KCCF would be affected.

A single comparison test of the two simulant formulations was performed in FY 1994. Results from that test indicated that strontium removal was enhanced in the less-caustic simulant, but the improved removal of cesium was inconsistent with other experimental results. The current study is a duplication of that test to check FY 1994 treatment results. Two minor procedural deviations were made from the FY 1994 test. These included switching from Calgon( WT-2466 to Betz@ 1138 settling agent for solids removal in the strontium coprecipitation unit operation and switching from Calgon $($ WT-2466I to MagniFloc $(1885 \mathrm{~A}$ flocculant to settle KCCF solids for cesium removal. Table 2 presents the DFs obtained in the 
FY 1995 test for each unit operation from both simulants. The overall DF for strontium removal was at least 5 times greater in the NGLLLW-B simulant than found in FY 1994 testing.

However, cesium removal in the NGLLLW-B was only about $10 \%$ of that obtained using the old simulant formulation. The results for the most recent test are more consistent with data obtained for cesium removal in lower-salt solutions. It appears that reducing the total quantity of salts in the LLLW reduces the effectiveness of cesium removal with KCCF. It was unclear from this study whether the change in the chemical composition of the NGLLLW simulant decreased the cesium sorption capacity of the KCCF particles or whether the liquid/solid separation at the completion of the KCCF unit operations was less effective in the less-caustic media.

\subsection{VARIATION IN CESIUM CONCENTRATION}

The removal of cesium from NGLLLW-B simulant was also tested as a function of the total quantity of cesium present in the LLLW. A majority of the development testing for the flow sheet has used a cesium concentration of $1.16 \mathrm{ppm}$, to reflect the estimated value of $99.4 \mathrm{mCi} / \mathrm{L}$ of ${ }^{137} \mathrm{Cs}$ that will be in NGLLLW. The total cesium concentration should be 2-3 times greater than the ${ }^{137} \mathrm{Cs}$ concentration, assuming that the ${ }^{137} \mathrm{Cs}$ is produced as the result of fission. ${ }^{6}$ The DFs for cesium in the new simulant containing either 1.16 or $3.48 \mathrm{ppm}$ cesium are summarized in Table 3. Cesium removal in the first KCCF treatment was approximately equivalent for both cesium concentrations. Additional solids separation of the samples with filtration did not improve the decontamination of the samples. When the KCCF solids were removed from the treated simulant with a high-speed centrifuge, the DFs for the second KCCF treatment were also similar for the two cesium concentrations. However, if the centrifuged solutions were additionally filtered with a $0.45-\mu \mathrm{m}$ nylon filter membrane, the overall DF for the $1.16-\mathrm{ppm}$ cesium sample was significantly better than for the 3.48-ppm sample. This implies that further 
Table 3. Effects of cesium concentration on KCCF treatment for cesium removal ${ }^{a}$

\begin{tabular}{|c|c|c|}
\hline KCCF unit operation & Initial Cs concentration (ppm) & $\begin{array}{c}\text { Cesium } \\
\text { decontamination factor }\end{array}$ \\
\hline First stage-centrifugation & 1.16 & 1,700 \\
\hline First stage-centrifugation & 3.48 & 1,300 \\
\hline First stage $-0.45-\mu \mathrm{m}$ filtration & 1.16 & 1,050 \\
\hline First stage $-0.45-\mu \mathrm{m}$ filtration & 3.48 & 1,000 \\
\hline Second stage-centrifugation & 1.16 & 40 \\
\hline Second stage- - centrifugation & 3.48 & 70 \\
\hline $\begin{array}{l}\text { Second stage }-0.45-\mu \mathrm{m} \\
\text { filtration }\end{array}$ & 1.16 & 15,000 \\
\hline $\begin{array}{l}\text { Second stage }-0.45-\mu \mathrm{m} \\
\text { filtration }\end{array}$ & 3.48 & 2,900 \\
\hline Cumulative-centrifugation & 1.16 & 68,000 \\
\hline Cumulative-centrifugation & 3.48 & 91,000 \\
\hline Cumulative $-0.45-\mu \mathrm{m}$ filtration & 1.16 & $15,750,000$ \\
\hline Cumulative $-0.45-\mu \mathrm{m}$ filtration & 3.48 & $2,900,000$ \\
\hline
\end{tabular}

-Procedure: $\underline{\mathrm{Sr} \text { Coprecipitation- }}-\mathrm{Stable} \mathrm{SrCl}_{2}(50 \mathrm{ppm} \mathrm{Sr})$ and $\mathrm{Fe}_{2}\left(\mathrm{SO}_{4}\right)_{3}(25 \mathrm{ppm} \mathrm{Fe})$ were added to NGLLLW simulants $\left(0.141 \mathrm{ppm} \mathrm{Sr}, 3.48 \mathrm{ppm} \mathrm{Cs}\right.$, and $0.0337 \mathrm{ppm} \mathrm{Ru}$, traced with ${ }^{85} \mathrm{Sr}$ and ${ }^{137} \mathrm{Cs}$ ), and the solutions were mixed for $1 \mathrm{~h}$ with a magnetic stirrer. The solutions were mixed an additional $10 \mathrm{~min}$ after the addition of $1 \mathrm{ppm}$ Betz@1138 polymer and centrifuged for $30 \mathrm{~min}$ at $5000 \mathrm{rcf}$. The ${ }^{85} \mathrm{Sr}$ and ${ }^{137} \mathrm{Cs}$ count rates of the centrifuged solutions were measured. $\mathrm{Al}(\mathrm{OH})_{3}$ Sorption- The centrifuged solutions were adjusted to $\mathrm{pH} 8$ with $5.4 \mathrm{~N} \mathrm{H}_{2} \mathrm{SO}_{4}$ and mixed for $1 \mathrm{~h}$ with a magnetic stirrer. Aliquots of the adjusted solutions were centrifuged for $30 \mathrm{~min}$ at $5000 \mathrm{rcf}$, and the ${ }^{85} \mathrm{Sr}$ and ${ }^{137} \mathrm{Cs}$ count rates of the centrifuged solutions were measured. First KCCF Treatment- The uncentrifuged solutions from the $\mathrm{pH}$ adjustment step were mixed for $1 \mathrm{~h}$ on a Labquake shaker with $100 \mathrm{ppm} \mathrm{KCCF}$ slurry, formed in situ by the sequential addition of $\mathrm{K}_{4} \mathrm{Fe}(\mathrm{CN})_{6}$ and $\mathrm{Co}\left(\mathrm{NO}_{3}\right)_{2}$ solutions. The samples were mixed for an additional $10 \mathrm{~min}$ after the addition of $2 \mathrm{ppm}$ MagniFloc(B 1885 A polymer. The samples were centrifuged for $30 \mathrm{~min}$ at 5000 rcf, and the ${ }^{85} \mathrm{Sr}$ and ${ }^{137} \mathrm{Cs}$ count rates were measured. Second KCCF Treatment- The centrifuged solutions from the first KCCF treatment were mixed for $1 \mathrm{~h}$ on a Labquake shaker with $50 \mathrm{ppm}$ in situ KCCF slurry. The samples were mixed for an additional $10 \mathrm{~min}$ after the addition of $2 \mathrm{ppm}$ MagniFloc@ 1885 A polymer. The samples were centrifuged for $30 \mathrm{~min}$ at $5000 \mathrm{rcf}$ and the ${ }^{85} \mathrm{Sr}$ and ${ }^{137} \mathrm{Cs}$ count rates measured. Finally, samples solutions from the first and second KCCF treatments were filtered through $0.45-\mu \mathrm{m}$ nylon filter membranes and the ${ }^{85} \mathrm{Sr}$ and ${ }^{137} \mathrm{Cs}$ count rates measured. 
filtration of the KCCF particles results in cumulative DFs for cesium treatment that are similar to those observed in the NGLLLW-A simulant formulation. The conclusions to this testing are as follows: (1) Variation in the total cesium concentration in the low-ppm range does not affect ${ }^{137} \mathrm{Cs}$ removal in the first-stage KCCF unit operation but might have a more significant effect in the second-stage KCCF unit operation. (2) The KCCF particles are more difficult to settle in a lower-salt matrix and will require additional liquid/solid separation processing to attain a maximum decontamination of the LLLW in less-caustic media.

\subsection{DECONTAMINATION OF NGLLLW BLENDED WITH MVST SUPERNATE_SIMULANT TESTING}

Studies were also undertaken to determine the strontium and cesium removal efficiency from simulants representing blends of MVST supernate with NGLLLW-B. A series of six runs of the flow sheet was completed to compare the decontamination efficiency for simulant samples containing $0,10,20,30,50$ and $100 \%$ MVST supernate simulant. The graphical results of the study appear in Figs. 3 and 4. Results indicate that there is a loss of 17 in the cumulative strontium DF with each additional percent increase in MVST supernate blended with NGLLLW. However, even with the progressive loss in the strontium DF, the cumulative DF in $100 \%$ MVST supernate exceeds the minimum strontium DF required for the entire process. The cumulative cesium DF for the process also decreases with the addition of MVST supernate to NGLLLW. The separation of cesium-bearing KCCF particles becomes increasingly difficult. The overall cesium DF decreases by $3 \times 10^{4}$ with each additional percent MVST supernate blended with NGLLLW. Again, even with the loss in the effectiveness of the KCCF treatments, the cumulative cesium DF for $100 \%$ MVST exceeds that required in the flow sheet. This 


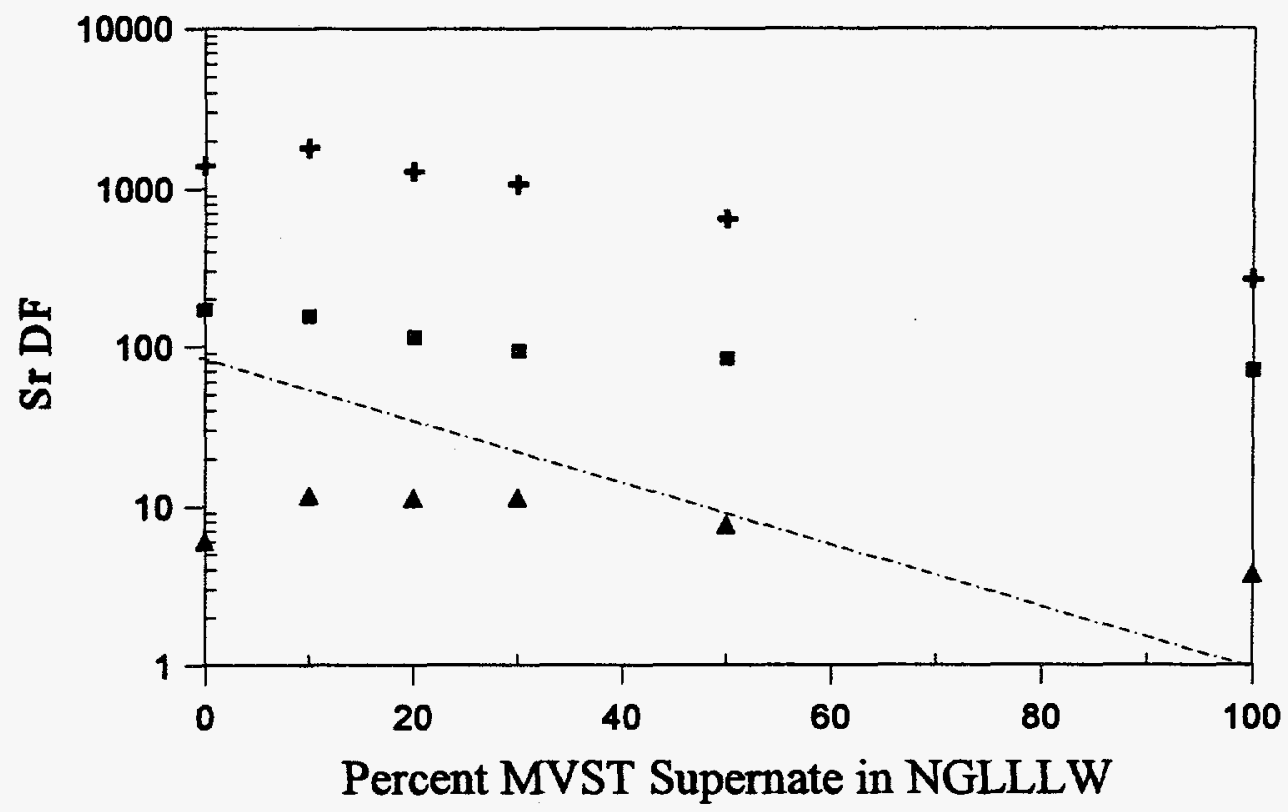

- Sr Coprecipitation $\triangle \mathrm{pH}$ Adjustment

- Sr Cumulative

\section{-..- Cumulative DF Required}

Fig. 3. Strontium DF in NGLLLW simulant blended with MVST supernate simulant.

Procedure: Strontium Coprecipitation- Stable $\mathrm{SrCl}_{2}(50 \mathrm{ppm} \mathrm{Sr})$ and $\mathrm{Fe}_{2}\left(\mathrm{SO}_{4}\right)_{3}$ (25 ppm Fe) were added to NGLLLW simulants $(0.141 \mathrm{ppm} \mathrm{Sr}, 3.48 \mathrm{ppm} \mathrm{Cs}$, and $0.0337 \mathrm{ppm} \mathrm{Ru}$, traced with ${ }^{85} \mathrm{Sr}$ and ${ }^{137} \mathrm{Cs}$ ), and the solutions were mixed for $1 \mathrm{~h}$ with a magnetic stirrer. The solutions were mixed an additional $10 \mathrm{~min}$ after the addition of $1 \mathrm{ppm}$ Betz@1138 polymer and centrifuged for $30 \mathrm{~min}$ at $5000 \mathrm{rcf}$. The ${ }^{85} \mathrm{Sr}$ and ${ }^{137} \mathrm{Cs}$ count rates of the centrifuged solutions were measured. $\mathrm{Al}(\mathrm{OH})_{3}$ Sorption- The centrifuged solutions were adjusted to $\mathrm{pH} 8$ with $5.4 \mathrm{NH}_{2} \mathrm{SO}_{4}$ and mixed for $1 \mathrm{~h}$ with a magnetic stirrer. Aliquots of the adjusted solutions were centrifuged for $30 \mathrm{~min}$ at $5000 \mathrm{rcf}$, and the ${ }^{85} \mathrm{Sr}$ and ${ }^{137} \mathrm{Cs}$ count rates of the centrifuged solutions were measured. First KCCF Treatment- The uncentrifuged solutions from the $\mathrm{pH}$ adjustment step were mixed for $1 \mathrm{~h}$ on a Labquake shaker with $100 \mathrm{ppm} \mathrm{KCCF}$ slurry, formed in situ by the sequential addition of $\mathrm{K}_{4} \mathrm{Fe}(\mathrm{CN})_{6}$ and $\mathrm{Co}\left(\mathrm{NO}_{3}\right)_{2}$ solutions. The samples were mixed for an additional $10 \mathrm{~min}$ after the addition of $2 \mathrm{ppm}$ MagniFloc@ 1885 A polymer. The samples were centrifuged for $30 \mathrm{~min}$ at $5000 \mathrm{rcf}$, and the ${ }^{85} \mathrm{Sr}$ and ${ }^{137} \mathrm{Cs}$ count rates were measured. Second KCCF TreatmentThe centrifuged solutions from the first KCCF treatment were mixed for $1 \mathrm{~h}$ on a Labquake shaker with $50 \mathrm{ppm}$ in situ KCCF slurry. The samples were mixed for an additional $10 \mathrm{~min}$ after the addition of $2 \mathrm{ppm}$ MagniFloc( 1885 A polymer. The samples were centrifuged for $30 \mathrm{~min}$ at $5000 \mathrm{rcf}$ and the ${ }^{85} \mathrm{Sr}$ and ${ }^{137} \mathrm{Cs}$ count rates measured. Finally, samples solutions from the first and second KCCF treatments were filtered through $0.45-\mu \mathrm{m}$ nylon filter membranes and the ${ }^{85} \mathrm{Sr}$ and ${ }^{137} \mathrm{Cs}$ count rates measured. 


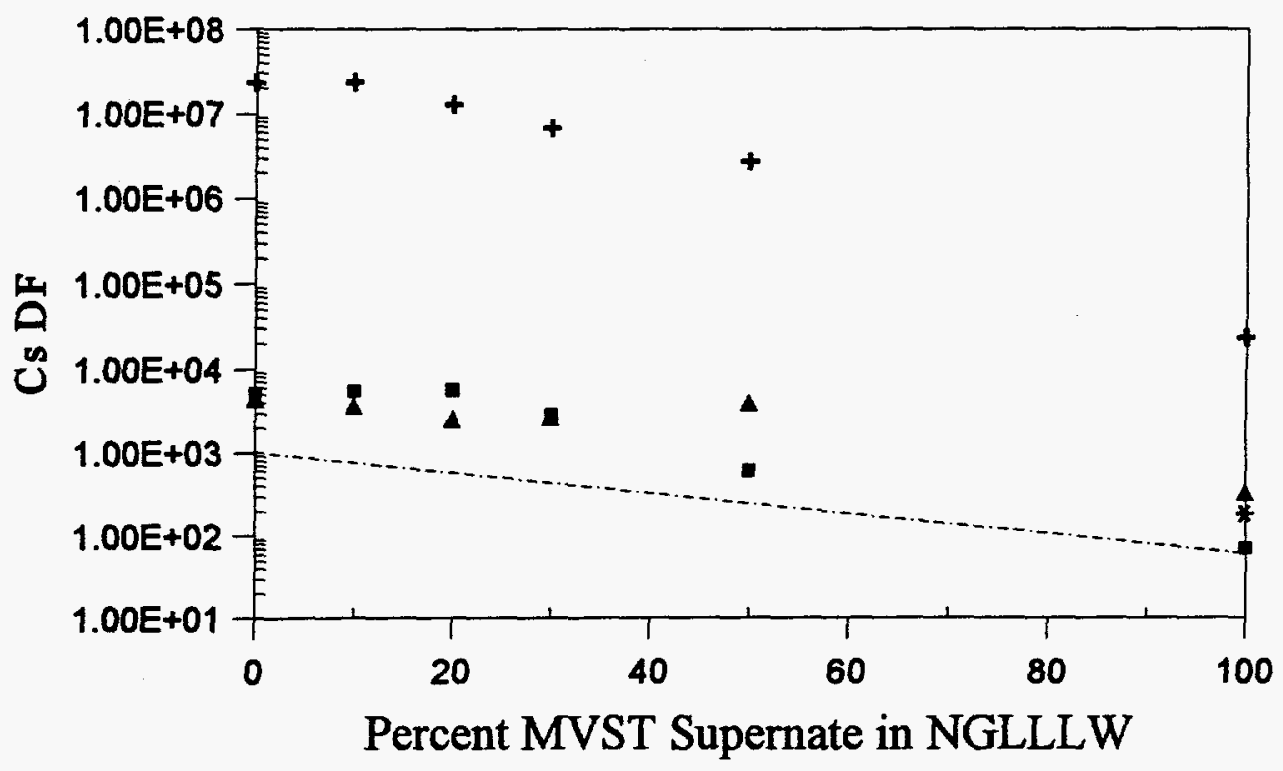

- First KCCF

$\triangle \quad$ Second KCCF

$+\quad$ KCCF Cumulative

-..- Cumulative DF Required

Fig. 4. Cesium DF in NGLLLW simulant blended with MVST supernate simulant.

Procedure: Strontium Coprecipitation-Stable $\mathrm{SrCl}_{2}(50 \mathrm{ppm} \mathrm{Sr})$ and $\mathrm{Fe}_{2}\left(\mathrm{SO}_{4}\right)_{3}(25 \mathrm{ppm}$ Fe) were added to NGLLLW/MVST supernate simulants $(0.141 \mathrm{ppm} \mathrm{Sr}, 3.48 \mathrm{ppm} \mathrm{Cs}$, and $0.0337 \mathrm{ppm} \mathrm{Ru}$, traced with ${ }^{85} \mathrm{Sr}$ and ${ }^{137} \mathrm{Cs}$ ), and the solutions were mixed for $1 \mathrm{~h}$ with a magnetic stirrer. The solutions were mixed an additional $10 \mathrm{~min}$ after the addition of $1 \mathrm{ppm}$ Betz@1 138 polymer and centrifuged for $30 \mathrm{~min}$ at $5000 \mathrm{rcf}$. The ${ }^{85} \mathrm{Sr}$ and ${ }^{137} \mathrm{Cs}$ count rates of the centrifuged solutions were measured. $\mathrm{Al}\left(\mathrm{OH}_{3}\right.$ Sorption- The centrifuged solutions were adjusted to $\mathrm{pH} 8$ with $5.4 \mathrm{~N} \mathrm{H}_{2} \mathrm{SO}_{4}$ and mixed for $1 \mathrm{~h}$ with a magnetic stirrer.

Aliquots of the adjusted solutions were centrifuged for $30 \mathrm{~min}$ at $5000 \mathrm{rcf}$, and the ${ }^{85} \mathrm{Sr}$ and ${ }^{137} \mathrm{Cs}$ count rates of the centrifuged solutions were measured. First KCCF Treatment- The uncentrifuged solutions from the $\mathrm{pH}$ adjustment step were mixed for $\mathbf{l} \mathrm{h}$ on a Labquake shaker with $100 \mathrm{ppm} \mathrm{KCCF}$ slurry, formed in situ by the sequential addition of $\mathrm{K}_{4} \mathrm{Fe}(\mathrm{CN})_{6}$ and $\mathrm{Co}\left(\mathrm{NO}_{3}\right)_{2}$ solutions. The samples were mixed for an additional $10 \mathrm{~min}$ after the addition of $2 \mathrm{ppm}$ MagniFloc 1885 A polymer. The samples were centrifuged for $30 \mathrm{~min}$ at $5000 \mathrm{rcf}$, and the ${ }^{85} \mathrm{Sr}$ and ${ }^{137} \mathrm{Cs}$ count rates were measured. Second $\mathrm{KCCF}$

Treatment-The centrifuged solutions from the first KCCF treatment were mixed for $1 \mathrm{~h}$ on a Labquake shaker with $50 \mathrm{ppm}$ in situ KCCF slurry. The samples were mixed for an additional $10 \mathrm{~min}$ after the addition of $2 \mathrm{ppm}$ MagniFloc $\& 1885$ A polymer. The samples were centrifuged for $30 \mathrm{~min}$ at $5000 \mathrm{rcf}$ and the ${ }^{85} \mathrm{Sr}$ and ${ }^{137} \mathrm{Cs}$ count rates measured. Finally, samples solutions from the first and second KCCF treatments were filtered through $0.45-\mu \mathrm{m}$ nylon filter membranes and the ${ }^{85} \mathrm{Sr}$ and ${ }^{137} \mathrm{Cs}$ count rates measured. 
conclusion assumes that the solids generated in both the strontium and cesium treatment unit operations can be removed efficiently.

\subsection{TREATING NGLLLW SIMULANT BLENDED WITH ACTUAL MVST SUPERNATE}

Up to this point, the development of the NGLLLW flow sheet had been accomplished using simulant solutions of NGLLLW and MVST supernate. The next level of testing was performed using NGLLLW simulant blended with actual MVST supernate from tank W-29. The intention of the testing was to validate the flow sheet using actual LLLW by treating blends of up to $75 \%$ actual MVST supernate in NGLLLW simulant. The study was performed in cooperation with staff members of the Chemical Development Section (CDS) of the ORNL Chemical Technology Division, who had access to MVST supernate solution, radiochemical hood space, and expertise in handling highly radioactive samples.

A mock cold test of the flow sheet was performed in the CDS laboratory to evaluate the radiation shielding devices fabricated in-house that would be used to reduce the radiation exposure from an actual MVST sample. The only difficulty experienced in the procedure was the inadequate separation of the KCCF particles using the available high-speed centrifuge. Adequate separation of the finely divided KCCF particles is possible only if the centrifuge is equipped with a free-swinging bucket rotor, rather than a fixed-angle rotor. The results from the cold test suggested that the solids generated in the treatment of samples containing actual MVST supernate would have to be removed by filtration.

Approximately $200 \mathrm{~mL}$ of MVST W-29 supernate, withdrawn in a 1989 sampling campaign, ${ }^{7}$ was secured for the testing of NGLLLW simulant/MVST supernate blends. The composition of the actual MVST supernate, after filtration through a $0.45-\mu \mathrm{m}$-pore membrane, 
is presented in Table $4 .^{8}$ The exposure rate for a $30-\mathrm{mL}$ aliquot of the filtered supernate, an amount required for each treatment test of the flow sheet, was 60 millirem per hour ( $\mathrm{mrem} / \mathrm{h}$ ). To help reduce the total exposure from handling the MVST sample, the majority of the ${ }^{137} \mathrm{Cs}$ was removed from the sample using multiple contacts with the cesium-selective Savannah River resin (SRR). An advantage of using pretreated MVST samples was that available in-house gamma counting equipment would be able to measure the lower-activity samples directly.

The SRR provided a simple and effective method for pretreating the supernate but was not as effective or as efficient as the KCCF to be evaluated in the testing. The pretreatment procedure developed and performed by Collins et al. ${ }^{9}$ included (1) performing five washes of the SRR with a 10:1 volume ratio of $0.16 M \mathrm{NaOH}$ for $15 \mathrm{~min}$, (2) equilibrating the washed SRR with MVST supernate simulant in a ratio of $5 \mathrm{~mL}$ of simulant to $1 \mathrm{~mL}$ of resin, and (3) contacting the actual MVST W-29 supernate in two stages with fresh, conditioned resin using $1 \mathrm{~g}$ of SRR for each $20 \mathrm{~mL}$ of supernate. A contact time of $24 \mathrm{~h}$ was used for the firststage resin contact; a 72-h contact time was used for a second-stage resin treatment of the supernate.

Using two contacts with SRR reduced the ${ }^{137} \mathrm{Cs}$ activity to approximately $1 \times 10^{3} \mathrm{~Bq} / \mathrm{mL}$ $\left(7 \times 10^{-10} \mathrm{mg} / \mathrm{mL}\right.$ total cesium), reducing the exposure rate for a $30-\mathrm{mL}$ aliquot to $0.75 \mathrm{mrem} / \mathrm{h}$. No viable method was found to remove the majority of ${ }^{90} \mathrm{Sr}$ in the sample without significantly altering the chemistry of the supernate sample. A portion of the prepared sample was submitted for the analysis of radionuclide, metal and anion content before flow sheet testing began. Table 4 summarizes the results obtained by the Analytical Services Organization (ASO) for the treated W-29 supernate.

The prepared MVST supernate was traced with a lower quantity of ${ }^{137} \mathrm{Cs}$ and used to study the proposed flow sheet. Tests were conducted using $80-\mathrm{mL}$ samples composed of 25 or $75 \%$ of the pretreated MVST in NGLLLW simulant. The liquid/solid separation required at the 


\begin{tabular}{|c|c|c|}
\hline & W-29, untreated ${ }^{a}$ & W-29, treated ${ }^{b}$ \\
\hline \multicolumn{3}{|l|}{ Radionuclides, Bq/L } \\
\hline${ }^{14} \mathrm{Cs}$ & $3.4 \mathrm{E}+06$ & $1.2 \mathrm{E}+00$ \\
\hline${ }^{137} \mathrm{Cs}$ & $2.2 \mathrm{E}+08$ & $2.7 \mathrm{E}+02$ \\
\hline${ }^{\infty} \mathrm{Co}$ & $4.0 \mathrm{E}+05$ & 8.1E+01 \\
\hline${ }^{250} \mathrm{Eu}$ & BDL $^{e}$ & $\mathrm{Na}^{\mathbf{4}}$ \\
\hline osr & $2.4 \mathrm{E}+06$ & $1.1 E+02$ \\
\hline "Tc & $2.0 \mathrm{E}+04$ & NA \\
\hline \multicolumn{3}{|l|}{ Other metals, mg/L } \\
\hline Al & 4.3E-01 & $<1.4 \mathrm{E}-01$ \\
\hline $\mathbf{B a}$ & $3.6 \mathrm{E}-01$ & $2.1 \mathrm{E}-02$ \\
\hline $\mathrm{Ca}$ & $3.5 E+\infty$ & $7.7 \mathrm{E}-01$ \\
\hline Total Cs & $5.7 \mathrm{E}-01$ & NA \\
\hline Cr & $2.2 E+\infty$ & $<2.59 \mathrm{E}-02$ \\
\hline $\mathrm{Cu}$ & $2.0 \mathrm{E}-01$ & $<2.03 E-02$ \\
\hline $\mathbf{K}$ & $1.14 E+04$ & $9.64 \mathrm{E}+03$ \\
\hline $\mathbf{N a}$ & $1.02 \mathrm{E}+05$ & $8.73 E+04$ \\
\hline $\mathbf{P b}$ & $7.1 \mathrm{E}+\infty$ & $<1.12 \mathrm{E}+\infty 0$ \\
\hline Total Sr & $1.0 E+02$ & $1.1 E+00$ \\
\hline Te & $3.1 E-02$ & NA \\
\hline Th & $<1.0 \mathrm{E}-01$ & $<2.80 \mathrm{E}-01$ \\
\hline $\mathbf{U}$ & $1.3 E+\infty$ & $<6.45 E-01$ \\
\hline $\mathbf{Z n}$ & $6.1 E+01$ & $7.35 \mathrm{E}-01$ \\
\hline \multicolumn{3}{|l|}{ Anions, mg/L } \\
\hline $\mathrm{Br}$ & $<5.0 \mathrm{E}+01$ & $1.21 E+03$ \\
\hline $\mathrm{Cl}^{-}$ & $3.0 \mathrm{E}+03$ & $2.61 E+03$ \\
\hline $\mathbf{F}$ & $<5.0 \mathrm{E}+00$ & $1.35 E+02$ \\
\hline $\mathrm{NO}_{3}$ & $2.80 \mathrm{E}+05$ & $2.38 \mathrm{E}+05$ \\
\hline $\mathrm{PO}_{4}{ }^{3}$ & $<5.0 \mathrm{E}+01$ & $1.4 \mathrm{E}+01$ \\
\hline $\mathrm{SO}_{4}^{2-}$ & $6.70 E+02$ & $2.84 \mathrm{E}+03$ \\
\hline Total inorganic carbon & $1.36 \mathrm{E}+03$ & NA \\
\hline Total organic carbon & $4.60 \mathrm{E}+02$ & NA \\
\hline
\end{tabular}

'J. L. Collins, B. Z. Egan, K. K. Anderson, C. W. Chase, and J. T. Bell, "Batch Test Equilibration Studies Examining the Removal of Cs, Sr, and Tc from Supernatants from ORNL Underground Storage Tanks by Selected Ion Exchangers" (see Reference section for full citation).

Supernate treated with Savannah River resin.

$\mathrm{BDL}=$ below detection limit.

NA $=$ not analyzed 
completion of the strontium and cesium removal unit operations was accomplished using $0.45-\mu \mathrm{m}$ nylon filters. Visual inspection of the clarified samples indicated that solids removal was successful. However, the radioactivity of the treated samples indicated that the decontamination process was not as successful as that observed with simulant solutions. These results are presented in Table 5. Only $15-25 \%$ of the strontium activity was removed from the actual supernate/NGLLLW blends as compared with $>99 \%$ obtained with only simulants. A DF of 5000-19,000 was obtained for cesium in the blended samples. Although this value is greater than the DF of 1000 required for the NGLLLW flow sheet, a DF of $>10^{6}$ is typically obtained in simulant samples.

Efforts were focused on determining what caused the loss in decontamination efficiency. Possible reasons include the presence of chemical complexants in the actual waste that might interfere with the flow sheet unit operations or a poor liquid/solid separation. When processed samples from the $25 \%$ MVST blend experiment were refiltered through $0.2-\mu \mathrm{m}$ nylon filters, the DF from the strontium coprecipitation unit operation improved by a factor of 25 ; however, the DFs for the KCCF unit operations were not significantly improved. Activated charcoal powder ( $40 \mathrm{mg} / \mathrm{mL}$ sample) was then added to the filtered samples in an effort to remove organic complexants that may be present in the actual waste. After a 2-day contact time, the strontium DF was increased by a further factor of 9 ; the cesium DF was unaffected. The combination of refiltration and carbon sorption produced a cumulative strontium DF of approximately 225 for the $25 \%$ MVST supernate samples. This value exceeds the required strontium DF of 80 for the process.

The pretreatment of the actual MVST supernate with conditioned SRR discolors the sample, indicating that organic material could be leaching from the resorcinol-formaldehyde-based SRR and interfering with the removal of strontium and cesium. This hypothesis was tested in two 
Table 5. NGLLLW flow sheet processing of pretreated actual MVST supernate in NGLLLW simulant

\begin{tabular}{lcccc}
\hline & \multicolumn{2}{c}{ Sr decontamination factor } & \multicolumn{2}{c}{ Cs decontamination factor } \\
\cline { 2 - 5 } Unit operation & $\begin{array}{c}\text { Unit } \\
\text { operation }\end{array}$ & Cumulative & $\begin{array}{c}\text { Unit } \\
\text { operation }\end{array}$ & Cumulative \\
\hline & $25 \%$ Actual MVST in NGLLLW Simulant & & \\
& & & & \\
Sr coprecipitation & 1.4 & - & 0.88 & - \\
Al(OH) $)_{3}$ sorption & 4.3 & 6.0 & 1.09 & 0.94 \\
First KCCF treatment & - & - & 70 & 7.3 \\
Second KCCF treatment & -- & - & 260 & 18,200 \\
& $75 \%$ Actual MVST in NGLLLW Simulant & & \\
Sr coprecipitation & 1.1 & -- & 1.0 & - \\
Al(OH) $)_{3}$ sorption & 1.3 & 1.4 & 1.0 & 1.0 \\
First KCCF treatment & -- & -- & 40 & 40 \\
Second KCCF treatment & -- & -- & 130 & 5,200 \\
\hline
\end{tabular}

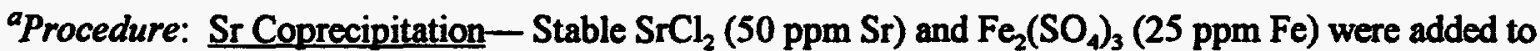
the MVST/NGLLLW blends (traced with ${ }^{85} \mathrm{Sr}$ and ${ }^{137} \mathrm{Cs}$ ), and the solutions were mixed for $1 \mathrm{~h}$ with a magnetic stirrer. The solutions were mixed an additional $10 \mathrm{~min}$ after the addition of $1 \mathrm{ppm}$ BetzQ1138 polymer and filtered with a $0.45-\mu \mathrm{m}$ nylon filter. The ${ }^{85} \mathrm{Sr}$ and ${ }^{137} \mathrm{Cs}$ count rates of the filtered solutions were measured. $\mathrm{Al}(\mathrm{OH})_{3}$ Sorption- The clarified solutions were adjusted to $\mathrm{pH} 8$ with $5.4 \mathrm{~N} \mathrm{H}_{2} \mathrm{SO}_{4}$ and mixed for $1 \mathrm{~h}$ with a magnetic stirrer. Aliquots of the adjusted solutions were filtered with a $0.45-\mu \mathrm{m}$ nylon filter, and the ${ }^{85} \mathrm{Sr}$ and ${ }^{137} \mathrm{Cs}$ count rates of the filtered solutions were measured. First KCCF Treatment- The unfiltered solutions from the $\mathrm{pH}$ adjustment step were mixed for $1 \mathrm{~h}$ on a Labquake shaker with $100 \mathrm{ppm} \mathrm{KCCF}$ slurry, formed in situ by the sequential addition of $\mathrm{K}_{4} \mathrm{Fe}(\mathrm{CN})_{6}$ and $\mathrm{Co}\left(\mathrm{NO}_{3}\right)_{2}$ solutions. The samples were mixed for an additional $10 \mathrm{~min}$ after the addition of $2 \mathrm{ppm}$ MagniFloc@ 1885 A polymer. The samples were filtered with a $0.45-\mu \mathrm{m}$ filter, and the ${ }^{85} \mathrm{Sr}$ and ${ }^{137} \mathrm{Cs}$ count rates were measured. Second KCCF Treatment- The filtered solutions from the first KCCF treatment were mixed for $1 \mathrm{~h}$ on a Labquake shaker with $50 \mathrm{ppm}$ in situ KCCF slurry. The samples were filtered with a $0.45-\mu \mathrm{m}$ nylon filter and the ${ }^{85} \mathrm{Sr}$ and ${ }^{137} \mathrm{Cs}$ count rates measured. 
separate studies. In the first test, a sample representing a blend of $25 \%$ MVST supernate simulant in NGLLLW simulant was pretreated with conditioned SRR similar to that used to treat the actual MVST supernate. The total organic carbon (TOC) level in the pretreated simulant was determined to be $215 \mathrm{ppm}$. The simulant sample was then processed by the NGLLLW flow sheet. Results of this study are presented in Table 6. The strontium coprecipitation DF was 26 and the $\mathrm{pH}$ adjustment DF was 6 after processing the sample. These results compare with a strontium coprecipitation DF of 200 and a pH adjustment DF of 6 obtained in $25 \%$ MVST simulant samples that had not been previously treated with the SRR. The $80 \%$ loss in the strontium coprecipitation unit operation suggests that a complexant does leach from the SRR into MVST supernate and complexes strontium at $\mathrm{pH} 13$ but does not complex strontium at $\mathrm{pH}$ 8. The presence of the soluble resin components did not affect either of the KCCF unit operations, provided that the liquid/solid separation was made using $0.2-\mu \mathrm{m}$-pore filter membranes.

The NGLLLW flow sheet was next tested with actual MVST supernate that was not pretreated with SRR. This study would determine if the leached organics from the SRR inhibited strontium removal from the actual supernate. Results from this study are also presented in Table 6. Strontium and cesium DFs from the processing of both a $25 \%$ and a $75 \%$ actual MVST supernate blend were obtained. The strontium coprecipitation DFs in the untreated supernate samples were greater than that observed in either the treated supernate samples or in simulant samples containing the SRR residues. The cesium DFs for the first-stage and secondstage KCCF unit operations were 1200 and 12, respectively, in samples containing $25 \%$ untreated supernate. The low cesium DF observed in the second KCCF unit operation is due to the fact that cesium was removed to background levels in the first KCCF unit operation. 
Table 6. NGLLLW flow sheet processing of NGLLLW simulant blended with untreated MVST supernate

\begin{tabular}{|c|c|c|c|c|}
\hline \multirow{2}{*}{ Unit operation } & \multicolumn{2}{|c|}{ Sr decontamination factor } & \multicolumn{2}{|c|}{ Cs decontamination factor } \\
\hline & $\begin{array}{c}\text { Unit } \\
\text { operation }\end{array}$ & Cumulative & $\begin{array}{c}\text { Unit } \\
\text { operation }\end{array}$ & Cumulative \\
\hline \multicolumn{5}{|c|}{$25 \%$ MVST Simulant in NGLLLW Simulant } \\
\hline Sr coprecipitation & 26 & - & - & - \\
\hline $\mathrm{Al}(\mathrm{OH})_{3}$ sorption & 6.2 & 160 & - & - \\
\hline First KCCF treatment & -- & - & 2,600 & - \\
\hline Second KCCF treatment & $\ldots$ & - & 1,200 & $3,120,000$ \\
\hline \multicolumn{5}{|c|}{$25 \%$ Actual MVST in NGLLLW Simulant } \\
\hline Sr coprecipitation & 62 & - & -- & - \\
\hline $\mathrm{Al}(\mathrm{OH})_{3}$ sorption & 2 & 120 & - & -- \\
\hline First KCCF treatment & -- & - & 1,200 & -- \\
\hline Second KCCF treatment & - & - & 12 & 14,000 \\
\hline \multicolumn{5}{|c|}{$75 \%$ Actual MVST in NGLLLW Simulant } \\
\hline Sr coprecipitation & 20 & - & -- & -- \\
\hline $\mathrm{Al}(\mathrm{OH})_{3}$ sorption & 1.5 & 30 & - & - \\
\hline First KCCF treatment & - & - & 31 & -- \\
\hline Second KCCF treatment & - & - & 25 & 775 \\
\hline \multicolumn{5}{|c|}{ 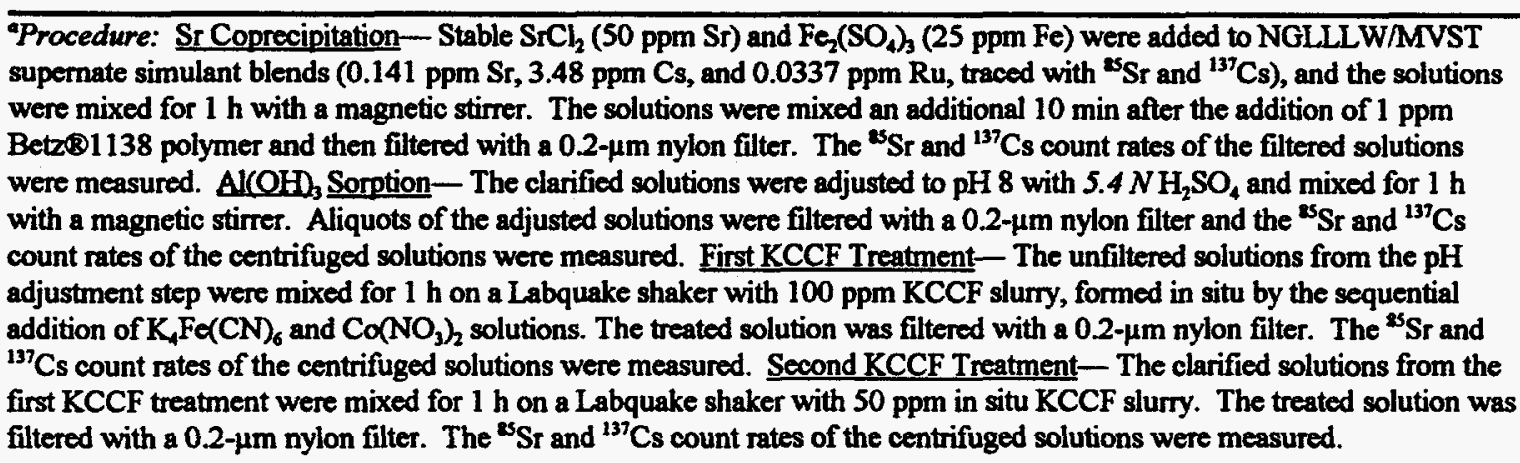 } \\
\hline
\end{tabular}
time of $24 \mathrm{~h}$ was used for the first resin treatment, a 72-h contact time was used for the second resin treatment. 
Conclusions from the testing of untreated MVST supernate are as follows: (1) pretreatment with SRR does appear to interfere with the strontium coprecipitation unit operation; (2) the NGLLLW flow sheet can adequately remove strontium and cesium from an untreated MVST supernate sample; (3) a reduction in the strontium coprecipitation DF over that observed in simulant studies may indicate the presence of small quantities of organic complexants in actual MVST supernate; and (4) only a single KCCF unit operation was needed to reduce the cesium activity in $25 \%$ actual MVST supernate to a comparable value of $44,000 \mathrm{~Bq} / \mathrm{mL}$, while a second treatment with $\mathrm{KCCF}$ reduced the cesium activity to $2700 \mathrm{~Bq} / \mathrm{mL}$ in the blended sample. An important implication of this study is that if the SRR resin is to be used in treatment flow sheets for the removal of both strontium and cesium, strontium removal at high $\mathrm{pH}$ should be made prior to removing cesium with the SRR. In such a sequence, strontium removal will occur prior to the introduction of resin components, which might otherwise interfere with strontium treatment at high $\mathrm{pH}$.

\subsection{EFFECT OF ORGANIC COMPOUNDS ON THE NGLLLW FLOW SHEET}

In addition to the inorganic components, LLLW from the REDC also contains organic constituents derived from the solvent extraction processes. Although no sampling effort has been performed to identify the specific organic compounds and their relative concentrations, the waste will probably contain the extractants di(2-ethylhexyl)phosphoric acid (DEHPA) and ADOGEN (a C8-C10 straight-chain tertiary amine); the diluents diethylbenzene (DEB), normal paraffin hydrocarbon (NPH), and di-isopropylbenzene (DIPB); and the diluent modifier 2-ethylhexanol (2EH). Dibutylhydroquinone is also used for metal valence control and is soluble in the organic extractants. MVST supernate contains up to $1000 \mathrm{ppm}^{\mathrm{TOC}}{ }^{3}$ The majority of the organic components in MVST supernate have not been identified, although polar species 
such as tributylphosphate (TBP), dibutylphosphate, DEHPA, and ethylenediaminetetraacetic acid (EDTA) were tentatively identified. ${ }^{10}$

Studies performed at Sandia National Laboratories indicate that the organic degradation products of EDTA in tank waste generated at Hanford are capable of complexing strontium. The majority of strontium treatment procedures available today were found to be less effective for this waste. The organic constituents, however, do not appear to complex cesium. ${ }^{11,12}$ Laboratory studies seem to indicate that a portion of KCCF might dissolve in the presence of organic degradation products as the iron or cobalt present in the KCCF sorbent was complexed. ${ }^{13}$

A series of experiments has been initiated to determine to what extent the most probable organic compounds present in NGLLLW might affect the flow sheet. The NGLLLW simulant was formulated to include DEHPA. The quantity of DEHPA to be included in NGLLLW simulant was determined by increasing the DEHPA in the simulant and observing the formation of a free organic phase. Only a single liquid phase is observed in the simulant at DEHPA concentrations of $0.1 \mathrm{vol} \%$ or less. A transition point occurs at $0.2-0.3 \%$ DEHPA, where a stable emulsion forms. Above this organic concentration, two immiscible aqueous phases develop. The lower phase is a highly salted solution, while the upper'phase is approximately of equal volume and constitutes an aqueous phase saturated with DEHPA. As the DEHPA content rises above $0.4 \%$, the volume of the upper phase decreases as more of the aqueous constituents are forced into the lower-salt phase. A true organic phase, containing predominately DEHPA, does not form until 4-5\% DEHPA has been added to the simulant. A value of $0.05 \%$ DEHPA was selected as the concentration of the organic phosphate in the NGLLLW simulant for further studies. This concentration conforms to the average TOC content observed in MVST supernate samples from tank W-29. 
A test of the proposed NGLLLW flow sheet was performed using the simulant containing DEHPA. An analytical value of $226 \mathrm{ppm}$ TOC content of the simulant was determined. Strontium-85 and ${ }^{137} \mathrm{Cs}$ tracers were added to the simulant and stirred for 1 week to allow the tracers to equilibrate between the aqueous and organic constituents of the simulant. After the simulant was equilibrated, the ${ }^{85} \mathrm{Sr}$ was removed using the strontium coprecipitation process; the cesium was removed by sorption on KCCF. Results of this test appear in Table 7. The presence of DEHPA improves the removal of strontium so that the cumulative strontium DF was 1225. The increase in strontium removal is tentatively attributed to the reduced solubility of strontium carbonate in a more hydrophobic solution matrix. Cesium removal using KCCF formed in situ or as a preformed slurry decreased as the DF dropped from several million to 8000 in the presence of DEHPA. However, the cesium DF is still greater than the minimum required for the process.

TBP is an organic extractant used at ORNL to isolate TRU wastes from fission products. It was also tentatively identified in an extract of the liquid phase in waste tank T-2. ${ }^{10}$ An initial attempt was made to create an NGLLLW simulant containing 0.05 vol \% TBP, the quantity of organic typically found in MVST supernates. The saturation limit of TBP in NGLLLW simulant appears to be much lower than this concentration, as noted by the presence of a free organic phase at the top of the simulant after contact. The NGLLLW simulant containing TBP was submitted for the analysis of TOC prior to testing the effect of TBP on the flow sheet. The dissolved TBP in the NGLLLW simulant was equivalent to a TOC concentration of $126 \mathrm{ppm}$. Again, the strontium DF for the strontium coprecipitation unit operation was improved by approximately a factor of 4 in the presence of the organophosphate. Cesium decontamination in the presence of TBP appears to be determined by the efficiency of the liquid/solid separation. The KCCF particles appear to be smaller in the presence of organic compounds and require a smaller-pore filter to remove the solids. Therefore, cesium sorption on KCCF particles is not 
influenced by limited quantities of organic phosphates. However, a more efficient filtering process is required to capture the cesium-bearing solids.

\section{LIQUID/SOLID SEPARATION TEST RESULTS}

The early development of the NGLLLW flow sheet has been based on laboratory results obtained in the treatment of small $(10-100 \mathrm{~mL})$ batch samples. Solids generated during the processing of these samples were removed using a high-speed laboratory centrifuge. A more realistic test of the proposed flow sheet was conducted during FY 1994 using a $500-\mathrm{mL} / \mathrm{min}$ pilot-scale test system. Solids removal in the dynamic testing of the flow sheet was effected using sludge blanket clarification. Removal of the strontium- and cesium-bearing solids using the sludge blanket clarifier was significantly poorer than that obtained using a laboratory centrifuge. Improved clarification and filtration methods were evaluated during this year's studies.

\subsection{POLYMERIC SETTLING AGENTS}

Subsequent to pilot-scale testing, an investigation was initiated in FY 1994 to locate a polymeric flocculating agent that might aid in the settling of solids formed in the strontium coprecipitation and KCCF unit operations. The settling characteristics of a number of flocculants were observed in $30-\mathrm{mL}$ and $1.5-\mathrm{L}$ samples of nonradioactive NGLLLW simulant. The performance of the settling agents was assessed by measuring the optical clarity of the supernate liquor above the settled polymer. Anionic polyacrylamide copolymers formed the best cohesive floc beds and clearest supernate when settling the strontium carbonate precipitate. 
Table 7. NGLLLW flow sheet processing of NGLLLW simulant containing organic complexants ${ }^{e}$

\begin{tabular}{|c|c|c|c|c|}
\hline \multirow{2}{*}{ Unit Operation } & \multicolumn{2}{|c|}{ Sr decontamination factor } & \multicolumn{2}{|c|}{ Cs decontamination factor } \\
\hline & $\begin{array}{c}\text { Unit } \\
\text { operation }\end{array}$ & Cumulative & $\begin{array}{c}\text { Unit } \\
\text { operation }\end{array}$ & Cumulative \\
\hline \multicolumn{5}{|c|}{$D E H P A(226 \mathrm{ppm})$} \\
\hline Sr coprecipitation & 140 & - & -- & - \\
\hline $\mathrm{Al}(\mathrm{OH})_{3}$ sorption & 9 & 1,260 & - & - \\
\hline First KCCF treatment & - & -- & 20 & -- \\
\hline Second KCCF treatment & -- & - & 400 & 8,000 \\
\hline \multicolumn{5}{|c|}{$T B P(126 p p m)$} \\
\hline Sr coprecipitation & 145 & - & - & -- \\
\hline $\mathrm{Al}(\mathrm{OH})_{3}$ sorption & 11 & 1,400 & -- & -- \\
\hline First KCCF treatment & - & - & $\begin{array}{r}29 \\
6000^{b}\end{array}$ & -- \\
\hline Second KCCF treatment & - & - & 1000 & $\begin{array}{r}29,000 \\
6,000,000^{b}\end{array}$ \\
\hline
\end{tabular}

'Procedure: Sr Coprecipitation-Stable $\mathrm{SrCl}_{2}\left(50 \mathrm{ppm} \mathrm{Sr}\right.$ ) and $\mathrm{Fe}_{2}\left(\mathrm{SO}_{4}\right)_{3}$ (25 ppm Fe) were added to NGLLLW simulants

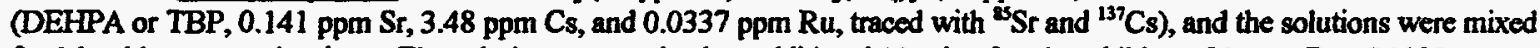
for $1 \mathrm{~h}$ with a magnetic stirrer. The solutions were mixed an additional $10 \mathrm{~min}$ after the addition of $1 \mathrm{ppm}$ Betz@1138 polymer and filtering with a $0.45-\mu \mathrm{m}$ nylon filter. The ${ }^{85} \mathrm{~S} r$ and ${ }^{137} \mathrm{Cs}$ count rates of the filtered solutions were measured. AlCOHD 3 Sorption- The clarified solutions were adjusted to $\mathrm{pH} 8$ with $5.4 \mathrm{~N} \mathrm{H}_{2} \mathrm{SO}_{4}$ and mixed for $1 \mathrm{~h}$ with a magnetic stirrer. Aliquots of the adjusted solutions were filtered with a $0.45-\mu \mathrm{m}$ nylon filter and the ${ }^{25} \mathrm{Sr}$ and ${ }^{137} \mathrm{Cs}$ count rates of the filtered solutions were measured. First KCCF Treatment- The filtered solutions from the pH adjustment step were mixed for $1 \mathrm{~h}$ on a Labquake shaker with $100 \mathrm{ppm} \mathrm{KCCF}$ slurry, formed in situ by the sequential addition of $\mathrm{K}_{4} \mathrm{Fe}(\mathrm{CN})_{6}$ and $\mathrm{Co}\left(\mathrm{NO}_{3}\right)_{2}$ solutions. KCCF solids were removed by filtering with a $0.45-\mu \mathrm{m}$ nylon filter, and the ${ }^{85} \mathrm{Sr}$ and ${ }^{137} \mathrm{Cs}$ count rates were measured. Second KCCF Treatment- The filtered solutions from the first KCCF treatment were mixed for $1 \mathrm{~h}$ on a Labquake shaker with $50 \mathrm{ppm}$ in situ KCCF. KCCF solids were removed by filtering with a $0.45-\mu \mathrm{m}$ nylon filter, and the ${ }^{85} \mathrm{Sr}$ and ${ }^{137} \mathrm{Cs}$ count rates were measured.

The solutions were refiltered using a $0.2-\mu \mathrm{m}$ nylon filter, and the ${ }^{85} \mathrm{Sr}$ and ${ }^{137} \mathrm{Cs}$ count rates were remeasured. 
Betz@1138 (Betz Laboratories, Inc., Trevose, Pennsylvania) and Magnifloc®1885A (Cytec, Wayne, New Jersey) had the best performance in this group. Both BetzQ1138 and Magnifloc(1885A were the optimum settling agents for solids formed in the KCCF unit operations. However, the floc bed formed with these polymers in $\mathrm{pH} 8$ solution was voluminous and fragile. The settling results were often inconsistent; the optical clarity of the supernate might appear clear or partially cloudy without an obvious reason for the different performances.

An FY 1995 goal was to perform the polymeric settling tests using NGLLLW simulant traced with ${ }^{85} \mathrm{Sr}$ and ${ }^{137} \mathrm{Cs}$, so that DFs could be measured in the clarified supernates. An effort was also made to determine what mechanism controlled the settling performance of polymeric agents used for the removal of KCCF solids. Polymer testing with traced solutions was accomplished by placing triplicate $1.5-\mathrm{L}$ simulant samples on a floc illuminator equipped with Teflon-coated stirring paddles. The solutions were stirred vigorously at $200 \mathrm{rpm}$ while $50 \mathrm{ppm}$ stable strontium (as $\left.\mathrm{SrCl}_{2}\right)$ and $25 \mathrm{ppm}$ iron as $\left[\mathrm{Fe}_{2}\left(\mathrm{SO}_{4}\right)_{3}\right]$ were added to the solutions. Once these reagents were added, the stirring speed was reduced to $150 \mathrm{rpm}$ for $1 \mathrm{~h}$. At the completion of the strontium coprecipitation unit operation, $3 \mathrm{~mL}$ of $0.05 \%$ Betz(1) 138 polymer was added to each sample so that the final polymer concentration was $1 \mathrm{ppm}$. The stirring speed was reduced to $30 \mathrm{rpm}$ for $15 \mathrm{~min}$ to allow the polymer floc to aggregate. Finally, the stirrers were turned off and the solids allowed to settle for $30 \mathrm{~min}$. Samples of the clarified supernate were then collected for analysis of ${ }^{85} \mathrm{Sr}$ activity.

Cesium removal was measured by decanting $1.2 \mathrm{~L}$ of the clarified supernate into clean $1-\mathrm{L}$ beakers and placing them on the floc illuminator. The stirrer speed was adjusted to $180 \mathrm{rpm}$, and stoichiometric quantities of $\mathrm{K}_{4} \mathrm{Fe}(\mathrm{CN})_{6}$ and $\mathrm{Co}\left(\mathrm{NO}_{3}\right)_{2}$ were added to produce $100 \mathrm{ppm} \mathrm{KCCF}$ solids in the samples. Stirring was continued for $1 \mathrm{~h}$ at a speed of $150 \mathrm{rpm}$. At the conclusion of the mixing time, the cesium-bearing KCCF particles were collected by adding $4.8 \mathrm{~mL}$ of 
$0.05 \mathrm{w} / \mathrm{v} \%$ Magnifloc( 1885 A polymer to the $1.2-\mathrm{L}$ samples to produce $2 \mathrm{ppm}$ polymer floc. The speed of the stirring blades was set at $100 \mathrm{rpm}$ to disperse the polymer throughout the simulant; the stirring speed was then reduced to $30 \mathrm{rpm}$ and the solution mixed for $10 \mathrm{~min}$. The solids were allowed to settle for $30 \mathrm{~min}$. Samples of the supernate were then withdrawn for cesium analysis.

A second KCCF treatment was performed on 1-L of the clarified supernate. The test conditions were similar to those used in the first KCCF unit operation. Again, samples were collected at the end of the solids settling time to determine the cesium decontamination efficiency of the second KCCF unit operation.

Results of several polymer settling tests are presented in Table 8. The type and concentration of the polymers used to settle the solids generated in each unit operation are given, as well as the DFs for ${ }^{85} \mathrm{Sr}$ and ${ }^{137} \mathrm{Cs}$ obtained in the clarified solutions. The decontamination efficiency of all three unit operations is significantly poorer when polymer settling, rather than centrifugation, is used to accomplish the liquid/solid separation. Table 9 illustrates the need for further filtration of the clarified supernates generated in the final polymer settling tests, in which both Betz@1138 and MagniFloc@1885A were used to settle the solids. The strontium DF for the strontium coprecipitation operation was 27 in the presence of 1 ppm Betz 1138 polymer. A DF of 150 is typically obtained if the solid separation is performed using a high-speed centrifuge. Nylon filter membranes (Gelman Acrodisc(B) of various pore sizes were used to filter the supernate remaining after polymer settling. Approximately $50 \%$ of the suspended ${ }^{85} \mathrm{Sr}$ activity could be removed from the liquid using a $0.8-\mu \mathrm{m}$-pore filter. The particle size of the remaining unsettled ${ }^{85} \mathrm{Sr}$ activity appears to be smaller than $0.2 \mu \mathrm{m}$. High-speed centrifugation of the filtered liquid removed the remaining fine strontium carbonate particles, indicating that the 
Table 8. Strontium and cesium decontamination factors using polymeric flocculating agents

\begin{tabular}{|c|c|c|c|c|c|c|}
\hline \multicolumn{2}{|c|}{ Strontium coprecipitation unit operation } & \multicolumn{3}{|c|}{ First KCCF unit operation } & \multicolumn{2}{|c|}{ Second KCCF unit operation } \\
\hline Polymer concentration & Sr DF & Polymer concentration & Sr DF & Cs DF & Polymer concentration & Cs DF \\
\hline 0.5 ppm Betz@1 138 & 57 & 1 ppm Betz@1138 & NA & 4 & 1 ppm Betz@1138 & 3 \\
\hline 0.5 ppm Betz@1138 & 40 & 1 ppm Betz@1138 & 13 & 2 & 1 ppm Betz@1138 & 4 \\
\hline 1 ppm Betz@1138 & 28 & 2 ppm MagniFloc@1138 & 29 & 3 & 2 ppm MagniFloc\&1138 & 4 \\
\hline
\end{tabular}

Table 9. Sequential filtering of $\mathrm{SrCO}_{3}$ and $\mathrm{KCCF}$ solids after addition of flocculating agents

\begin{tabular}{|c|c|c|c|c|c|c|}
\hline \multicolumn{2}{|c|}{ Strontium coprecipitation unit operation } & \multicolumn{3}{|c|}{ First KCCF unit operation } & \multicolumn{2}{|c|}{ Second KCCF unit operation } \\
\hline Separation mechanism & Sr DF & Separation mechanism & Sr DF & Cs DF & Separation mechanism & Cs DF \\
\hline Polymer settling & $28 \pm 1$ & Polymer settling & $\begin{array}{c}700 \\
\pm 200\end{array}$ & $\begin{array}{c}2.78 \\
\pm 0.03\end{array}$ & Polymer settling & $\begin{array}{c}4.41 \\
\pm 0.05\end{array}$ \\
\hline $0.8-\mu \mathrm{m}$ nylon filter & $55 \pm 5$ & $0.8-\mu \mathrm{m}$ nylon filter & NA & $\begin{array}{l}2,900 \\
\pm 300\end{array}$ & $0.8-\mu \mathrm{m}$ nylon filter & $\begin{array}{l}19,000 \\
\pm 7,000\end{array}$ \\
\hline $0.45-\mu \mathrm{m}$ nylon filter & $57 \pm 4$ & $0.45-\mu \mathrm{m}$ nylon filter & NA & $\begin{array}{l}1,500 \\
\bullet 100\end{array}$ & $0.45-\mu \mathrm{m}$ nylon filter & $\begin{array}{l}16,000 \\
\pm 8,000\end{array}$ \\
\hline $0.2-\mu \mathrm{m}$ nylon filter & $60 \pm 3$ & $0.2-\mu \mathrm{m}$ nylon filter & NA & $\begin{array}{l}250 \\
\pm 50\end{array}$ & $0.2-\mu \mathrm{m}$ nylon filter & $\begin{array}{r}2,500 \\
\pm 800\end{array}$ \\
\hline
\end{tabular}


poorer DF with polymer settling is a result of poor solids removal rather than insufficient formation of the strontium carbonate solids.

The clarified supernate from the strontium coprecipitation unit operation is neutralized with sulfuric acid before the KCCF unit operation is performed. Neutralization of the NGLLLW precipitates aluminum hydroxide $\left[\mathrm{Al}(\mathrm{OH})_{3}\right]$, which acts as a sorbent media for strontium. The liquid/solid separation of the $\mathrm{Al}(\mathrm{OH})_{3}$ solids is performed in conjunction with the removal of the KCCF solids at the end of the first KCCF unit operation. Two ppm of MagniFloc(8) 1885A was used to settle the solids formed in this unit operation. The strontium DF for the first KCCF unit operation was approximately 70 . When the strontium removal efficiency of both unit operations was combined, the overall strontium DF for the process was 1900 , surpassing the required strontium DF of 80 . The cesium DF for the first KCCF unit operation was 3 when the settling agent was used, as compared with 5000 if a high-speed centrifuge is used for solution clarification. The majority of the suspended KCCF particles could be removed with a $0.8-\mu \mathrm{m}-$ pore-size filter; the cesium DF of the filtered solution was 3000 . If finer-pore-size filters were used, the fragile KCCF particles broke apart, perhaps because of the higher pressures required to force the sample through the $0.2-\mu \mathrm{m}$ filter, and the activity of the filtered solution increased slightly.

The solids generated in the second KCCF unit operation were also settled with 2 ppm Magnafloc 1885A. Again, the cesium DF in the settled solution was a disappointing value of 4, compared with 3700 observed using a high-speed centrifuge. All suspended KCCF solids were removed with a $0.8-\mu \mathrm{m}$-pore membrane, giving a cesium DF of 18,000 for the filtered supernate. The cumulative cesium DF for the entire process in the presence of polymers was 12 , while the cumulative cesium DF was $5.4 \times 10^{7}$ if the unsettled fines were removed with a 0.8 - $\mu \mathrm{m}$-pore-size filter. The required cesium DF for the NGLLLW flow sheet is 1000 . 
A number of tests using untraced, 1.5-L simulant samples were also run to help understand the inconsistency in settling results obtained for the KCCF unit operations. Variables studied were mixing speed and mixing time after polymer addition, age of the stock $(0.5 \%)$ and diluted (0.05\%) polymer solutions, type of sample container, and age of the $\mathrm{K}_{4} \mathrm{Fe}_{2}(\mathrm{CN})_{6}$ reagent. The optical absorbance of the clarified solutions indicated that the age of the MagniFloc@ 1885A stock reagents, the container type, and the ferrocyanide reagent used in these studies had no significant impact on the settling characteristics of the KCCF particles. The efficiency of the liquid/solid separation in neutral solutions is primarily dependent on careful control of mixing speeds and mixing times after polymer addition. The KCCF particles, as well as the flocculants, formed in neutral $\mathrm{pH}$ are fragile and easily sheared at high mixing speeds or extended mixing times. Reliance on polymer settling of KCCF particles in a process environment appears to be difficult at best; filtering under low-shear conditions may represent a more viable approach to removing KCCF solids from treated LLLW.

\subsection{LIQUID/SOLID SEPARATION USING CROSS-FLOW FILTRATION}

The primary goals of this study are to (1) design and construct a bench-scale unit to study the removal of the radioactive contaminants in NGLLLW by treatment steps such as precipitation, adsorption, and ion exchange, followed by a liquid/solid separation step to concentrate the solids generated in the treatment step, and (2) carry out experiments on the bench-scale unit with simulated waste streams to determine the optimum operating conditions for the treatment and the liquid/solid separation steps and the DFs that can be attained. Options for the liquid/solid separation step include "dead-end" filtration, cross-flow filtration, and highgradient magnetic separation (HGMS). 
In the NGLLLW treatment process, the objectives of the liquid/solid separation operation are (1) to achieve a high solids separation efficiency, especially in the case of contaminants requiring high DFs, and (2) to generate a pumpable slurry of the concentrated solids. The latter will facilitate the transfer of the solids containing the removed contaminants to other processing steps. Settling, or clarifying, with and without the addition of flocculants, has been tested in the laboratory. However, the long settling times, due to the physical characteristics of the particles, and the low solids concentrations make this method of liquid/solid separation questionable. Of particular concern is the efficiency of solids separation, as affected by the entrainment of fine particles in the overflow from a settler/clarifier.

Filtration has the potential to meet the liquid/solid separation objectives. By using filter elements with small-diameter pores and, if necessary, filter aids, high solids separation efficiencies can be obtained. In "dead-end" filtration, a wet cake is collected on the filter element as essentially all of the liquid in the feed passes through the element. Operation is semicontinuous as the filter must be taken off-line periodically for cleaning by back-flushing or for replacement. By back-flushing the filter element, a pumpable slurry of concentrated solids is produced. In cross-flow filtration, a fraction of the liquid in the feed slurry is collected along with the separated solids, resulting in a slurry with a higher solids concentration than that of the feed. The solids concentration in this product slurry can be varied by adjusting the filtrate-toslurry ratio. The cross-flow filter can be operated in a continuous mode at relatively constant conditions.

HGMS may also be a viable liquid/solid separation technique for this application. Preliminary experiments ${ }^{14}$ were conducted with solutions from the contaminant treatment steps. It was demonstrated that both paramagnetic and diamagnetic colloidal particles could be effectively separated using a magnetic field after magnetic-seeding flocculation. In operation, 
hematite or magnetite particles, when needed, are added to the slurry prior to introduction to the high-gradient magnetic filter (HGMF). In the HGMF, the solid particles are removed by the bed of a ferromagnetic material (in the form of a mesh) upon which a magnetic field is applied. When the bed is loaded, the magnetic field is shut off and the solids are collected by backflushing. Compared with the filtration techniques described previously, potential advantages of HGMS include (1) less tendency to plug with solids and (2) more efficient recovery of small particles. HGMS could be used either as the main liquid/solid separation method or as a downstream polishing treatment.

Figure 5 shows the flow diagram of the bench-scale unit that is to be assembled. The main components are the reaction/feed tank and the filter module. The configuration for testing crossflow filtration is shown in the figure.

The first step in the operation of the bench-scale unit will be to carry out one of the treatments described previously for contaminant removal. A solution containing a stable isotope of the contaminant of concern is added to the reaction/feed tank at the expected molar concentration. For counting purposes, the solution is traced with the radioactive isotope. The appropriate treatment chemicals are then added by pumping from the chemicals feed tank. Operational parameters affecting this reaction/precipitation process are the feed rate of chemicals and the degree of mixing (i.e., agitator speed) in the reaction/feed tank.

Filtration of the product slurry is the next step in the operation. With the cross-flow filter, the filtration step may be carried out in one of two modes of operation. In the first, a diaphragm pump supplies the slurry from the reaction tank to the filter circulation loop. The pressure in the circulation loop, and consequently the pressure drop across the filter, is controlled by adjusting the air pressure to the diaphragm pump. The circulating pump is adjusted to produce the desired axial flow rate through the filter tubes. In the second mode of operation, the diaphragm pump is 


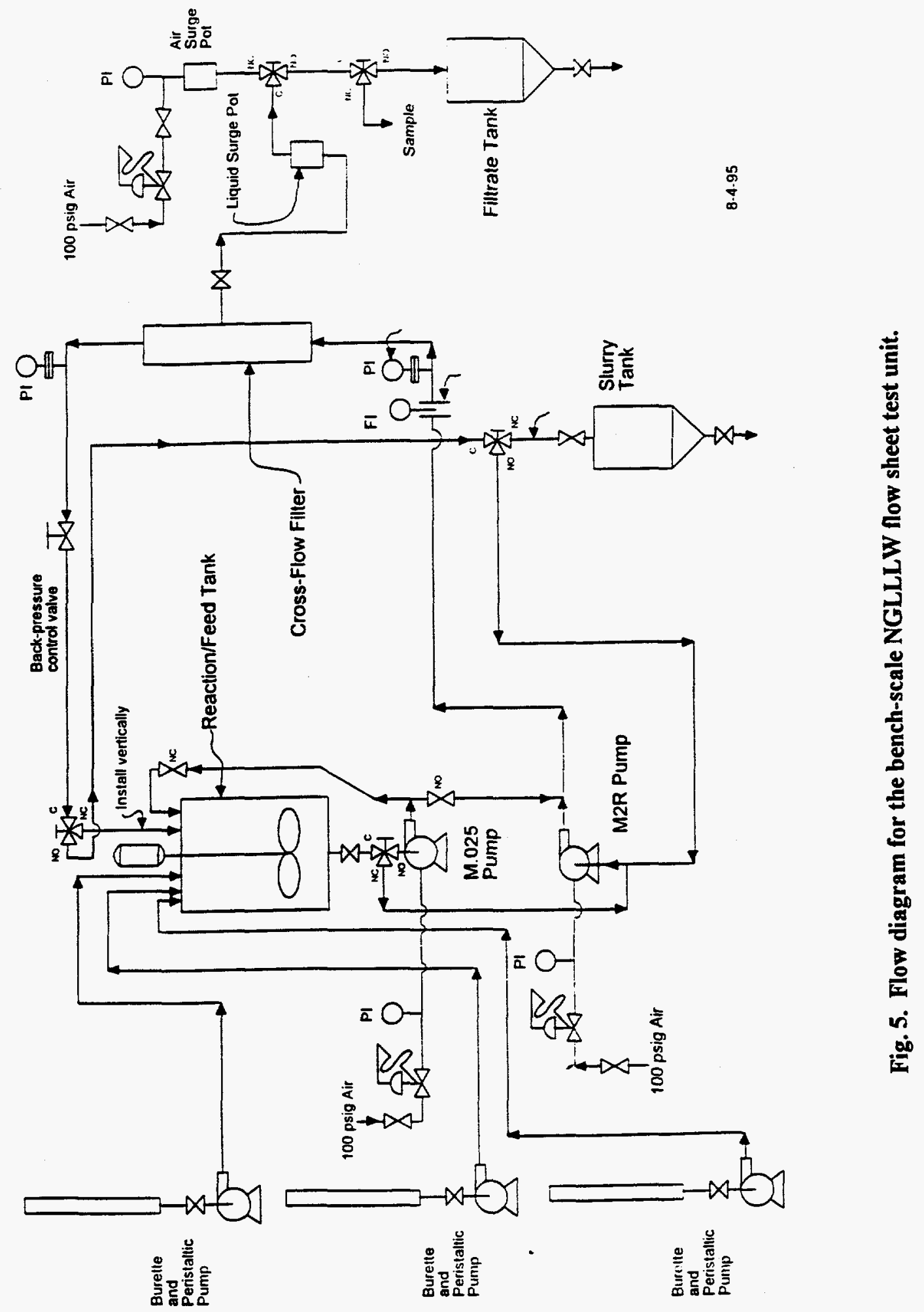


bypassed and the slurry is transferred by the circulating pump to the filter and back to the reaction tank. The valve on the filter exit line is adjusted to produce the desired .pressure drop across the filter while maintaining a constant flow rate. The purpose of these two operational modes is to determine if filtration efficiency is affected by the generation of fines due to the attrition of the solids across a back-pressure control valve. After circulation rate and filter pressure drop have been adjusted to their target settings, the filtrate is collected and sampled and its flow rate measured as a function of operating time.

"Dead-end" filters and the HGMF may also be tested in the bench-scale unit. These filters, which would be installed in place of the cross-flow filter, would be operated in a once-through rather than a circulating-flow configuration. The cross-flow filter may also be operated as a "dead-end" filter by plugging the slurry exit line. Plans are to complete the construction of the bench-scale unit and to carry out startup operations by the beginning of FY 1996.

In support of the design and operation of the bench-scale unit, "cold" tests were run on cross-flow filtration systems at the REDC at ORNL and the Savannah River Technology Center at the Savannah River Site (SRS). In the REDC tests, a clay material was used as the solid. Whereas filtrate flow rate was independent of axial velocity through the filter tube, the flow rate demonstrated a positive dependence on the differential pressure (across the tube wall) of the filter. In tests in which the filtrate and the concentrate were recycled to the filter feed tank, the filtrate became cloudy with time, indicating breakthrough of solids. A possible explanation for this phenomenon is that fines were being generated by shearing of the solids as the concentrate passed through the back-pressure control valve.

In the SRS tests, which used a NGLLLW simulant, the strontium precipitation treatment step was studied. The effects of axial velocity and differential pressure on filtrate flow rate were the same as found in the REDC tests. The filtrate had a low turbidity, indicating good liquid/solid separation. The strontium content in the filtrate remained low immediately following 
liquid/solid separation. The strontium content in the filtrate remained low immediately following a back pulse, indicating little or no passage of solids through the filter element.

\section{REMOVAL OF ${ }^{99}$ Tc FROM NGLLLW}

\subsection{BACKGROUND}

The scope of the proposed NGLLLW flow sheet is being expanded to review the need for the removal of ${ }^{99} \mathrm{Tc}$ from NGLLLW and MVST supernate. Estimates of the quantity of ${ }^{99} \mathrm{Tc}$ in NGLLLW are based on the assumption that the majority of the radionuclide will be derived from wastes generated at REDC. Under a normal operating schedule, approximately $800 \mathrm{mCi}{ }^{99} \mathrm{Tc}$ is generated annually in the processing of a Mark 42 and a High Flux Isotope Reactor (HFIR) reactor target at REDC. The average ${ }^{99} \mathrm{Tc}$ activity in the $45,000 \mathrm{~L}$ of waste transferred annually from REDC to the ORNL central waste LLLW management system will be about $18 \mu \mathrm{Ci} / \mathrm{L}$. The peak ${ }^{99} \mathrm{Tc}$ activity in the waste can be calculated based on the fact that about one-fourth of a Mark 42 reactor target is processed at a time. The LLLW from this portion of a target is accumulated in about $3000 \mathrm{~L}$ of alkaline waste in tank F-126 at REDC, at a ${ }^{99} \mathrm{Tc}$ content of $4 \mathrm{mg} / \mathrm{L}$ or $69 \mu \mathrm{Ci} / \mathrm{L}$. The waste is then transferred to tank WC-20 and fed in stages to the evaporator system so that the total activity level of the LLLW is manageable. ${ }^{15}$

Assuming that no ${ }^{99} \mathrm{Tc}$ is volatilized from the waste during the evaporation process and that the LLLW volume is reduced by $90 \%$, the ${ }^{99} \mathrm{Tc}$ content in the concentrate will be a factor of 10 higher than in the original REDC waste. Thus, the average and peak ${ }^{99} \mathrm{Tc}$ content in the concentrated LLLW will be approximately $180 \mu \mathrm{Ci} / \mathrm{L}$ and $690 \mu \mathrm{Ci} / \mathrm{L}$, respectively. The salt cake formed from the concentrate will contain an average and a peak activity of $1.8 \times 10^{2} \mathrm{mCi} / \mathrm{m}^{3}$ and $6.9 \times 10^{2} \mathrm{mCi} / \mathrm{m}^{3}$ of ${ }^{99} \mathrm{Tc}$, respectively. 
A proposal has been made to treat MVST supernate by blending it with NGLLLW prior to processing. If this occurs, the MVST supernate would represent a second source of ${ }^{99} \mathrm{Tc}$ in LLLW. The technetium content in the MVSTs has been analyzed and published in a previous report. ${ }^{3}$ Since the publication of this data, the contents of the tanks have been air-sparged in an effort to reduce the waste inventory. A more recent sampling campaign has just been completed to determine the composition of the concentrated supernate. The revised values for ${ }^{99} \mathrm{Tc}$ content in the tanks ranged from 7 to $52 \mu \mathrm{Ci} / \mathrm{L}$, with an average value of $21 \mu \mathrm{Ci} / \mathrm{L}$. Based on the average ${ }^{99} \mathrm{Tc}$ in MVST supernate, the salt cake remaining when $90 \%$ of the liquid is evaporated will contain approximately $210 \mu \mathrm{Ci} / \mathrm{L}$ or $2.1 \times 10^{2} \mathrm{mCi} / \mathrm{m}^{3}$ of ${ }^{99} \mathrm{Tc}$. The maximum ${ }^{99} \mathrm{Tc}$ concentration is found in tank W-26 and will produce a salt cake having a ${ }^{99} \mathrm{Tc}$ content 6 times higher than the average value in MVST supernates.

The ${ }^{99} \mathrm{Tc}$ content in the salt cake of either the NGLLLW or the MVST supernate is roughly equivalent. Therefore, solid low-level waste derived from either of these sources individually or from blends of the wastes will present the same storage problems. The waste acceptance criteria for the disposal of solid low-level waste on the ORR is governed by Class LII limits. The maximum ${ }^{99} \mathrm{Tc}$ content in the dried evaporator salt cake cannot exceed the Class LII level for ${ }^{99} \mathrm{Tc}$ of $22.75 \mathrm{mCi} / \mathrm{m}^{3}$ (ref. 2). Based on the estimates for ${ }^{99} \mathrm{Tc}$ in either NGLLLW or MVST supernate, it appears that a minimum DF of approximately 10 , and more realistically of 30 , will be required to remove sufficient quantities of ${ }^{99} \mathrm{Tc}$ from the LLLW so that the ${ }^{99} \mathrm{Tc}$ activity in the final evaporator salt cake does not exceed the waste acceptance criteria (WAC) for disposal onsite. 


\subsection{LABORATORY STUDIES}

Recent laboratory investigations have reported the treatment options for the removal of the radionuclide ${ }^{99} \mathrm{Tc}$ (as the pertechnetate anion, $\mathrm{TcO}_{4}{ }^{-}$) from simulated NGLLLW. ${ }^{16}$ Sorbents selected for initial evaluation are briefly described below:

1. Dowex ${ }^{\text {TM }}$ SBR (Dowex ${ }^{\text {TM }} 1-X 8$, chloride form, 50/100 mesh; lot \# 23104). This material is a Type 1 tertiary amine $\left(-\mathrm{NR}_{3}\right.$, where $\left.\mathrm{R}=\mathrm{CH}_{3}\right)$, strongly basic polystyrene gel anionexchange resin. The as-tested material contained $\sim 18 \%$ moisture (as estimated by weight loss upon drying at $\sim 100^{\circ} \mathrm{C}$ ). Vendor literature suggests a total ion-exchange capacity of $\sim 3.2 \mathrm{eq} / \mathrm{kg}(\mathrm{dry})$ and a moisture content of $\sim 43-48 \%$.

2. Dowex ${ }^{\mathrm{TM}} 2-\mathrm{X} 8$ (chloride form, 20/50 mesh; lot \# M1566). This material is a Type 2 tertiary amine $\left(-\mathrm{NR}_{2} \mathrm{R}^{\prime}\right.$, where $\mathrm{R}=\mathrm{CH}_{3}$ and $\left.\mathrm{R}^{\prime}=\mathrm{CH}_{2} \mathrm{CH}_{2} \mathrm{OH}\right)$, strongly basic polystyrene gel anion-exchange resin. The as-received material contained $\sim 34 \%$ moisture (as estimated by weight loss upon drying at $\sim 100^{\circ} \mathrm{C}$ ). Vendor literature suggests a total ion-exchange capacity of $\sim 3.2 \mathrm{eq} / \mathrm{kg}$ (dry) and a moisture content of $\sim 38-45 \%$.

3. Bio-Rad ${ }^{\mathrm{TM}}$ AG 1-X8 (hydroxide form, 20/50 mesh; lot \# 42001A). The as-tested material contained $\sim 58 \%$ moisture (as estimated by weight loss upon drying at $\sim 100^{\circ} \mathrm{C}$ ). The material is an analytical grade equivalent to Dowex ${ }^{\mathrm{TM}} 1-\mathrm{X} 8$.

4. Reillex ${ }^{\mathrm{TM}} \mathrm{HP}$ (30/60 mesh, lot \# 88-1, Reilley Industries, Indianapolis, Indiana). The material is a macroporous copolymer of 4-vinylpyridine and divinylbenzene (CAS Registery Number $9017-40-7$ ). The as-tested material contained $~ 31 \%$ moisture (as estimated by weight loss upon drying at $\sim 100^{\circ} \mathrm{C}$ ). Vendor literature suggests a total ion-exchange capacity of $\sim 5.5 \mathrm{eq} / \mathrm{kg}$ (dry). 
5. Reillex ${ }^{\mathrm{IM}} \mathrm{HPQ}$ (chloride form, 30/60 mesh, lot \# 90928AC; Reilley Industries, Indianapolis, Indiana). The material is a copolymer of partially quaternized 4-vinylpyridine and divinylbenzene (CAS Registery Number 125200-80-8). The exchange groups are $\sim 70 \%$ strong-base (methyl pyridinium) and $\sim 30 \%$ weak-base (pyridinium) sites. The as-tested material contained $\sim 58 \%$ moisture (as estimated by weight loss upon drying at $\sim 100^{\circ} \mathrm{C}$ ). Vendor literature suggests a total ion-exchange capacity of $\sim 4.6 \mathrm{eq} / \mathrm{kg}$ (dry).

6. Rohm \& Haas Duolite ${ }^{\mathrm{R}}$ GT-73 (lot \# 890394-8). The functionality of this resin is provided mainly by the thiol (-SH) group, with minor contribution by sulfonic acid groups; the product is a cation-exchange resin, with selectivity in the sequence: $\mathrm{Hg}>\mathrm{Ag}>\mathrm{Cu}>\mathrm{Pb}>$ $\mathrm{Cd}>\mathrm{Ni}>\mathrm{Co}>\mathrm{Fe}>\mathrm{Ca}>\mathrm{Na}$. The as-received material contained $\sim 66 \%$ moisture (as estimated by weight loss upon drying at $\sim 100^{\circ} \mathrm{C}$ ).

7. Bronze wool (Elephant brand). This material was determined to be copper metal (with trace silicon impurity) and had a median strand diameter of $42.7 \pm 3.8 \mu \mathrm{m}$.

8. Steel wool. The material tested was removed from an Eastman Kodak chemical recovery canister (catalog no. 173-4953; lot \# 17934). The canister contains $\sim 3.4 \mathrm{~kg}$ steel in a nominal volume of $\sim 5.5 \mathrm{gal}(\sim 20 \mathrm{~L})$, or a nominal packing density for the steel of $\sim 0.17 \mathrm{~g} / \mathrm{cm}^{3}$. The iron metal strands (ribbon) had a median diameter $93 \pm 36 \mu \mathrm{m}$.

In small batch testing (Fig. 6), Dowex ${ }^{\mathrm{TM}}$ 1-X8 and Reillex ${ }^{\mathrm{TM}}$ HPQ resins were notably effective (with equilibrium distribution coefficients $\sim 2000 \mathrm{~mL} / \mathrm{g}$, as-received basis). Steel wool was effective, but only at $\mathrm{pH}$ values at which the iron could act as a reagent to chemically reduce and sorb ${ }^{99} \mathrm{Tc}$. At $\mathrm{pH}$ values above $\sim 10$, the iron surface was passivated and became ineffective as a reagent for technetium. However, as the test solution $\mathrm{pH}$ value was adjusted to near neutrality (e.g., pH 8-9), the steel was noted to be more effective than the organic resins tested. 
In dynamic flow conditions (Fig. 7), steel wool packed in a column was noted to continuously leak $\sim 1-3 \%$ of the amount of ${ }^{99} \mathrm{Tc}$ activity in the feed solution, although no additional increase in eluant activity was noted for the duration of the testing ( 1200 bed volumes of $\sim 0.11 \mathrm{mg} / \mathrm{L}{ }^{99} \mathrm{Tc}$ flowed at a rate equivalent to $\sim 0.5 \mathrm{gal} / \mathrm{ft}^{2}$ of column crosssectional area). Although no breakthrough was noted (other than the 1-3\% continuous "bleed" noted previously) during the column operation ( 2 weeks), the steel in the column was deteriorated, causing plugging and erratic flow toward the end of the testing interval. The steel wool column demonstrated a significant sorption capacity for ${ }^{99} \mathrm{Tc}$. However, the difficulty in packing a column of uniform density and the continuous oxidation of the steel wool probably caused channeling of the column feed that produced the continuous bleed of ${ }^{99} \mathrm{Tc}$ from the column.

Dowex ${ }^{\text {TM }}$ SBR (Dowex 1-X8, chloride form) was also selected for testing in a packed-bed configuration. In contrast to the steel wool experiment, little or no bleed of ${ }^{99} \mathrm{Tc}$ activity was noted in the column effluent (at a flow rate of $\sim 0.8 \mathrm{gal} / \mathrm{ft}^{2}$ of column cross-sectional area). During the prolonged testing period, the ${ }^{99} \mathrm{Tc}$ in the column feed was increased from an initial value of $\sim 0.8 \mathrm{mg} / \mathrm{L}$ to a final value of $\sim 22.4 \mathrm{mg} / \mathrm{L}$. The loading of ${ }^{99} \mathrm{Tc}$ on the resin at an eluant activity of $\sim 1 \%$ of the final feed value corresponded to $\sim 12.3 \mathrm{mg}$ of ${ }^{99} \mathrm{Tc}$ per cubic centimeter of bed volume.

It should be noted that loading of ${ }^{99} \mathrm{Tc}$ on Type 1 strongly basic anion-exchange resin (such as Dowex ${ }^{\mathrm{TM}} 1-\mathrm{X} 8$ ) is adversely affected by high concentrations of competing nitrate ion. This situation could occur if NGLLLW is blended with a relatively large proportion of high-nitrate legacy waste from the MVST supernates. For aqueous wastes with relatively large concentrations of nitrate, polyvinylpyridine resins (such as Reillex ${ }^{\mathrm{TM}} \mathrm{HPQ}$ ) may yield a higher 


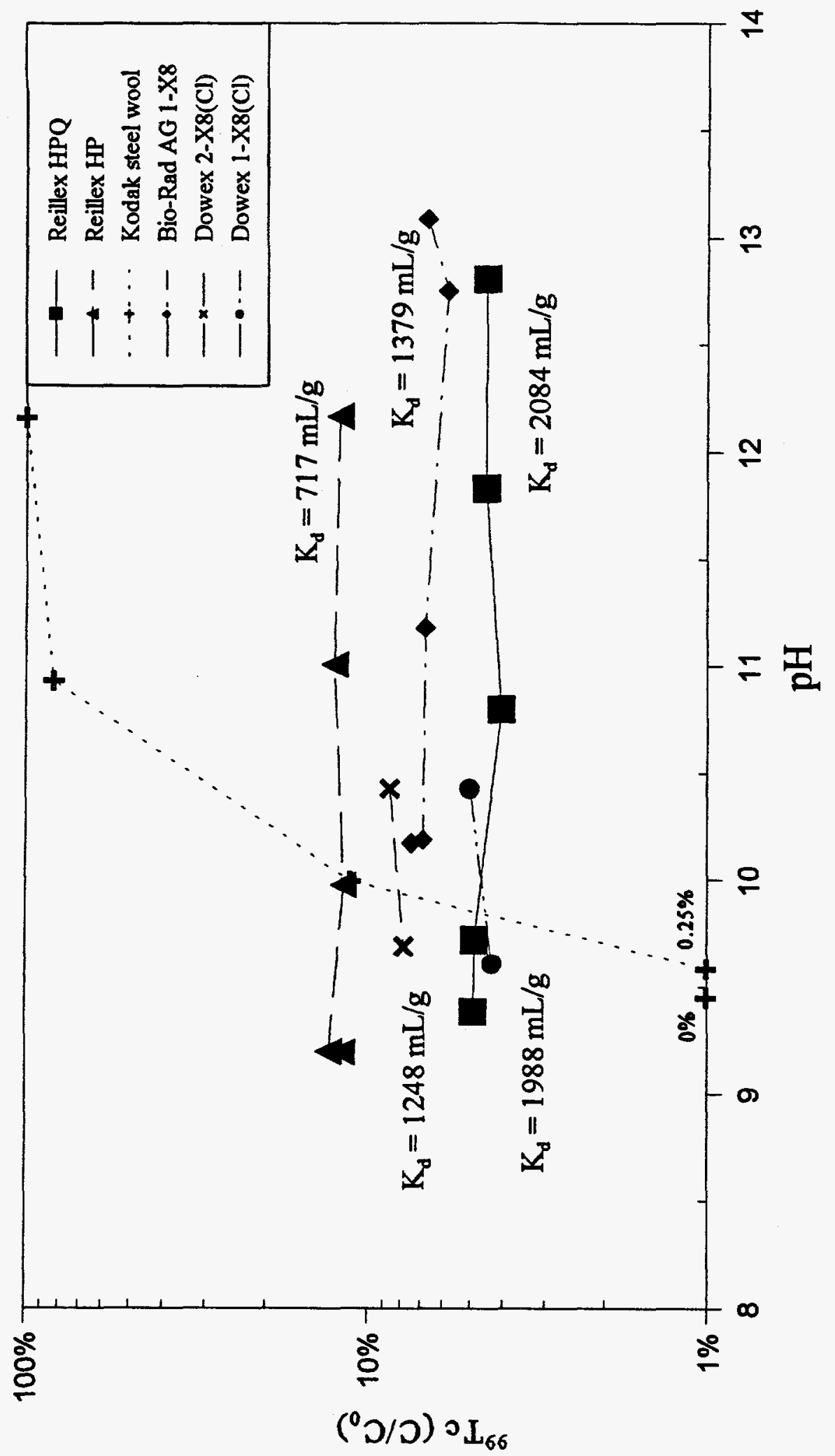

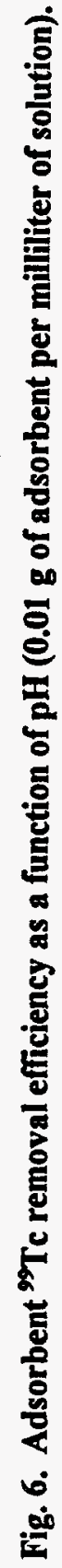




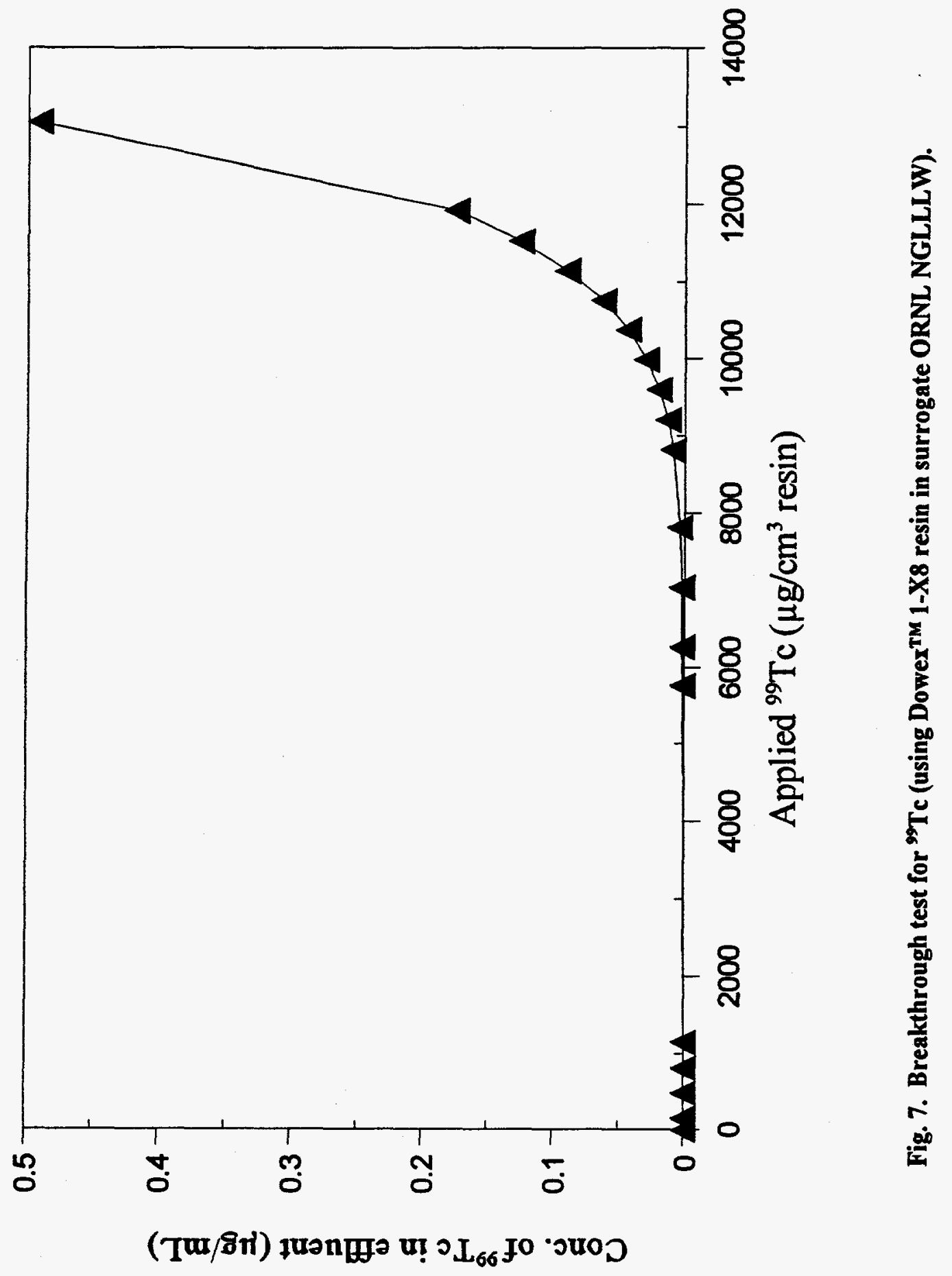


effective loading capacity (due to greater inherent selectivity for pertechnetate ion in the presence of excess nitrate ion).

\subsection{RECOMMENDATIONS}

Use of Type 1 strongly basic anion-exchange medium, such as Dowex ${ }^{\mathrm{TM}} 1-\mathrm{X} 8$, is an established technology for removal of pertechnetate ion from aqueous waste. It is likely to be the technology of choice for removal of soluble ${ }^{99} \mathrm{Tc}$ from the NGLLLW. The chief limitation in the use of this type of sorptive medium is the interference caused by high concentrations of nitrate ion, an interferant that exists at relatively modest concentrations in NGLLLW (see Table 2).

For Dowex ${ }^{\mathrm{TM}}$ 1-X8 resin in media at constant ionic strength, the sorptive distribution coefficient $\left(K_{d}\right)$ for pertechnetate decreases in the order hydroxide $>$ chloride $>$ nitrate $>$ perchlorate, and selectivity decreases in the order pertechnetate $>$ perchlorate $>$ nitrate $>$ chloride $>$ hydroxide. ${ }^{17}$ Thus, for this type of medium, high concentrations of nitrate ion decrease the effective sorption of pertechnetate for a given mass of resin sorbent, and bound pertechnetate can only be displaced from the resin by high concentrations of strong ligand, such as perchloric or nitric acid. ${ }^{17,18}$ Although the use of concentrated strongly oxidative acid solutions for column elution and recovery of trace ${ }^{99} \mathrm{Tc}$ may be useful on a microanalysis scale, these chemicals present serious safety concerns for large-scale application. Thus, industrial-scale regeneration of spent Type 1 strongly basic anion-exchange resin containing ${ }^{99} \mathrm{Tc}$ appears to be impractical, and the resin medium must be discarded after its exchange capacity has become saturated.

Relative to Type 1 strongly basic anion-exchange resin, polyvinylpyridine resins are not as adversely affected by high nitrate ion concentration and show enhanced chemical, thermal, and radiation stability. ${ }^{19}$ If the NGLLLW is to be blended with strongly alkaline MVST legacy waste containing much higher concentrations of nitrate ion $(\sim 5.4 \mathrm{~mol} / \mathrm{L}$ in the concentrated 
supernate), then a resin such as Reillex ${ }^{\mathrm{TM}} \mathrm{HPQ}$ may be preferred. (See Schroeder and coworkers $^{20-22}$ for a discussion on the use of Reillex ${ }^{\mathrm{TM}}$ HPQ resin in high-nitrate alkaline tank waste from the Hanford Operations Site.) Recent work suggests that bound pertechnetate can be readily stripped from Reillex ${ }^{\mathrm{TM}} \mathrm{HPQ}$ resin with use of a reductive solution (containing stannous chloride), which allows the resin to be reused. ${ }^{22}$ The possibility of regeneration/reuse of resin could shift the life-cycle processing costs in favor of the use of this type of sorptive medium. The desorbed, reduced technetium concentrate must be conditioned to prevent accidental release back into the environment.

Iron metal could remain a candidate for removal of ${ }^{99} \mathrm{Tc}$ from high-nitrate waste but would require prior neutralization of the wastewater. ${ }^{23}$ Although use of iron is an economical, innovative treatment technology, it may be more difficult to accurately predict its sorptive capacity or functional lifetime (before rusting of substrate causes flow restriction).

Spent sorptive media must be conditioned for disposal. Recently, McGinnes and Dyer ${ }^{24}$ reviewed disposal options for ${ }^{99} \mathrm{Tc}$-laden ion-exchange resins, including incineration, wet oxidation, and compaction; they concluded, however, that encapsulation is the simplest method.

Durable waste forms can be prepared by imbedding the resin in special grout blends or in polymer (such as vinyl ester styrene, VES). ${ }^{25.26}$ Volumetric loading efficiencies for the stabilization of spent anion-exchange resin in waste forms are $\sim 50 \%$ for grout and $\sim 90 \%$ for VES. ${ }^{25}$ Assuming disposal of spent Dowex ${ }^{\mathrm{TM}} 1-\mathrm{X} 8 \mathrm{resin}$ laden with $\sim 10 \mathrm{mg}{ }^{99} \mathrm{Tc}$ per cubic centimeter (or $\sim 170 \mathrm{Ci} / \mathrm{m}^{3}$ ), the stabilized waste forms would contain $\sim 85 \mathrm{Ci} / \mathrm{m}^{3}$ (grout) to $\sim 150$ $\mathrm{Ci} / \mathrm{m}^{3}$ (VES), well in excess of the draft criterion of $5.5 \times 10^{-6} \mathrm{Ci} / \mathrm{m}^{3}$ for disposal of ${ }^{99} \mathrm{Tc}$ as Class LII solid waste at the ORR ${ }^{2}$

A more complete discussion of the laboratory results for the removal of ${ }^{99} \mathrm{Tc}$ from NGLLLW simulant can be found in a recently published technical report. ${ }^{27}$ 


\section{NITRATE DESTRUCTION}

\subsection{BACKGROUND}

The nitrate content in NGLLLW processed by the proposed flow sheet is one of the factors defining the final disposition of the secondary LLLW. If the waste is to be transferred to the Process Waste Treatment Plant (PWTP) for further processing, the nitrate concentration must be less than the WAC of $10 \mathrm{ppm}$. Assuming that the effluent from the NGLLLW flow sheet will be diluted by a factor of 20 with other LLLW entering the PWTP, the upper limit for nitrate concentration in the secondary waste should not exceed $200 \mathrm{ppm}$. If the secondary LLLW does not meet the established WAC for the PWTP, the liquid waste will probably be concentrated by a factor of 10 and incorporated into cement grout. Under this disposal scenario, the nitrate concentration in the concentrated waste should be held below $5 \mathrm{M}$ so that the grouting process is not compromised. The estimated nitrate concentration in NGLLLW is $0.06 M$ or $3700 \mathrm{ppm}$. To meet the nitrate WAC for the PWTP, the nitrate concentration will have to be reduced by a factor of 370 . The nitrate concentration in the secondary LLLW generated in the flow sheet should not pose a problem in terms of grouting if it is concentrated by evaporation to $10 \%$ of its original volume.

MVST supernate contains $5.1 \mathrm{M}$ nitrate, approximately 100 times more nitrate than found in NGLLLW. In order to discharge blended LLLW containing significant portions of MVST supernate to the PWTP or to grout the concentrated secondary LLLW, the nitrate in the LLLW must be greatly reduced. The hazards involved in the long-term storage of solid wastes containing high nitrate content provide an additional incentive for removing the majority of the anion from the LLLW. The nitrate to ammonia and ceramic (NAC) process has recently been reviewed for denitrifying NGLLLW alone and in mixtures with MVST supernate. The added 
advantage of employing the NAC process is that the denitrified LLLW is incorporated into a solid waste suitable for long-term storage. The goal of this study was to determine the degree to which nitrate could be removed from the LLLW, as well as to document the effect of introducing the NAC process into the proposed NGLLLW flow sheet.

The NAC process involves the chemical reduction of nitrate ions to ammonia by powdered aluminum. ${ }^{28}$ The process must take place in highly alkaline solutions $(\mathrm{pH}>11.5)$ to dissolve the oxide layer coating the aluminum powder's surface so that the NAC reaction can be initiated. The $\mathrm{pH}$ at the head end of the proposed NGLLLW flow sheet is greater than 12.5; therefore, the NGLLLW will not have to be pretreated with caustic to meet the $\mathrm{pH}$ requirement of the NAC process. During the nitrate reduction reaction, aluminum oxides $\left(94 \% \mathrm{Al}_{2} \mathrm{O}_{3} \cdot 3 \mathrm{H}_{2} \mathrm{O}\right.$ and $4 \%$ $\mathrm{NaAlO}_{2}$ ) precipitate, sorbing many inorganic contaminants including heavy metals and ${ }^{90} \mathrm{Sr}$. The chemical reaction for the NAC process, assuming $100 \%$ efficiency, is given in Eq. (1):

$$
16 \mathrm{Al}+6 \mathrm{NaNO}_{3}+24 \mathrm{H}_{2} \mathrm{O} \rightarrow 6 \mathrm{NH}_{3}(\mathrm{~g})+25 \mathrm{Al}_{2} \mathrm{O}_{3} \cdot 3 \mathrm{H}_{2} \mathrm{O}+\mathrm{NaAlO}_{2}
$$

The NAC process is typically only $90 \%$ efficient; the chemical equation representing this case is given in Eq. (2):

$$
32 \mathrm{Al}+6 \mathrm{NaNO}_{3}+72 \mathrm{H}_{2} \mathrm{O} \rightarrow 6 \mathrm{NH}_{3}(\mathrm{~g})+13 \mathrm{Al}_{2} \mathrm{O}_{3} \cdot 3 \mathrm{H}_{2} \mathrm{O}+6 \mathrm{NaAlO}_{2}+24 \mathrm{H}_{2}(\mathrm{~g})
$$

The reaction produces a granular, sand-like material that can be dried, pressed, and sintered to form an insoluble alumina-silica ceramic as the final waste form. 


\subsection{LABORATORY STUDIES}

The NAC process was evaluated using several treatment scenarios for NGLLLW. These treatment options included (1) placing the NAC process at the head of the NGLLLW flow sheet, (2) denitrifying the waste at the completion of the NGLLLW flow sheet, and (3) treating NGLLLW blended with MVST supernate. The final nitrate content, radionuclide activity, and volumes of secondary solid and liquid waste produced were compared for these treatment scenarios. Experiments were conducted by adding powdered aluminum metal to $75-\mathrm{mL}$ simulant samples, a process that represents one of the treatment options. The amount of added aluminum was maintained at a ratio of $2.67 \mathrm{~g}$ of aluminum per gram of nitrate present in the sample. The aluminum was added to the samples in small portions and stirred until the exothermic reaction subsided to reduce the chance of the solution boiling over. Addition of the aluminum powder was then continued until the required amount of the metal had been added to the sample. The initial and final nitrate concentrations of the samples were determined spectrophotometrically; the strontium DF for the denitrification process was determined by comparing the beginning and final gamma count rates of the processed samples. The results of this testing are summarized in

Table 10. The first treatment option simulated the use of the NAC process at the head end of the proposed NGLLLW flow sheet to treat $100 \%$ NGLLLW. The concentration of $\mathrm{NaOH}$ in NGLLLW is $M$. This quantity of alkali was sufficient to initiate the NAC reaction in the $75-\mathrm{mL}$ NGLLLW sample but not enough to completely dissolve the aluminum oxide layer present on $0.494 \mathrm{~g}(0.018 \mathrm{~mol})$ of aluminum that was added to the sample. An additional $0.02 \mathrm{~mol}$ of $\mathrm{NaOH}$ was added to the sample to permit complete reaction of the aluminum powder. The total nitrate concentration at the completion of the NAC reaction was reduced from an initial value of $4500 \mathrm{ppm}$ to $200 \mathrm{ppm}$, with nitrite formation noted in the sample. Cesium-137 was not removed from the LLLW by the NAC process. A strontium DF of about 1000 was observed in the 
Table 10. NAC Processing of 75-mL NGLLLW/MVST supernate samples

\begin{tabular}{|c|c|c|c|c|c|c|}
\hline $\begin{array}{l}\text { NAC unit } \\
\text { process } \\
\text { position }\end{array}$ & $\begin{array}{l}\text { Percentage } \\
\text { of MVST } \\
\text { supernate } \\
\text { in } \\
\text { NGLLLW }\end{array}$ & $\begin{array}{c}\text { Initial } \\
{\left[\mathrm{NO}_{3}^{-}\right]} \\
(M)\end{array}$ & $\begin{array}{l}\text { Final } \\
{\left[\mathrm{NO}_{3}{ }^{-}\right]} \\
(\mathrm{ppm})\end{array}$ & $\begin{array}{c}\text { Sr DF } \\
\text { after NAC } \\
\text { processing }\end{array}$ & $\begin{array}{c}\mathrm{Sr} \mathrm{DF} \\
\text { after } \mathrm{pH} \\
\text { adjustment }\end{array}$ & $\begin{array}{l}\text { Cum. } \\
\text { Sr DF }\end{array}$ \\
\hline $\begin{array}{l}\text { Before } \\
\text { NGLLLW } \\
\text { flow sheet }\end{array}$ & 0 & 0.073 & $50-100$ & 16,000 & 1 & 16,000 \\
\hline $\begin{array}{l}\text { Before } \\
\text { NGLLLW } \\
\text { flow sheet }\end{array}$ & 0 & 0.075 & $50-100$ & 730 & 10 & 7,300 \\
\hline $\begin{array}{l}\text { After } \\
\text { NGLLLW } \\
\text { flow sheet }\end{array}$ & 0 & 0.10 & $250-500$ & 1,537 & NA & NA \\
\hline $\begin{array}{l}\text { After } \\
\text { NGLLLW } \\
\text { flow sheet }\end{array}$ & 0 & 0.073 & $250-500$ & 1,537 & NA & NA \\
\hline $\begin{array}{l}\text { Before } \\
\text { NGLLLW } \\
\text { flow sheet }\end{array}$ & 10 & 0.54 & $100-150$ & 859 & 5 & 4,295 \\
\hline $\begin{array}{l}\text { Before } \\
\text { NGLLLW } \\
\text { flow sheet }\end{array}$ & 10 & 0.54 & $100-150$ & 1,393 & 4 & 5,572 \\
\hline $\begin{array}{l}\text { Before } \\
\text { NGLLLW } \\
\text { flow sheet }\end{array}$ & 30 & 1.52 & $100-150$ & 252 & 19 & 4,788 \\
\hline $\begin{array}{l}\text { Before } \\
\text { NGLLLW } \\
\text { flow sheet }\end{array}$ & 30 & 1.52 & $100-150$ & 2,061 & 4 & 8,244 \\
\hline $\begin{array}{l}\text { Before } \\
\text { NGLLLW } \\
\text { flow sheet }\end{array}$ & 50 & 2.49 & $100-150$ & 926 & 7 & 6,482 \\
\hline
\end{tabular}


supernate after the gibbsite $\left(\mathrm{Al}_{2} \mathrm{O}_{3} \cdot 3 \mathrm{H}_{2} \mathrm{O}\right)$ solids settled from the treated waste. This value is much larger than the DF of 120 typically obtained using the strontium coprecipitation unit operation. The alkaline supernate from the denitrified LLLW was subsequently neutralized to $\mathrm{pH} 8$ to precipitate the dissolved sodium aluminate as aluminum hydroxide. Because strontium sorbs to the precipitated aluminum hydroxide, an additional decontamination of the denitrified waste was achieved. The cumulative strontium DF for the NAC process, including the waste neutralization step, was approximately 8000 .

The large strontium DF obtained with the NAC process would negate the need for the strontium coprecipitation unit operation in the NGLLLW flow sheet. If the NAC process is placed at the head of the proposed NGLLLW flow sheet, approximately $60 \mathrm{~g}$ of air-dried solid waste will be produced per liter of treated NGLLLW. This amount of secondary solid waste is in addition to the solid low-level waste that will be generated in the treatment of cesium remaining in the final denitrified LLLW. In contrast, the proposed NGLLLW flow sheet will generate only $0.2 \mathrm{~g}$ of secondary solid waste in the strontium coprecipitation unit operation and $1 \mathrm{~g}$ of aluminum hydroxide per liter of treated NGLLLW when the waste is neutralized. Thus, the NAC process placed at the head end of the flow sheet will remove nitrate and negate the need for the strontium coprecipitation unit operation but at the expense of producing a large amount of secondary waste. On the other hand, the proposed NGLLLW flow sheet will produce relatively little waste, but a mechanism for removing nitrates from blended MVST/NGLLLW streams must still be identified.

A second treatment option studied was to place the NAC process at the end of the NGLLLW flow sheet. The majority of the ${ }^{90} \mathrm{Sr}$ and ${ }^{137} \mathrm{Cs}$ would be removed from the LLLW at this point. The $\mathrm{pH}$ of the LLLW at the end of the second KCCF strike would be near neutral; concentrated $\mathrm{NaOH}$ would have to be added to readjust the $\mathrm{pH}$ to greater than 11 for the NAC process. The 
nitrate concentration was reduced from 4500 to $500 \mathrm{ppm}$ in samples treated under this process scenario. The advantage in performing a final NAC treatment is that the activity of the relatively large amount of secondary waste generated by this process will be relatively low because a majority of the strontium and cesium will have already been removed from the LLLW at this point. The NAC process could also act as a final polishing step for strontium removal for the NGLLLW flow sheet. A strontium DF of 1500 was obtained in samples representing denitrified LLLW obtained when the NAC process was positioned at the end of the NGLLLW flow sheet.

Laboratory studies also defined the impact of using the NAC process to treat NGLLLW that had been blended with up to $50 \%$ MVST supernate. Because MVST supernate has a nitrate concentration about 100 times greater than that found in NGLLLW, significant quantities of aluminum must be added to blended waste samples to completely react with the nitrate. Approximately 90,250 , and $410 \mathrm{~g}$ of aluminum powder are required to remove the nitrate in $1 \mathrm{~L}$ of blended waste containing 10,30 , and $50 \%$ MVST supernate, respectively. In actual practice, it appears that the NAC process is limited to treating LLLW samples containing less than $10 \%$ MVST supernate. Higher blends of MVST supernate require the addition of so much aluminum that the samples become too viscous to stir. Complete nitrate removal in high blends of MVST cannot be accomplished without diluting the waste stream with nearly equivalent amounts of NGLLLW or water and $\mathrm{NaOH}$. Although the added liquid permits the addition of the required amount of aluminum to the blended waste, it seems rather counterproductive to go to this extreme to treat a blended sample. Results for nitrate removal for the various blends of MVST supernate in NGLLLW are also presented in Table 10. The final nitrate content in all blended samples was less than $150 \mathrm{ppm}$. 
The NAC process may also represent a possible alternative treatment process for the removal of ${ }^{99} \mathrm{Tc}$ in NGLLLW. The pertechnetate anion will be reduced to technetium dioxide $\left(\mathrm{TcO}_{2}\right)$ during the NAC process. If the $\mathrm{LLLW}$ is treated in an inert atmosphere, the $\mathrm{TcO}_{2}$ solids will not be autooxidized to the soluble pertechnetate ion during processing. The gibbsite solids, produced during the NAC process, should then be able to coprecipitate the $\mathrm{TcO}_{2}$ and, thereby, decontaminate the LLLW. The efficiency of the coprecipitation process was tested by tracing a $35-\mathrm{mL}$ aliquot of NGLLLW simulant with $8.8 \times 10^{2} \mathrm{~Bq} / \mathrm{mL}{ }^{99} \mathrm{Tc}$. The sample was processed in an inert argon atmosphere to prevent the oxidation of $\mathrm{TcO}_{2}$ to the more the soluble pertechnetate ion. The final ${ }^{99} \mathrm{Tc}$ activity in the treated LLLW waste was $2.1 \times 10^{1} \mathrm{~Bq} / \mathrm{mL}$; the resulting ${ }^{99} \mathrm{Tc}$ DF for the treatment process was 42 .

\section{LITERATURE SURVEY: SAFETY OF CESIUM REMOVAL WITH KCCF}

\subsection{BACKGROUND}

A significant concern in implementing the NGLLLW flow sheet is assessing the safety issues arising from the use of KCCF for the removal of cesium under operating conditions to be encountered in the treatment of NGLLLW. Sodium nickel hexacyanoferrate, $\mathrm{Na}_{2} \mathrm{NiFe}(\mathrm{CN})_{6}$, was used at Hanford in the 1950 s to remove cesium from alkaline sodium nitrate waste solutions stored in tanks. ${ }^{29}$ Because exothermic reactions can occur under certain conditions between hexacyanoferrates and oxidizers such as nitrates, concerns arose in the 1980s over the stability of the wastes in the Hanford storage tanks, and an extensive research program was undertaken to determine the safety of the stored wastes. As a result of the safety concerns with the ferrocyanide wastes stored in the Hanford tanks, a literature survey was made to examine the proposed ORNL treatment flow sheet, shown in Fig. 2, with regard to the potential for 
exothermic reactions in the dried waste solids produced in the flow sheet and the potential for the formation of toxic cyanide compounds in the waste solutions treated with hexacyanoferrates. The approximate compositions of the waste solutions expected to be treated with the ORNL flow sheet are shown in Table 1. The calculated compositions of the dried solids combined from the two cesium removal treatments with $\mathrm{KCCF}$ are shown in Table $11 .^{30}$ Two cases are considered, for treatment of NGLLLW alone and for treatment of a $50 / 50 \mathrm{vol} \%$ blend of NGLLLW and MVST supernate. The calculated compositions of the dried solids assume the waste slurry from the liquid/solid separations contained $10 \mathrm{wt} \% \mathrm{KCCF}$ solids and $90 \mathrm{wt} \%$ entrained waste solution and that the solids were not washed to remove entrained solution before drying.

\subsection{HANFORD WASTES AND TREATMENT FLOW SHEET}

The high-level wastes stored in the Hanford tanks, which resulted from defense production activities, are strongly alkaline and contain significant quantities of ${ }^{137} \mathrm{Cs}$. In order to gain storage space, some of the wastes were treated between 1953 and 1957 with sodium nickel hexacyanoferrate to remove the cesium from the solutions, which were then disposed of in soil columns after the precipitates had settled. ${ }^{1}$ The settled precipitates, along with entrained solution, remained in the storage tanks. Additional wastes were later added to some of the tanks that contained the hexacyanoferrate solids. The flow sheet used to treat the wastes was similar to the proposed ORNL flow sheet for treating NGLLLW. It contained the following steps:

1. adding $\mathrm{Ca}\left(\mathrm{NO}_{3}\right)_{2}$ and later $\mathrm{Sr}\left(\mathrm{NO}_{3}\right)_{2}$ to remove strontium from the wastes,

2. adding $\mathrm{Na}_{4} \mathrm{Fe}(\mathrm{CN})_{6}$ to the alkaline solution after separation of the strontium-containing solids,

3. adjusting the $\mathrm{pH}$ of the solution to $9 \pm 1$, and 
Table 11. Composition of dried solids from Cs separation

$50 \mathrm{vol} \%$

NGLLLW

$+$

50 vol $\%$

\begin{tabular}{lll} 
& NGLLLW & $\begin{array}{c}50 \mathrm{vol} \% \\
\text { supernate }\end{array}$ \\
\hline Total solids, g/L waste & 1.359 & 2.593
\end{tabular}

Composition of solids, wt \%

$\begin{array}{lll}\mathrm{LiCl} & 0.71 & 0.13 \\ \mathrm{NaHCO}_{3} & 5.6 & 2.86 \\ \mathrm{NaNO}_{3} & 3.48 & 52.69 \\ \mathrm{Na}_{2} \mathrm{SO}_{4} & 10.66 & 6.19 \\ \mathrm{NaCl} & 1.34 & 1.16 \\ \mathrm{KNO}_{3} & 0 & 3.8 \\ \mathrm{Al}(\mathrm{OH})_{3} & 67.17 & 27.38 \\ \mathrm{KCCF} & 11.04 & 5.78 \\ & & \\ \mathrm{Mole} \text { ratio }\left(\mathrm{NO}_{3} / \mathrm{KCCF}\right) & 1.3 & 39.68 \\ & & \\ { }^{37} \mathrm{Cs} \text { in solids, } \mu \mathrm{Ci} / \mathrm{g} & 9.34 & 6.22 \\ \end{array}$

'Basis: Slurry containing $10 \mathrm{wt} \%$ solids and $90 \mathrm{wt} \%$ entrained solution combined from the two KCCF treatments and dried without washing. 
4. adding $\mathrm{NiSO}_{4}$ stoichiometrically to the $\mathrm{Na}_{4} \mathrm{Fe}(\mathrm{CN})_{6}$ to form $\mathrm{Na}_{2} \mathrm{NiFe}(\mathrm{CN})_{6}$ and $\mathrm{Cs}_{2} \mathrm{NiFe}(\mathrm{CN})_{6}$.

After the precipitates had settled, the treated solutions were decanted and disposed of in soil columns. The treatment effectively removed the cesium from the waste solutions.

\subsection{STABILITY OF SOLID HEXACYANOFERRATES}

Hexacyanoferrates can be oxidized under conditions that could result in an uncontrolled reaction or explosion. Sodium nitrate and/or sodium nitrite can act as oxidants:

$$
\begin{aligned}
& \mathrm{Na}_{2} \mathrm{NiFe}(\mathrm{CN})_{6}+6 \mathrm{NaNO}_{3} \rightarrow 4 \mathrm{Na}_{2} \mathrm{CO}_{3}+\mathrm{NiO}+\mathrm{FeO}+2 \mathrm{CO}_{2}+6 \mathrm{~N}_{2} \text {, and } \\
& \mathrm{Na}_{2} \mathrm{NiFe}(\mathrm{CN})_{6}+10 \mathrm{NaNO}_{2} \rightarrow 6 \mathrm{Na}_{2} \mathrm{CO}_{3}+\mathrm{NiO}+\mathrm{FeO}+\mathrm{N}_{2} .
\end{aligned}
$$

The hexacyanoferrate solids that remained in the Hanford tanks held entrained waste solution that contained significant quantities of sodium nitrate and sodium nitrite formed from radiolysis of the sodium nitrate. The above reactions are exothermic and can proceed to explosions under certain conditions. In small-scale reactivity tests and time-to-explosion tests, Scheele et al. ${ }^{29}$ found that exothermic reactions began at about 200 to $220^{\circ} \mathrm{C}$ and that the maximum exotherm appeared in the range from about 280 to $320^{\circ} \mathrm{C}$. The maximum explosive behavior appeared to be with near-stoichiometric mixtures of hexacyanoferrate and oxidant, but excesses of either still sometimes produced explosions. Smaller amounts of oxidant would be expected to result in incomplete reaction, while larger amounts could slow the reaction rate and absorb the energy released. In tests described by Scheele, Burger, and $\mathrm{Sell}_{,}{ }^{31} \mathrm{Cs}_{2} \mathrm{NiFe}(\mathrm{CN})_{6} \cdot 1.5 \mathrm{H}_{2} \mathrm{O}$ reacted explosively at $400^{\circ} \mathrm{C}$ with an equimolar ratio of $\mathrm{NaNO}_{3}$ and $\mathrm{NaNO}_{2}$ at oxidant-tohexacyanoferrate ratios from 0.1 to 2.5 times the stoichiometric ratio, while ratios of 0.5 to 1.0 
times stoichiometric were explosive at $320^{\circ} \mathrm{C}$. Mixtures containing more or less oxidant did not explode. In tests described by Scheele et al., ${ }^{29}$ reactions involving nitrites were faster and more vigorous and occurred at slightly lower temperatures than those with nitrates alone. The reactions achieved with a typical mixed nitrate/nitrite salt were complex and showed multiple exothermic peaks. Burger and Scheele ${ }^{32}$ reported that a molten oxidant was required for a rapid exothermic reaction with $\mathrm{Cs}_{2} \mathrm{NiFe}(\mathrm{CN})_{6}$ to begin. Small samples of $\mathrm{Cs}_{2} \mathrm{NiFe}(\mathrm{CN})_{6}$ were oxidized by $\mathrm{NaNO}_{3}$ but usually not violently when the temperature was increased at a rate of 2 to $3^{\circ} \mathrm{C}$ per minute. Faster or slower heating rates often resulted in explosions, starting at about $300^{\circ} \mathrm{C}$. Mixtures of $\mathrm{Cs}_{2} \mathrm{NiFe}(\mathrm{CN})_{6}$ with a $10 \%$ excess of an equimolar mixture of sodium nitrate and sodium nitrite were not sensitive to mechanical impact or friction and were relatively insensitive to sparks in standard explosive sensitivity tests reported by Scheele and Cady. ${ }^{33}$ However, reactions between the mixture components were initiated by elevated temperature and by high-energy sparks. Exothermic reactions were observed in their tests as low as $210^{\circ} \mathrm{C}$.

In studies of the radiolytic stability of solid hexacyanoferrates, Lehto and Szirtes ${ }^{34}$ found granular $\mathrm{Na}_{2} \mathrm{CoFe}(\mathrm{CN})_{6}$ to be stable to gamma radiation doses up to $5 \mathrm{MGy}$. The irradiated exchanger showed a small increase in crystal size, which resulted in slightly decreased cesium uptake in subsequent sorption tests. On the basis of radiation stability tests with $\mathrm{Cs}_{2} \mathrm{NiFe}(\mathrm{CN})_{6}$, Martin, Burger, and Morgan ${ }^{35}$ predicted that solid hexacyanoferrates would likely be very stable to radiation and that radiolytic decomposition would be more likely in the aqueous phase.

Lehto et al. ${ }^{36}$ studied the thermal decomposition of $\mathrm{K}_{2} \mathrm{CoFe}(\mathrm{CN})_{6} \cdot 1.4 \mathrm{H}_{2} \mathrm{O}$. No oxidants were present in these studies. The water of hydration was lost at temperatures up to $170^{\circ} \mathrm{C}$, and the anhydrous compound began to decompose above $230^{\circ} \mathrm{C}$. The hexacyanoferrate groups decomposed to form $\mathrm{K}_{2} \mathrm{CO}_{3}, \mathrm{Fe}_{2} \mathrm{O}_{3}, \mathrm{Co}_{3} \mathrm{O}_{4}$, and $\mathrm{CoFe}_{2} \mathrm{O}_{4}$ between 230 and $350^{\circ} \mathrm{C}$. At 550 to 
$900^{\circ} \mathrm{C}$, the cobalt-containing compounds became $\mathrm{CoO}$, and $\mathrm{K}_{2} \mathrm{CO}_{3}$ was partially converted to $\mathrm{K}_{2} \mathrm{O}$. The conversion of $\mathrm{K}_{2} \mathrm{CO}_{3}$ to $\mathrm{K}_{2} \mathrm{O}$ was completed above $900^{\circ} \mathrm{C}$. Only solid products were identified in this study; gaseous products formed but were not identified. No exothermic reactions were reported during the decomposition of the hexacyanoferrate. Finnish researchers ${ }^{37}$ determined that the thermal decomposition of KCCF began above $230^{\circ} \mathrm{C}$ and was complete above $900^{\circ} \mathrm{C}$. The material decomposed to nitrogen and carbon compounds under aerobic conditions and to cyanide compounds under anaerobic conditions.

The studies described previously were made with mixtures of dry ingredients with no liquids present. Scheele et al. ${ }^{29}$ reported that the presence of water or other waste components could affect the reactions of the hexacyanoferrate and oxidants by changing the thermal conductivity of the mixture or the rates of the reaction steps. These diluents also would introduce an additional heat capacity that could control the temperature during an adiabatic heat rise. They calculated that about $50 \mathrm{~mol}$ of $\mathrm{H}_{2} \mathrm{O}, 35 \mathrm{~mol}$ of excess $\mathrm{NaNO}_{3}$, or $108 \mathrm{~mol}$ of $\mathrm{NaAlO}_{2}$ per mole of hexacyanoferrate would prevent a runaway reaction at $300^{\circ} \mathrm{C}$.

\subsection{STABILITY OF SOLUBLE HEXACYANOFERRATES}

Transition-metal hexacyanoferrates are considered to be nontoxic because of their limited solubility and because they do not readily dissociate in aqueous solutions. Scheele et al. ${ }^{29}$ reported that sodium nickel hexacyanoferrate complexes are soluble in $\mathrm{H}_{2} \mathrm{SO}_{4}$ heated to fuming or in excess EDTA. Nitric acid depressed cesium sorption with potassium cupric hexacyanoferrate, ${ }^{38}$ and $8 \mathrm{MHNO}_{3}$ was used to elute cesium from potassium copper nickel hexacyanoferrate. ${ }^{39}$ No dissolution of the hexacyanoferrates was observed in these tests, and the reduced cesium sorption was attributed to oxidation of the ferrocyanides to ferricyanides by the $\mathrm{HNO}_{3}$. 
Lilga et al. ${ }^{40}$ measured the dissolution of $\mathrm{Na}_{2} \mathrm{NiFe}(\mathrm{CN})_{6} \cdot \mathrm{Na}_{2} \mathrm{SO}_{4} \cdot 4.5 \mathrm{H}_{2} \mathrm{O}$ in $\mathrm{NaOH}$ solutions. Based on analyses of the solutions and the undissolved solids, they concluded that $\mathrm{Na}_{2} \mathrm{NiFe}(\mathrm{CN})_{6}$ reacts with $\mathrm{NaOH}$ at $\mathrm{pH} 12$ to 14 to form soluble $\mathrm{Na}_{4} \mathrm{Fe}(\mathrm{CN})_{6}$ and insoluble $\mathrm{Ni}(\mathrm{OH})_{2}$ :

$$
\mathrm{Na}_{2} \mathrm{NiFe}(\mathrm{CN})_{6}+2 \mathrm{NaOH} \rightarrow \mathrm{Na}_{4} \mathrm{Fe}(\mathrm{CN})_{6}+\mathrm{Ni}(\mathrm{OH})_{2}
$$

In the tests using $1 \mathrm{~g}$ of solid material and $50 \mathrm{~mL}$ of solution, dissolution was $95 \%$ complete after $0.5 \mathrm{~h}$ of stirring with $1 \mathrm{M} \mathrm{NaOH}(\mathrm{pH} 14)$ at room temperature. At $\mathrm{pH} 13$, where only a slight excess of base was present, the dissolution was rapid initially, but then slowed to reach about $85 \%$ completion in $144 \mathrm{~h}$. The reaction at $\mathrm{pH} 12$ was limited by the amount of base present, but the available base was rapidly consumed within $0.1 \mathrm{~h}$. The addition of $1 \mathrm{M} \mathrm{Na}^{+}$as $\mathrm{Na}_{2} \mathrm{SO}_{4}$ at $\mathrm{pH} 13$ resulted in a decreased dissolution rate, but $1 \mathrm{M} \mathrm{Na}^{+}$added as tank simulant salts (sodium salts of phosphate, carbonate, nitrate, nitrite, sulfate, and hydroxide) caused the dissolution rate to increase. The dissolution rate in $1 M \mathrm{NaOH}$ was slower in static solutions than in stirred solutions. Very little of the $\mathrm{Fe}(\mathrm{CN})_{6}^{-}$that dissolved in these tests dissociated to free cyanide; the maximum free cyanide concentration measured in solution was about $6 \mathrm{ppm}$ $\left(2.3 \times 10^{-4} M\right)$ compared with about $2000 \mathrm{ppm}\left(3.6 \times 10^{-2} M\right)$ soluble iron. The free cyanide concentration increased in proportion to the increase in soluble iron concentration as the reactions proceeded. Burger ${ }^{A 1}$ calculated the free cyanide concentration at $\mathrm{pH} 10$ and $350 \mathrm{~K}$ from the dissociation of $\mathrm{Ni}_{2} \mathrm{Fe}(\mathrm{CN})_{6}$ to be $10^{-6}$ to $10^{-5} M(0.026$ to $0.26 \mathrm{ppm})$. He also calculated that most of the free cyanide that formed would be oxidized to cyanate:

$$
\mathrm{CN}^{-}+2 \mathrm{OH}^{-} \rightarrow \mathrm{CNO}^{-}+\mathrm{H}_{2} \mathrm{O}+2 e
$$


Gamma irradiation did not greatly affect the dissolution or the free cyanide concentration in static solutions in the tests by Lilga et al. ${ }^{40}$ Similar dissolution rates were observed in unstirred control and irradiated solutions. However, the extent of reaction in these experiments, which were conducted in stainless steel vessels, was lower than that in a static experiment conducted in Teflon labware. The free cyanide concentration of the solutions increased when exposed to ultraviolet light (sunlight). Rader et al. ${ }^{42}$ also reported that free cyanide was produced when solutions of potassium ferrocyanide or potassium ferricyanide were exposed to sunlight and that the free cyanide produced was oxidized to cyanate. No cyanate ion was produced upon exposure of potassium cyanide solutions to sunlight in these tests.

No significant concentrations of flammable gases, hydrazine, hydrogen cyanide, or oxides of nitrogen were found in a program to measure flammable and toxic gases in the vapor spaces of the Hanford tanks that contain hexacyanoferrates. ${ }^{43}$ Concentrations of ammonia above the threshold limit value and small concentrations of organic compounds (e.g., normal paraffin hydrocarbons) were found. According to Babad et al., ${ }^{44}$ the presence of ammonia in the tank vapor spaces could be indicative of ferrocyanide dissolution. In a study of Hanford waste tank chemistry as a function of age, they indicated that the principal reactions during aging are the reaction of $\mathrm{NaOH}$ with sodium nickel hexacyanoferrate to form sodium ferrocyanide and nickel hydroxide [Eq. (5)] and a slower hydrolysis of the sodium ferrocyanide to form sodium formate, ferric hydroxide, and ammonia:

$$
\mathrm{Na}_{4} \mathrm{Fe}(\mathrm{CN})_{6}+2 \mathrm{NaOH}+12 \mathrm{H}_{2} \mathrm{O} \rightarrow 6 \mathrm{NaHCO}_{2}+\mathrm{Fe}(\mathrm{OH})_{3}+6 \mathrm{NH}_{3}
$$


Scheele et al. ${ }^{29}$ reported that the ferrocyanide ion is easily oxidized to ferricyanide by radiolysis in the presence or absence of oxygen. Burger ${ }^{41}$ also predicted that oxidation of the dissolved ferrocyanides in the Hanford storage tanks to ferricyanides would occur.

Dissolved organics such as EDTA in the waste solution can cause dissolution of the hexacyanoferrates and result in reduced cesium sorption. Marsh et al. ${ }^{11}$ observed the characteristic colors of transition-metal ions in irradiated Hanford tank simulant that contained dissolved EDTA and its radiolytic degradation products after a few minutes contact with nickel hexacyanoferrate or cobalt hexacyanoferrate. They interpreted the colored solutions as indicative of dissolution of the hexacyanoferrates. The cesium distribution coefficients from the strongly alkaline tank simulant decreased sharply as contact time with either compound was increased.

\subsection{IMPLICATIONS FOR ORNL TREATMENT FLOW SHEET}

Based on the results of this literature survey, uncontrolled exothermic reactions or explosions do not appear likely from using KCCF for cesium removal from waste solutions in the proposed ORNL treatment flow sheet. As shown in Table 11, the nitrate/hexacyanoferrate ratios in the dried solids from the KCCF treatment, assuming the solids contained the dried salts from the $90 \%$ entrained solution, are not in the range that reacted explosively in the studies by Scheele, Burger, and Sell. ${ }^{31}$ For treating NGLLLW, the nitrate/KCCF ratio in the unwashed dried solids is about $20 \%$ of the stoichiometric ratio and less than half the explosive range minimum at $320^{\circ} \mathrm{C}$. The solids produced from treating a $50 / 50 \mathrm{vol} \%$ mixture of NGLLLW and supernate would contain about 6 times the stoichiometric nitrate ratio, a factor of 6 higher than the explosive range maximum at $320^{\circ} \mathrm{C}$.

Because the KCCF treatment will be in the near-neutral $\mathrm{pH}$ range and because the KCCF will be in contact with the waste solutions for only a short time, essentially no KCCF or its 
cesium salt is expected to dissolve in the solutions. Consequently, little or no dissociation of $\mathrm{Fe}(\mathrm{CN})_{6}^{-}$and subsequent $\mathrm{CN}^{-}$or $\mathrm{CNO}^{-}$formation would be expected in the treated solutions. As a precautionary measure, exposure of the treated solutions to sunlight or ultraviolet light should be minimized to prevent $\mathrm{CN}^{-}$formation from any soluble $\mathrm{Fe}(\mathrm{CN})_{6}^{-}$in the solutions.

The KCCF solids are very finely divided and are difficult to separate from the solution. It is likely that a method such as cross-flow filtration will be needed to separate the solids from the treated solutions. For cleaning filter elements or other equipment, KCCF-containing solids could be removed by dissolution in excess EDTA or by the use of high-pressure water rather than by dissolving the $\mathrm{KCCF}$ in strong acids or strong caustic solutions. This would minimize the potential for free cyanide and cyanate formation.

Techniques such as the VERITM process $^{45}$ might merit consideration for preparing a final waste form. This process involves passing a catalyzed, promoted vinyl ester resin through a waste container to displace superficial water and surround the solid waste particles with resin. The resin polymerizes and solidifies in approximately $1 \mathrm{~h}$ at ambient temperature. According to the developers, the final waste form is highly leach resistant and the process produces no hazardous, toxic, or mixed waste.

\section{EVALUATION OF INTERIM AND FINAL WASTE FORMS FOR THE NGLLLW FLOW SHEET}

A literature review was initiated in FY 1994 to evaluate the final waste forms that have been proposed for radioactive-containing solid wastes and to determine their application to the solid wastes that will be generated from each unit operation during the treatment of the NGLLLW and MVST supernate at ORNL. Since cesium and strontium are the predominant radionuclides in NGLLLW and MVST supernate, the review focused on the stabilization and solidification of 
strontium carbonate and KCCF solid wastes containing these radionuclides. Waste matrices including cement, polymeric materials, and glass are the principal waste forms that have been tested on these types of wastes. The literature review was completed in FY 1995, and results are summarized in a draft report. ${ }^{30}$

The literature study found that cesium and strontium are both leached by distilled water from solidified cement, although cesium leachabilities are generally higher than those of strontium under similar conditions. The situation is exacerbated by the presence of sulfates in the solution, as manifested by cracking of the grout. Additives such as bentonite, blast furnace slag, fly ash, montmorillonite, pottery clay, silica, and zeolites generally reduce cesium and strontium release rates. Longer cement curing times ( $>28$ days) and high ionic strengths of the leachates, such as those that occur in seawater, also reduce the leach rates of the radionuclides.

Lower cesium leach rates are observed from vitrified wastes than from grout waste forms. However, significant quantities of cesium are volatilized due to the elevated temperatures required to vitrify the waste. Hence, vitrification will generally require the use of gas cleanup systems for the off-gases to prevent their emission into the atmosphere.

Although the addition of transition-metal hexacyanoferrates to grout has been suggested as a mechanism to control cesium leaching from the waste form, very little information is available on the final waste forms for potassium cobalt hexacyanoferrate wastes. Studies on the solidification and stabilization of these wastes are required.

Due to the complexities of the wastes at ORNL compared with those that have been reported in the literature, the waste stabilization/solidification results reported in this review cannot be completely extrapolated to the wastes at ORNL. However, the review should be a very good resource for including or eliminating certain factors in selecting the final waste forms for the ORNL wastes. For those waste components (e.g., KCCF) for which adequate literature information is not available, it will be useful to determine the effects of these constituents on 
cesium or strontium retention in cement, polymeric materials, or glass before deciding on a final waste form.

Once the solids have been removed, the treated LLLW exiting the flow sheet will be evaporated to a salt cake that will contain approximately $3.5 \times 10^{-5} \mathrm{mCi}$ of ${ }^{90} \mathrm{Sr}$ per gram dry weight and $4.4 \times 10^{-8} \mathrm{mCi}$ of ${ }^{134,137} \mathrm{Cs}$ per gram dry weight, in addition to ${ }^{103,106} \mathrm{Ru}$ and ${ }^{99} \mathrm{Tc}$ activity. The primary chemical components of the salt cake will be sodium sulfate $\left(\mathrm{Na}_{2} \mathrm{SO}_{4}\right)$ and sodium bicarbonate $\left(\mathrm{NaHCO}_{3}\right)$. A second phase of the literature study is under way to identify treatment options for strontium and cesium in the final salt cake. The effect of the presence of sulfate, alkali metals, bicarbonate, and nitrate on waste stabilization processes will be reviewed.

Preliminary literature findings indicate that sulfate is commonly added to cement in the form of calcium sulfate to accelerate the rate of hydration. However, the introduction of sulfate ion causes swelling of the grout by enhancing ettringite and gypsum crystal formation and water uptake. Sodium sulfate may also leach from the grout, although this appears to have no effect on the leachabilities of other waste constituents such as copper, zinc, and lead. ${ }^{46}$

Alkali metals are reported to increase the basicity of the pore water in cement paste and can adversely affect the long-term performance of the grout by reducing the compressive strength of the waste form. Sodium hydroxide concentrations of 0.5 and $1 M$ have been shown to accelerate the rates of sulfate ion depletion from grouts and adversely affect the properties of grout through the formation of ettringite. Addition of $\mathrm{NaOH}$ also increases the $\mathrm{pH}$ of the leachate of the waste form and suppresses the release of transition metals from the stabilized waste..$^{47,48}$

Further literature research will be conducted to address the influence of other salt cake constituents; results will be summarized in an ORNL technical report. 


\section{CONCLUSIONS}

A number of parameters were addressed in FY 1995 to further the implementation of the NGLLLW flow sheet. These variables included determining the effect of waste composition on the removal efficiency for strontium and cesium in NGLLLW. The cumulative strontium DF in the less-caustic simulant, representing the current LLLW waste composition generated at REDC, improved from 360 to 2000 as compared with simulant representing LLLW formerly produced at REDC. Cesium removal in the current NGLLLW is only $10 \%$ of that observed in the older formulation of the NGLLLW simulant. The KCCF solids in the less-caustic waste appear to have a smaller particle size and, thus, require a finer membrane filter $(0.2 \mu \mathrm{m})$ to obtain cesium DFs similar to those observed in the older simulant. As a side issue to this observation, the filtering of the fragile KCCF solids is significantly improved if the filtering mechanism is performed in a manner that reduces the shear pressure on the particles.

Organic constituents in the waste simulant also affected the decontamination efficiency of the flow sheet. The treatment NGLLLW simulant was tested in the presence of two organophosphates, DEHPA and TBP, which will most probably be present in LLLW generated at REDC or stored in MVSTs. The strontium DF in the presence of $226 \mathrm{ppm}$ DEHPA or $126 \mathrm{ppm}$ TBP improved slightly over that observed in the absence of the organic compounds. The increase in strontium removal is tentatively attributed to the reduced solubility of strontium carbonate in a more hydrophobic solution matrix. Cesium removal in the presence of the organophosphate decreased by several orders of magnitude. Again, it was observed that the KCCF particles in these simulants were smaller and more difficult to separate. If a $0.2-\mu \mathrm{m}$-pore membrane was used to make the liquid/solid separation, the cesium DF was recovered. 
MVST supernate may be blended with NGLLLW in the future as a possible treatment option. The effect of varying the amount of MVST supernate in NGLLLW was tested using simulants for both waste sources. Approximately $0.5 \%$ of the value for the strontium DF is lost for each $1 \%$ addition of MVST supernate blended into NGLLLW. However, even with the continuous loss in the strontium DF, the cumulative strontium DF in $100 \%$ supernate exceeds by a factor of 4 the required strontium DF of 80 for the flow sheet. The cesium DF also decreased with the addition of MVST supernate. The cumulative cesium DF decreases by 10,000 with each $1 \%$ addition of the MVST supernate. Again, the cesium DF in $100 \%$ MVST supernate still exceeds that required by the flow sheet $(D F=1000)$ by a factor of 100 .

These simulant studies were supported by testing the flow sheet using actual MVST supernate blended with NGLLLW simulant. The first series of samples used W-29 MVST supernate that had been pretreated with SRR to remove the majority of ${ }^{137} \mathrm{Cs}$ activity. The strontium DFs in samples containing either 25 or $75 \%$ treated MVST supernate were only slightly greater than one. The cesium removal was similar to that observed in simulant samples containing the organophosphates DEHPA and TBP. It was later determined that organic complexants are leached from conditioned SRR and interfere significantly with the strontium coprecipitation unit operation. The cumulative strontium DFs in 25 and $75 \%$ untreated MVST supernate were 120 and 30 , respectively. The cumulative cesium DFs were 14,000 and 775 , respectively. The improved decontamination of cesium is the result of using a $0.2-\mu \mathrm{m}$ filtering assembly that created very little shear stress during the filtering of the samples. The important conclusion from this testing is that the NGLLLW flow sheet adequately decontaminates actual MVST supernate. Additionally, any treatment process that might use the SRR for cesium removal should place this unit operation after the strontium removal processes to eliminate the complexation of the strontium with SRR leachants. 
The variation in LLLW composition appears to significantly affect the liquid/solid separation of the cesium-bearing KCCF particles. If an efficient separation process were available, the composition of the waste might have little impact on the cesium removal efficiency in the flow sheet. A study was completed that evaluated possible polymeric settling agents for the removal of solids generated from the strontium coprecipitation and KCCF unit operation. Betz® 1138, an anionic polyacrylamide, was found to be the best settling agent for strontium carbonate solids. No polymeric flocculant was found to successfully settle the KCCF solids.

A filtering system was determined to be the best approach for the liquid/solid separations required at the completion of the KCCF unit operation. This endeavor was supported by developing a design concept for a liquid/solid separation testing facility. The bench-scale unit will be able to evaluate the filtration efficiency for "dead-end" filtration, cross-flow filtration, and HGMS. Additionally, the test facility will also be used to determine the operational parameters for the flow sheet, which will include feed rate of chemicals and degree of mixing. As part of the design effort, cold tests were run on cross-flow filtration systems at REDC and SRS. Bids for the construction of components for the liquid/solid separation testing facility are currently being sought. Actual construction of the test equipment is currently taking place; construction should be completed in October 1995.

The need to introduce a unit operation for the removal of ${ }^{99} \mathrm{Tc}$ was reviewed during FY 1995. It was determined that a DF of approximately 30 will be required to remove sufficient quantities of ${ }^{99} \mathrm{Tc}$ from the LLLW so that the final salt cake generated from the NGLLLW flow sheet does not exceed the Class LII level. If only NGLLLW is processed, the best technology for LLLW decontamination appears to be the use of Dowex ${ }^{\mathrm{TM}}$ 1-8X anion-exchange resin. However, if MVST supernate will be blended into the waste, Reillex ${ }^{\mathrm{TM}}$ HPQ may be preferred to overcome the interference of high nitrate concentrations. Either of these resins maintains a relatively 
constant ${ }^{99} \mathrm{Tc}$ sorption capacity over a broad $\mathrm{pH}$ range. Steel wool columns are also an option for waste treatment; the inexpensive columns are available commercially. However, the iron surface passivates at solution $\mathrm{pH}$ above 10 and will, therefore, require neutralization of the waste prior to use. The steel wool columns are also prone to plugging and channeling of the liquid flow.

The NAC process was reviewed as a final waste treatment option for the NGLLLW. The gibbsite precipitated as a result of the process was found to sorb strontium to such an extent that the NAC process could replace the strontium coprecipitation process at the head of the flow sheet. However, this would be done at the expense of creating significant quantities of secondary solid low-level waste. The strontium coprecipitation unit operation creates $0.2 \mathrm{~g}$ of secondary solid low-level waste, as compared with approximately $60 \mathrm{~g}$ of solid waste in the NAC process. NAC processing reduced the nitrate content of the NGLLLW from 4500 to $150 \mathrm{ppm}$. If the NGLLLW is blended with MVST supernate, the nitrate content of the combined LLLW significantly increases. It appears that the NAC process is limited to streams containing less than $10 \%$ MVST supernate because higher contents of the supernate require the addition of so much aluminum that additional liquid must be added to the stream. The NAC process also removes sufficient ${ }^{99} \mathrm{Tc}$ from the LLLW to meet the flow sheet requirement of a DF of 30 . A ${ }^{99} \mathrm{Tc} \mathrm{DF}$ of 42 was observed in the treatment of a single simulant sample.

A literature survey was performed to ascertain the possibility for uncontrolled exothermic reactions or explosions in the use of KCCF. The nitrate/hexacyanoferrate ratios that will be present in dried solids from the KCCF unit operation are not in the range that were found to react explosively. Additionally, it was determined that little or no free cyanide will be generated in solutions treated with $\mathrm{KCCF}$, both because of the neutral $\mathrm{pH}$ at which the solutions are treated and the short time that the KCCF solids will be in contact with the liquid. 
Future work in the development of the NGLLLW flow sheet will continue many of these investigations. The solid/liquid filtration system will be used to identify the best mechanism to remove strontium carbonate and KCCF solids from the treated waste. The facility will also be used to optimize operational parameters for the flow sheet. An effort will be made to treat a greater number of actual waste samples to validate the flow sheet. These studies will be supported with the identification and quantification of the organic components in actual NGLLLW and MVST supernates. 


\section{REFERENCES}

1. J. B. Berry, D. O. Campbell, D. D. Lee, and T. L. White, "Process Development for Remote-Handled Mixed-Waste Treatment," presented at the 1990 AIChE Summer National Meeting, San Diego, Calif., August 1990.

2. W. D. Arnold, D. T. Bostick, M. W. Burgess, P. A. Taylor, J. J. Perona, and T. E. Kent, Laboratory Development of Methods for Centralized Treatment of Liquid Low-Level Waste at Oak Ridge National Laboratory, ORNL/TM-12786, Oak Ridge National Laboratory, Oak Ridge, Tenn., October 1994.

3. M. B. Sears, J. L. Botts, R. N. Ceo, J. J. Ferrada, W. H. Griest, J. M. Keller, and R. L. Schenley, Sampling and Analysis of Radioactive Liquid Wastes and Sludges in Melton Valley and Evaporator Facility Storage Tanks at ORNL, ORNL/TM-11652, Oak Ridge National Laboratory, Oak Ridge, Tenn., September 1990.

4. J. F. Walker, Jr., J. J. Perona, and S. M. Robinson, In-Tank Evaporator Demonstrations During 1990/1991 at the ORNL Melton Valley Storage Tanks, ORNL/TM-12036, Oak Ridge National Laboratory, Oak Ridge, Tenn.,October 1992.

5. T. J. Abraham, S. M. DePaoli, A. B. Walker, and S. M. Robinson, Preliminary Analysis of the ORNL Liquid Low-Level Waste System, ORNL/TM-11250, Oak Ridge National Laboratory, Oak Ridge, Tenn., July 1994.

6. A. G. Croff, ORIGEN2-A Revised and Updated Version of the Oak Ridge Isotope Generation and Depletion Code, ORNL-5621, Oak Ridge National Laboratory, Oak Ridge, Tenn., March 1986.

7. M. B. Sears, J. L. Botts, R. N. Ceo, J. J. Ferrada, W. H. Griest, J. M. Keller, and R. L. Schenley, Sampling and Analysis of Radioactive Liquid Wastes and Sludges in the Melton Valley and Evaporator Facility Storage Tanks at ORNL, ORNL/TM-11652, Oak Ridge National Laboratory, Oak Ridge, Tenn., September 1990.

8. J. L. Collins, B. Z. Egan, K. K. Anderson, C. W. Chase, and J. T. Bell, "Batch Test Equilibration Studies Examining the Removal of Cs, Sr, and Tc from Supernatants from ORNL Underground Storage Tanks by Selected Ion Exchangers," in Challenges and Innovations in the Management of Hazardous Waste, proceedings of the 2nd International Conference of Waste Management, May 10-12, 1995, Washington, D.C.

9. J. L. Collins, B. Z. Egan, K. K. Anderson, C. W. Chase, J. E. Mrochek, J. T. Bell, and G. E. Jernigan, Evaluation of Selected Ion Exchangers for the Removal of Cesium from MVST W-25 Supernate, ORNL/TM-12938, Oak Ridge National Laboratory, Oak Ridge, Tenn., April 1995.

10. J. W. Autrey, D. A. Costanzo, W. H. Griest, L. L. Kaiser, J. M. Keller, C. E. Nix, and B. A. Tompkins, Sampling and Analysis of the Inactive Waste Storage Tank Contents at ORNL, ORNL/ER-13, Oak Ridge National Laboratory, Oak Ridge, Tenn., September 1990. 
11. S. F. March, Z. V. Svitra, and S. M. Bowen, Effects of Aqueous-Soluble Organic Compounds on the Removal of Selected Radionuclides from High-Level Waste-Part I: Distribution of $\mathrm{Sr}, \mathrm{Cs}$, and Tc on 18 Absorbers from an Irradiated, Organic-Containing Leachate Simulant for Hanford Tank 101-SY, LA-12862, Sandia National Laboratories, Albuquerque, N.M., January 1995.

12. S. F. March, Z. V. Svitra, and S. M. Bowen, Effects of Aqueous-Soluble Organic Compounds on the Removal of Selected Radionuclides from High-Level Waste-Part II: Distribution of Sr, Cs, Tc and Am onto 32 Absorbers from Four Variations of Hanford Tank 101-SY Simulant Solution, LA-12943, Sandia National Laboratories, Albuquerque, N.M., April 1995.

13. S. F. Marsh, Sandia National Laboratories, Albuquerque, N.M., personal communication, June 19, 1995.

14. D. W. DePaoli, ORNL, personal communication, April 1995.

15. W. Bond, ORNL, personal communication to W. D. Bostick, Oak Ridge K-25 Site, Nov. 18, 1994.

16. W. D. Bostick, P. E. Osborne, G. D. Del Cul, and D. W. Simmons, Treatment of Aqueous Solutions Contaminated with Technetium-99 Originating from Uranium Enrichment Activities: Final Report, K/TCD-1120, Martin Marietta Energy Systems, Inc., Oak Ridge, Tenn., 1995.

17. M. Kawasaki, T. Omori, and K. Hasegawa, "Adsorption of Pertechnetate on an Anion Exchange Resin," Radiochim. Acta 63, 53 (1993).

18. N. Momoshima, M. Sayad, and Y. Takashima, "Analytical Procedure for Technetium-99 in Seawater by ICP-MS," Radiochim. Acta 63, 73 (1993).

19. T. E. Gangwer, M. Goldstein, and K. K. S. Pillay, Radiation Effects on Ion Exchange Materials, BNL-50781, Brookhaven National Laboratory, Upton, N.Y., 1977.

20. N. C. Schroeder et al., Technetium Partitioning for the Hanford Tank Waste Remediation System: Adsorption and Extraction of Technetium from Double-Shell Slurry Waste Simulant, LAUR-93-4092, Los Alamos National Laboratory, Los Alamos, N.M., 1993.

21. N. C. Schroeder et al., Technetium Partitioning for the Hanford Tank Waste Remediation System: Sorption and Extraction of Technetium from Simple Caustic Solutions, LAUR-9462, Los Alamos National Laboratory, Los Alamos, N.M., 1994.

22. N. C. Schroeder et al., Technetium Partitioning for the Hanford Tank Waste Remediation System: Sorption of Technetium from DDN aind DSSF-7 Waste Simulants Using Reillex ${ }^{\mathrm{TM}}-H P Q$ Resin, LAUR-95-40, Los Àlamos National Laboratory, Los Alamos, N.M., 1995. 
23. G. D. Del Cul and W. D. Bostick, "Simple Method for Technetium Removal from Aqueous Solutions," Nucl. Technol. 101(1), 161 (1995).

24. D. F. McGinnes and A. Dyer, "Disposal of Organic Ion Exchange Resins Contaminated with Technetium-99," pp. 1557-1562 in Waste Management '92, Vol. 2, ed. R. G. Post, Arizona Board of Regents, Tucson, Ariz., 1992.

25. I. L. Morgan and W. D. Bostick, "Performance Testing of Grout-Based Waste Forms for the Solidification of Anion Exchange Resins," pp. 133-145 in Stabilization and Solidification of Hazardous, Radioactive, and Mixed Wastes, ASTM STP 1123, eds. T. M. Gilliam and

C. C. Wiles, American Society for Testing and Materials, Philadelphia, 1992.

26. G. D. Del Cul, I. L. Morgan, W. D. Bostick, and P. E. Osborne, Grout-Based Waste Forms for the Solidification of Anion Exchange Resins: Final Report, K/TCD-1004, Martin Marietta Energy Systems, Inc., Oak Ridge, Tenn., 1991.

27. W. D. Bostick, P. E. Osborne, D. E. Beck, D. H. Bunch, R. L. Fellows, G. F. Sellers, J. L. Shoemaker, K. T. Bowser, and D. T. Bostick, Removal of Technetium-99 from Simulated Oak Ridge National Laboratory Newly-Generated Liquid Low-Level Waste, K/TCD-1141, Oak Ridge K-25 Site, Oak Ridge, Tenn., June 1995.

28. A. J. Mattus and D. D. Lee, "The Nitrate to Ammonia and Ceramic (NAC) Process: A Newly Developed Low-Temperature Technology," pp. 1.1.1-1.1.11 in Mixed Waste, proceedings of the 2nd International Symposium, Baltimore, Maryland, August 17-20, 1993, eds. A. A. Moghissi, R. K. Blauvelt, B. A. Benda, and N. E. Roghermich.

29. R. D. Scheele, L. L. Burger, J. M. Tingley, S. A. Bryan, G. L. Borsheim. B. C. Simpson, R. J. Cash, and H. H. Cady, Ferrocyanide-Containing Waste Tanks: Ferrocyanide Chemistry and Reactivity, PNL-SA-19924, Pacific Northwest Laboratory, Richland, Wash., 1991.

30. G. M. K. Abotsi, D. A. Bostick, W. D. Bostick, and W. D. Amold, Evaluation of Interim and Final Waste Forms for the Newly-Generated Liquid Low-Level Waste Flow Sheet, ORNL/TM-13028, Oak Ridge National Laboratory, Oak Ridge, Tenn., December 1995.

31. R. D. Scheele, L. L. Burger, and R. L. Sell, Effect of Potential Hanford Ferrocyanide Waste Constituents on the Reaction Between Ferrocyanides and Nitrates/Nitrites, PNL-SA21455, Pacific Northwest Laboratory, Richland, Wash., 1993.

32. L. Burger and R. D. Scheele, The Reactivity of Cesium Nickel Ferrocyanide Towards Nitrate and Nitrite Salts, PNL-7550, Pacific Northwest Laboratory, Richland, Wash., 1991.

33. D. Scheele and H. H. Cady, Preliminary Safe-Handling Experiments on a Mixture of Cesium Nickel Ferrocyanide and Equimolar Sodium Nitrate/Nitrite, PNL-7928, Pacific Northwest Laboratory, Richland, Wash., 1992. 
34. J. Lehto and L. Szirtes, "Effects of Gamma Irradiation on Cobalt Hexacyanoferrate(II) Ion Exchangers," Radiat. Phys. Chem. 43(3), 261-264 (1994).

35. C. Martin, L. L. Burger, and L. G. Morgan, Radiation Stability of Cs, $\mathrm{NiFe}(\mathrm{CN})_{\sigma}$, PNL-7174, Pacific Northwest Laboratory, Richland, Wash., 1985.

36. J. Lehto, S. Haukka, P. Koskinen, and M. Blomberg, "Mechanism of Cesium Ion Exchange on Potassium Cobalt Hexacyanoferrate(II)," Thermochim. Acta 160, 343-347 (1990).

37. Jukka Rautakallio, The Valley Group, Inc., Ridgefield, Conn., personal communication to $T$. E. Kent, ORNL, June 21, 1995.

38. K. Tanihara, "Influence of Various Additives on the Sorption of Cesium from Strong Nitric Acid Medium on Potassium Cupric Ferrocyanide,"J. Radioanal. Nucl. Chem. 173(1), $37-45$ (1993).

39. M. Ishfaq, H. M. A. Karim, and M. A. Kahn, "Adsorption Studies of Cesium on Potassium Copper Nickel Hexacyanoferrate(II) from Aqueous Solutions," J. Radioanal. Chem. Artic. 170(2), 321-331 (1993).

40. M. A. Lilga, M. R. Lumetta, W. F. Riemath, R. O. Rimine, and G. F. Schiefelbein, Ferrocyanide Safety Project Subtask 3.4, Aging Studies, FY1992 Annual Report, PNL8387, Pacific Northwest Laboratory, Richland, Wash., 1992.

41. L. L. Burger, Complexant Stability Investigation Task I-Ferrocyanide Studies, PNL5441, Pacific Northwest Laboratory, Richland, Wash., 1984.

42. W. S. Rader, L. Solujic, E. B. Milosavijevic, and J. L. Hendrix, "Sunlight-Induced Photochemistry of Aqueous Solutions of Hexacyannoferrate(II) and (III) Ions," Environ. Sci. Technol. 27, 1875-1879 (1993).

43. K. D. Fowler, Ferrocyanide Waste Tank Stability, WHC-EP-0347-Suppl.2, Westinghouse Hanford Company, Richland, Wash., 1993.

44. H. Babad, D. M. Camaioni, M. A. Lilga, W. D. Samuels, and D. M. Starchan, "Tank Waste Chemistry-A New Understanding of Waste Aging," pp. 1177-1182 in Proceedings of the Symposium on Waste Management, Tucson, Ariz., Feb 28-Mar 4, 1993, Vol. 2, pp. 1177-1182, 1993.

45. Diversified Technologies Services, Inc., "VERI (Vinyl Ester Resin In-Situ) Solidification Process for Low-Level Radioactive Waste (Docket No. WM105)," T. R. No. DT-VERI100-NP-A, Rev. 1, Vol. 1, 1993.

46. L. W. Jones, R. M. Bricka, and J. J. Cullinane, Jr., "Effects of Selected Waste Constituents on Solidified/Stabilized Waste Leachability," pp. 193-203 in Stabilization and Solidification of Hazardous, Radioactive, and Mixed Wastes, 2nd Volume, ASTM STP 1123, eds. T. M. Gilliam and C. C. Wiles, American Society for Testing and Materials, Philadelphia, 1992. 
47. M. D. Cohen, "Theories of Expansion in Sulfoaluminate-Type Expansive Cements: Schools of Thought," Cement Concr. Res. 13(6), 809 (1983).

48. K. M. Alexander and C. E. S. Davis, "Effect of Alkali on the Strength of Portland-Cement Paste," J. Appl. Sci. 11(1), 146 (1960). 
ORNL/TM-13101

\section{INTERNAL DISTRIBUTION}

1. P. E. Arakawa
2. J. M. Begovich
3. W. D. Bond
4-13. D. A. Bostick
14. W. D. Bostick
15. R. R. Brunson
16. M. W. Burgess
17. M. D. Boring
18. C. H. Byers
19. E. D. Collins
20. J. L. Collins
21. A. G. Croff
22. N. H. Cutshall
23. D. J. Davidson
24. D. L. Daugherty
25. S. M. DePaoli
26. T. O. Early
27. B. Z. Egan
28. T. M. Gilliam
29. B. B. Guo

1. P. E. Arakawa

2. J. M. Begovich

3. W. D. Bond

4-13. D. A. Bostick

14. W. D. Bostick

15. R. R. Brunson

16. M. W. Burgess

17. M. D. Boring

19. D. D. Collins

20. J. L. Collins

21. A. G. Croff

22. N. H. Cutshall

23. D. J. Davidson

24. D. L. Daugherty

25. S. M. DePaoli

26. T. O. Early

27. B. Z. Egan

29. B. B. Guo
30. J. S. Jubin

31-32. T. E. Kent

33. D. D. Lee

34. J. J. Maddox

35. A. P. Malinauskas

36. C. P. Manrod

37. R. C. Mason

38. C. P. McGinnis

39. B. A. Moyer

40. L. E. McNeese

41. D. R. McTaggart

42. T. H. Monk

43. B. D. Patton

44. W. R. Reed

45. S. M. Robinson

46. S. T. Rudell

47. T. F. Scanlan

48. C. B. Scott

49. R. B. Shelton
50. J. L. Snyder

51. W. T. Thompson

52. J. R Trabalka

53. P. A. Taylor

54. J. H. Wilson

55. S. D. Van Hoesen

56. J. F. Walker

57. J. S. Watson

58. G. D. West

59. Central Research Library

60-61. Laboratory Records

62. Laboratory Records, $\mathrm{RC}$

63. ORNL Patent Section

64. Y-12 Technical Library, Document Reference Center

\section{EXTERNAL DISTRIBUTION}

65-66. Office of Scientific and Technical Information, P.O. Box 62, Oak Ridge, TN 37831

67. G. Abotsi, Dept. of Chemistry, Clark Atlanta University, 223 Brawley Drive, SW, Atlanta, GA 30314-4391.

68. W. D. Amold, Jr., 107 Normandy Road, Oak Ridge, TN 37830

69. T. A. Fryberger, Trevion II Building, 12800 Middlebrook Road, Germantown, MD 20874

70. D. W. Geiser, Cloverleaf Bldg., 19901 Germantown Road, Germantown, MD 20874-1290

71. T. M. Kafka, 3M Company, \#M Center-209-1W-24, St. Paul, MN 35114

72. S. M. Gibson, Department of Energy, Oak Ridge Operations, P.O. Box 2001, Oak Ridge, TN 37831-8620

73. W. L. Kuhn, Pacific Northwest Laboratory, Battelle Boulevard, P.O. Box 999, Richland, WA 99352

74. J. Noble-Dial, Department of Energy, Oak Ridge Operations, P.O. Box 2001, Oak Ridge, TN 37831-8620

75. Joseph J. Perona, Chemical Engineering Department, The University of Tennessee, Dougherty Hall, Knoxville, TN 37996-2200.

76. I. Tasker, Waste Policy Institute, 555 Quince Orchard Road, Suite 600, Gaithersburg, MD 20878-1437 